\title{
Mineração de dados em redes complexas: estrutura e dinâmica
}

\author{
Guilherme Ferraz de Arruda
}



SERVIÇO DE PÓS-GRADUAÇÃO DO ICMC-USP

Data de Depósito:

Assinatura:

\title{
Mineração de dados em redes complexas: estrutura e dinâmica
}

\author{
Guilherme Ferraz de Arruda
}

Orientador: Prof. Dr. Francisco Aparecido Rodrigues

Dissertação apresentada ao Instituto de Ciências

Matemáticas e de Computação - ICMC-USP, como parte dos requisitos para obtenção do título de Mestre em Ciências - Ciências de Computação e Matemática Computacional. VERSÃO REVISADA 
Ficha catalográfica elaborada pela Biblioteca Prof. Achille Bassi e Seção Técnica de Informática, ICMC/USP, com os dados fornecidos pelo(a) autor(a)

FF773m $\begin{aligned} & \text { Ferraz de Arruda, Guilherme } \\ & \text { Mineração de dados em redes complexas / Guilherme } \\ & \text { Ferraz de Arruda; orientador Francisco Aparecido } \\ & \text { Rodrigues. - - São Carlos, } 2013 . \\ & 105 \text { p. } \\ & \text { Dissertação (Mestrado - Programa de Pós-Graduação } \\ & \text { em Ciências de Computação e Matemática } \\ & \text { Computacional) - Instituto de Ciências Matemáticas } \\ & \text { e de Computação, Universidade de São Paulo, 2013. } \\ & \text { 1. Redes complexas. 2. Mineração de dados. 3. } \\ & \text { Sistemas complexos. 4. Aprendizado de máquina. I. } \\ & \text { Aparecido Rodrigues, Francisco, orient. II. Título. }\end{aligned}$


À minha família e amigos. 


\section{Agradecimentos}

Ao meu orientador, pesquisador e amigo Francisco Aparecido Rodrigues, pela orientação, ajuda, apoio e paciência durante todo o mestrado.

Ao professor Luciano da Fontoura Costa, pelo apoio, ajuda e amizade.

À todos os professores que participaram da minha formação.

À Fundação de Amparo à Pesquisa do Estado de São Paulo (Fapesp) e a Coordenação de Aperfeiçoamento de Pessoal de Nível Superior (CAPES) pelo fornecimento das bolsas de estudo.

Ao Instituto de Ciências Matemáticas e de Computação (ICMC) por me acolher e fornecer estrutura para realizar minhas pesquisas. Em especial ao Laboratório de Matemática Aplicada e Computação Científica (LMACC).

Aos meus amigos de laboratório Josuel, Rodolfo e Leonardo pela ajuda, paciência e amizade.

À toda minha família, especialmente meus pais Ana Sylvia e Juarez e meu irmão Henrique, por todo apoio e carinho.

Às secretárias do ICMC, pela atenção e ajuda em todos os momentos.

Aos meus amigos Andre Luiz Barbieri, Bruno Rogani, Bruno Kim Medeiros Cesar, César Comin, Cleiton Caltran, Job Nicolau Travaini, Juliano Alberto Paulino e Thomas Peron; minhas amigas Gabriela Alberini, Estela Maris, Luzia Romanetto, Marianna Medeiros e Roberta Novaes, pela amizade, ajuda e apoio ao longo deste período.

Especialmente ao meu irmão Henrique e meu amigo Bruno Kim pela ajuda, sugestões e contribuições nesta reta final.

E a todas as pessoas que colaboraram para a elaboração desta dissertação. 



\section{Resumo}

A teoria das redes complexas é uma área altamente interdisciplinar que oferece recursos para o estudo dos mais variados tipos de sistemas complexos, desde o cérebro até a sociedade. Muitos problemas da natureza podem ser modelados como redes, tais como: as interações protéicas, organizações sociais, o mercado financeiro, a Internet e a World Wide Web. A organização de todos esses sistemas complexos pode ser representada por grafos, isto é, vértices conectados por arestas. Tais topologias têm uma influencia fundamental sobre muitos processos dinâmicos. Por exemplo, roteadores altamente conectados são fundamentais para manter o tráfego na Internet, enquanto pessoas que possuem um grande número de contatos sociais podem contaminar um grande número de outros indivíduos. Ao mesmo tempo, estudos têm mostrado que a estrutura do cérebro esta relacionada com doenças neurológicas, como a epilepsia, que está ligada a fenômenos de sincronização. Nesse trabalho, apresentamos como técnicas de mineração de dados podem ser usadas para estudar a relação entre topologias de redes complexas e processos dinâmicos. Tal estudo será realizado com a simulação de fenômenos de sincronização, falhas, ataques e propagação de epidemias. A estrutura das redes será caracterizada através de métodos de mineração de dados, que permitirão classificar redes de acordo com um conjunto de modelos e determinar padrões de conexões presentes na organização de diferentes tipos de sistemas complexos. As análises serão realizadas com aplicações em neurociências, biologia de sistemas, redes sociais e Internet.

Palavras-chave: Redes complexas, Sistemas complexos, Mineração de dados e Aprendizado de máquina. 


\section{Abstract}

The theory of complex networks is a highly interdisciplinary reseach area offering resources for the study of various types of complex systems, from the brain to the society. Many problems of nature can be modeled as networks, such as protein interactions, social organizations, the financial market, the Internet and World Wide Web. The organization of all these complex systems can be represented by graphs, i.e. a set of vertices connected by edges. Such topologies have a fundamental influence on many dynamic processes. For example, highly connected routers are essential to keep traffic on the Internet, while people who have a large number of social contacts may infect many other individuals. Indeed, studies have shown that the structure of brain is related to neurological conditions such as epilepsy, which is relatad to synchronization phenomena. In this text, we present how data mining techniques data can be used to study the relation between complex network topologies and dynamic processes. This study will be conducted with the simulation of synchronization, failures, attacks and the epidemics spreading. The structure of the networks will be characterized by data mining methods, which allow classifying according to a set of theoretical models and to determine patterns of connections present in the organization of different types of complex systems. The analyzes will be performed with applications in neuroscience, systems biology, social networks and the Internet.

\section{Keywords: Complex networks, Complex systems, Data mining and Machine Learning.}




\section{Sumário}

Resumo $\quad$ v

$\begin{array}{ll}\text { Abstract } & \text { ix }\end{array}$

Sumário $\quad$ xi

Lista de Figuras $\quad$ xv

Lista de Tabelas $\quad$ xix

1 Introdução 1

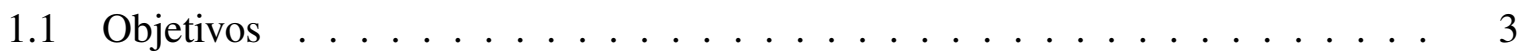

1.2 Descrição dos capítulos . . . . . . . . . . . . . . . . . . 4

2 Caracterização e modelos de redes complexas $\quad 7$

2.1 Caracterização de redes complexas . . . . . . . . . . . . . . . . 8

2.1.1 Medidas relacionadas a conectividade . . . . . . . . . . . 8

2.1.2 Coeficiente de aglomeração . . . . . . . . . . . . . . . 9

2.1.3 Menores caminhos e medidas relacionadas . . . . . . . . . . . 11

2.1.4 Medidas relacionadas à busca por informação . . . . . . . . . . . . . . 12

$2.1 .5 \quad K$-Core ............................ 13

2.1.6 Medidas espectrais e baseadas em caminhadas aleatórias . . . . . . . . 14

2.1.7 Modularidade e estrutura de comunidades . . . . . . . . . . . . . . . . 17

2.2 Modelos de redes complexas . . . . . . . . . . . . . . . . . . . 18

2.2.1 Modelo Aleatório: Erdös - Renyi . . . . . . . . . . . . . . . . . . 19

2.2.2 Modelo de pequeno mundo: Watts - Strogatz . . . . . . . . . . . . . . . . 19

2.2.3 Modelo Geográfico . . . . . . . . . . . . . . . . . . . . . 20

2.2.4 Modelo Livre de escala: Barabási - Albert . . . . . . . . . . . . . 20

2.2 .5 Barabási não-linear . . . . . . . . . . . . . . . . . 21

3 Processos dinâmicos em redes 23

3.1 Propagação de epidemias . . . . . . . . . . . . . . . . . . . . 23

3.2 Sincronização . . . . . . . . . . . . . . . . . . . . 28

3.3 Robustez de redes complexas . . . . . . . . . . . . . . . . . 31

3.3 .1 Falhas e ataques . . . . . . . . . . . . . . . . . 32

3.3.2 Entropia dinâmica ......................... 33 
4 Mineração de dados $\quad 35$

4.1 Normalização de dados . . . . . . . . . . . . . . . . . . . . 36

4.2 Extração de atributos . . . . . . . . . . . . . . . . . . . 36

4.2.1 Linear Discriminant Analysis (LDA) . . . . . . . . . . . . . . . 37

4.2.2 Principal Component Analysis (PCA) . . . . . . . . . . . . . 38

4.3 Ordenação de atributos . . . . . . . . . . . . . . . . . . . . . . . 39

4.4 Seleção de atributos . . . . . . . . . . . . . . . . . . . . . 41

4.5 Classificação . . . . . . . . . . . . . . . . . . . 43

$4.5 .1 \quad$ Árvores C4.5 . . . . . . . . . . . . . . . . . 43

4.5.2 Classificação Bayesiana . . . . . . . . . . . . . . . . 44

4.6 Avaliação de modelos preditivos . . . . . . . . . . . . . . . . . . 47

4.6 .1 Validação . . . . . . . . . . . . . . . . . . . 47

4.6 .2 Problemas de duas classes . . . . . . . . . . . . . . . . 48

4.7 Agrupamento de dados . . . . . . . . . . . . . . . . . . . . . 49

5 Identificação dos principais propagadores de epidemias 5

5.1 Introdução . . . . . . . . . . . . . . . . . . 54

5.2 Base de dados . . . . . . . . . . . . . . . . . . . 55

5.3 Metodologia e resultados . . . . . . . . . . . . . . . 55

5.4 Conclusões . . . . . . . . . . . . . . . . . . . . . 61

6 Seleção e ordenação de propriedades estruturais e dinâmicas de redes complexas 63

6.1 Introdução . . . . . . . . . . . . . . . . . . . . . . . 64

6.2 Base de dados . . . . . . . . . . . . . . . . . . . . 65

6.3 Metodologia e resultados . . . . . . . . . . . . . . . 66

$6.3 .1 \quad$ Estrutura . . . . . . . . . . . . . . . . . 67

6.3.2 Caracterização dinâmica: Propagação de epidemias . . . . . . . . . . . 74

6.4 Conclusões . . . . . . . . . . . . . . . . . . . . . . . 77

7 Análise estrutural e dinâmica de redes corticais de pacientes com esquizofrenia 81

7.1 Introdução . . . . . . . . . . . . . . . . . . . . . . 82

7.2 Base de dados . . . . . . . . . . . . . . . . . . 83

7.3 Metodologia e resultados . . . . . . . . . . . . . . . . 84

7.3.1 Estrutura . . . . . . . . . . . . . . . . 84

7.3 .2 Dinâmica . . . . . . . . . . . . . . . . . 88

7.4 Conclusões . . . . . . . . . . . . . . . . . . . . . . 91

8 Trabalhos futuros $\quad 93$

9 Conclusão $\quad 95$

Referências Bibliográficas $\quad 99$ 


\section{Lista de Símbolos}

$\mathcal{N} \quad$ Conjunto de vértices

$N \quad$ Número de vértices

$\mathcal{L} \quad$ Conjunto de arestas

$M \quad$ Número de arestas

A Matriz de adjacências

$a_{i j} \quad$ Elemento $(i, j)$ da matriz de adjacências

$k_{i} \quad$ Grau do vértice $i$

$P(k) \quad$ Distribuição de probabilidades da conectividade

$P\left(k^{\prime} \mid k\right) \quad$ Probabilidade condicional

$\rho \quad$ Assortatividade

$k n n(i) \quad$ Conectividade média dos vizinhos de $i$

C Transitividade

$C(i) \quad$ Clustering coefficient do vértice $i$

$k_{s} \quad$ Número de caixas para um histograma segundo a fórmula de Sturges

$d_{i j} \quad$ Comprimento do menor caminho entre $i$ e $j$

$L \quad$ Menor caminho médio

E Eficiência

$b_{i} \quad$ Betweenness centrality do vértice $i$

$C P D \quad$ Central point dominance

$C_{i} \quad$ Closeness centrality do vértice $i$

$\mathcal{S} \quad$ Busca média por informação

$\mathcal{A}_{i} \quad$ Acesso à informação partindo do vértice $i$

$\mathcal{H}_{b} \quad$ Informação escondida, para se encontrar o vértice $b$

$k_{S}(v) \quad$ Índice $\mathrm{K}$-core do vértice $v$

$\rho(\lambda) \quad$ Densidade espectral

$M_{l} \quad$ l-ésimo momento espectral

$A c c_{h}(i) \quad$ Acessibilidade do vértice $i$ para uma distância $h$

$A c c(i) \quad$ Acessibilidade do vértice $i$

$\mathcal{C} \quad$ Matriz de comunicabilidade

$P R_{i} \quad$ Page Rank do vértice $i$

$V_{i} \quad$ Eigenvector centrality do vértice $i$

$\alpha \quad$ Coeficiente de ligação preferencial do modelo Barabási não-linear 


$\begin{array}{ll}\beta & \text { Taxa de infecção } \\ \mu & \text { Taxa de recuperação } \\ I & \text { Número de indivíduos infectados } \\ S & \text { Número de indivíduos susceptíveis } \\ R & \text { Número de indivíduos recuperados } \\ i & \text { Fração de indivíduos infectados } \\ s & \text { Fração de indivíduos susceptíveis } \\ r & \text { Fração de indivíduos recuperados } \\ I_{k} & \text { Número de indivíduos infectados com grau } k \\ S_{k} & \text { Número de indivíduos susceptíveis com grau } k \\ R_{k} & \text { Número de indivíduos recuperados com grau } k \\ i_{k} & \text { Fração de indivíduos infectados com grau } k \\ s_{k} & \text { Fração de indivíduos susceptíveis com grau } k \\ r_{k} & \text { Fração de indivíduos recuperados com grau } k \\ N_{k} & \text { Número de vértices com grau } k \\ \theta_{i} & \text { Fase do i-ésimo oscilador } \\ \sigma_{i j} & \text { Força do acoplamento entre os osciladores } i \text { e } j \\ H_{d} & \text { Entropia dinâmica } \\ \mathbf{X} & \text { Matriz de atributos } \\ x_{i} & \text { i-ésimo atributo } \\ S & \text { Matriz de dispersão ou scatter matrix do inglês } \\ H(x) & \text { Entropia de } x \\ H(x \mid y) & \text { Entropia condicional de } x \text { dado } y \\ U(x, y) & \text { Incerteza simétrica de } x \text { e } y \\ I(x, y) & \text { Informação mútua entre de } x \text { e } y \\ I G(x, y) & \text { Ganho de informação entre de } x \text { e } y \\ & \end{array}$




\section{Lista de Figuras}

2.1 Redes complexas podem ser representadas por matrizes de adjacência. Em (a) temos uma rede não-dirigida e em (b) uma rede dirigida. No caso (a), os elementos $a_{i j}$ da matriz são iguais a 1 se há uma ligação entre os vértices $i$ e $j$ e iguais a zero, caso contrário. Já no caso (b), os elementos da matriz $a_{i j}$ são iguais a 1 se existe uma conexão dirigida do vértice $i$ para o vértice $j$. . . . .

2.2 Ilustração esquemática de três situações onde o coeficiente de aglomeração tem diferentes valores. Em (a) é apresentado um exemplo de clique, onde todos os vértices estão conectados entre si. Neste caso, $C_{i}=1$. Na figura (b), $C_{i}=$ $3 / 10$. Já em (c) $C_{i}=0$, pois os vizinhos do vértice $i$ não possuem conexões entre si. . . . . . . . . . . . . . . . . .

2.3 Exemplo do algoritmo de decomposição em núcleos. Em (a) a rede original com a respectiva divisão em núcleos; em (b), (c) e (d) os subgrafos induzidos que compõe os núcleos de $k_{S}=1, k_{S}=2$ e $k_{S}=3$ respectivamente. Figura adaptada de (Kitsak et al., 2011) . . . . . . . . . . . . . . . . . . 14

2.4 Visualização do conceito de acessibilidade. Figura adaptada de (Barbieri, 2010)

2.5 Exemplos de redes complexas gerada por diferentes modelos. Todas as redes possuem grau médio $\langle k\rangle=2$ e $N=500$ nós. Em todas as figuras o tamanho do nó e a cor do nó representam o grau, ou seja, quanto maior e mais próxima do vermelho maior o grau do nó e quanto menor e mais próximo da cor verde menor é o grau. . . . . . . . . . . . . . . . . . . .

3.1 Resposta temporal dos modelos para propagação de epidemias. (a) Modelo SI: um pequeno número de indivíduos infectados inicialmente (1\% neste exemplo), apresentará um crescimento exponencial no inicio, chegando a saturação em 1 no estado estacionário; (b) Modelo SIR: mostra as frações da população susceptíveis, infectadas e recuperadas. Os parâmetros desta simulação foram $\beta=1, \gamma=0.2, s_{0}=0.99, x_{0}=0.01$ e $r_{0}=0$; (c) Modelo SIS: a fração dos indivíduos infectados neste modelo cresce de acordo com a curva logística, de maneira semelhante ao modelo SI, entretanto, a fração de infectados nunca

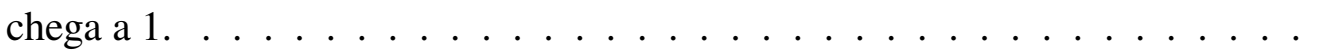


3.2 Representação esquemática do parâmetro de ordem do sistema, $r$. O módulo deste é dado pelo comprimento deste vetor, enquanto a fase de cada oscilador é dada pela posição de cada um deles pelo círculo. Os itens de (a) - (b) mostram a variação deste parâmetro desde uma oscilação de maneira incoerente em (a), $|r|=0.18$, até uma oscilação onde todos os osciladores oscilam de maneira coerente, $|r|=0.99$, em (d). . . . . . . . . . . . . .

3.3 Coerência de fases, $|r|$, em função da força de acoplamento, $\sigma$. Sincronização para 50 redes dos modelos Barabási e Albert em (a) e Erdös-Renyi em (b). Ambas com grau médio $\langle k\rangle=4$ e $N=1000$ nós. . . . . . . . . . . . . .

3.4 Variação do diâmetro, $d$ em função da fração de nós removidos da rede, $f$. Em (a) é feita a comparação entre as dinâmicas de falhas e ataques para redes livres de escala $S F$ (modelo Barabási - Albert) e redes exponenciais (por meio do modelo de Erdös - Renyi). Cada rede possui $N=10000$ e $\langle k\rangle=4$. Em (b) foi avaliada a rede da uma amostra da Internet $\operatorname{com} N=6209$ e $\langle k\rangle=3.4$. Por fim, em (c), a rede World - Wide Web, sendo uma amostra com $N=325729$ e $\langle k\rangle=4.59$. Figura adaptada do artigo de Albert, Jeong e Barabási (Albert et al., 2000)

4.1 Diagrama esquemático para representação da entropia, entropia condicionada e informação mútua. Figura adaptada de Press, Teukolsky, Vetterling e Flannery (Press et al., 1992) . . . . . . . . . . . . . . . . . . . .

4.2 Exemplo de árvore de decisão em (a) para um espaço de características bidimensional com os atributos $x_{1}, x_{2}$ e as classes $w_{1}, w_{2}, w_{3}$ e $w_{4}$ em (b). Figura adaptada de (Theodoridis e Koutroumbas, 2003). . . . . . . . . . . .

4.3 Os diagramas mostram de maneira qualitativa a interação entre as variáveis, onde $C$ é a classe e $X_{i}$ são os atributos. Em (a) para o modelo Naive Bayes, onde há apenas a interação entre a classificação e os atributos. Em (b) o modelo de rede Bayesiana, onde considera-se que há interação entre os atributos e estes são considerados durante o processo de classificação. . . . . . . . . . . . . . . .

5.1 Distribuição de probabilidade para a rede Santa74: (a) pico de infectados para simulação do modelo SIR em cada um dos grupos obtidos, (b) medida $M_{i}$ em cada um dos grupos obtidos.

5.2 Distribuição de probabilidade para a rede Santa74 considerando medida $M_{i}$ para o melhor grupo em comparação com os demais. . . . . . . . . . . . .

5.3 Esta visualização é baseada no algoritmo force-directed proposto por Kamada e Kawai (Kamada e Kawai, 1989). Em (a) os nós com cores mais próximas ao vermelho são aqueles com maiores índices de $M_{i}$, enquanto aqueles com menores valores estão mais próximos da cor verde. Em (b) os nós pertencentes ao cluster mais central estão em vermelho. . . . . . . . . . . . . . . 
5.4 Pico de indivíduos infectados após os processos de imunização discutidos: grau, k-core, aleatória e a metodologia proposta (chamada aqui por kernel). Para quatro redes reais: rede de emails (a) - (c), rede de blogs de politica (d) - (f), rede Smith60 do Facebook (g) - (i) e rede Santa74 do Facebook (j) - (l). . . . . 60

5.5 Pico de indivíduos infectados para a árvore artificial após os processos de imunização discutidos: grau, k-core, aleatória e a metodologia proposta (chamada aqui por kernel). . . . . . . . . . . . . . . . . . . . . . .

6.1 Projeções segundo a técnica PCA considerando apenas propriedades estruturais e modelos de Watts - Strogatz. . . . . . . . . . . . . . . . . . . . . . . .

6.2 Projeções segundo a técnica PCA considerando apenas propriedades estruturais e modelos livres de escala. . . . . . . . . . . . . . . . . . . . . . . . .

6.3 Projeções segundo a técnica PCA considerando apenas propriedades estruturais e todos os modelos. . . . . . . . . . . . . . . . . . . . . . . . 73

6.4 Projeções segundo a técnica PCA considerando os os atributos selecionados para todos os modelos, isto é, tabela 6.3 . . . . . . . . . . . . . . . . .

6.5 Distribuição do pico de infectados em todos os modelos para o melhor par de parâmetros, em (a) e pior, em (b). . . . . . . . . . . . . . . . . . . . . . 76

7.1 Distribuições de probabilidade estimadas para as medidas que obtiveram as melhores posições na ordenação: (a) variância de closeness centrality; (b) Primeiro momento estatístico do k-core; (c) Máxima modularidade e (d) variância da acessibilidade. . . . . . . . . . . . . . . . . . . 86

7.2 Distribuições de probabilidade para o primeiro momento estatístico do (a) clustering coefficient e (b) menor caminho médio para redes saudáveis e portadoras de esquizofrenia. . . . . . . . . . . . . . . .

7.3 Distribuição de probabilidades da entropia dinâmica para redes saudáveis e esquizofrênicas. . . . . . . . . . . . . . . . . . . . 89

7.4 Eficiência relativa obtida pela remoção aleatória em (a) e ataques em (b). . . . . 89

7.5 Coerência de fases para redes saudáveis em (a) e para pacientes com esquizofrenia em (b). Cada ponto é o resultado para uma rede. . . . . . . . . . . . . . 90

7.6 Comparação entre as médias das coerências de fase obtidas para as duas classes em (a). Distribuição de probabilidades do segundo momento estatístico da distribuição de grau em (b) . . . . . . . . . . . . . . . . . . . . . . . . . 


\section{Lista de Tabelas}

4.1 Diagrama para uma matriz de confusão. Onde PPV e NPV correspondem as siglas Positive predictive value e Negative predictive value respectivamente. . . 48

5.1 Propriedades estruturais da base de dados. . . . . . . . . . . . . 55

6.1 Ordenação das 15 melhores medidas considerando a incerteza simétrica para duas classes de problemas: (i) modelo de Watts - Strogatz com probabilidades de reconexão de $p=0,01, p=0,1, p=0,2$ e $p=0,3$; (ii) modelos livres de escala: Barabási - Albert e Barabási não linear com $\alpha=3, \alpha=2, \alpha=1.5$. . .

6.2 Ordenação das 15 melhores medidas considerando a incerteza simétrica e a base com todos os modelos: aleatório de Erdös - Renyi; pequeno mundo de Watts - Strogatz com probabilidades de reconexão de $p=0,01, p=0,1, p=0,2 \mathrm{e}$ $p=0,3$; Barabási - Albert; Barabási não linear com $\alpha=3, \alpha=2, \alpha=1.5 \mathrm{e}$ redes geográficas segundo o modelo de Waxman. . . . . . . . . . . . . .

6.3 Melhor subconjunto encontrado por busca exaustiva considerando a metodologia CFS para duas classes de problemas: (i) todas as redes, isto é, aleatório de Erdös - Renyi; pequeno mundo de Watts - Strogatz com probabilidades de reconexão de $p=0,01, p=0,1, p=0,2$ e $p=0,3$; Barabási - Albert; Barabási não linear com $\alpha=3, \alpha=2, \alpha=1.5$ e redes geográficas segundo o modelo de Waxman; (ii) modelos livres de escala: Barabási - Albert e Barabási não linear $\operatorname{com} \alpha=3, \alpha=2, \alpha=1.5 . \ldots \ldots \ldots \ldots$

7.1 Ordenação de atributos para propriedades estruturais das redes funcionais utilizando incerteza simétrica e a estatística $\mathcal{X}^{2}$. As medidas foram ordenadas de acordo com a incerteza simétrica. . . . . . . . . . . . . . . . 85

7.2 Classificação de redes saudáveis e portadoras de esquizofrenia. . . . . . . . . . 87 


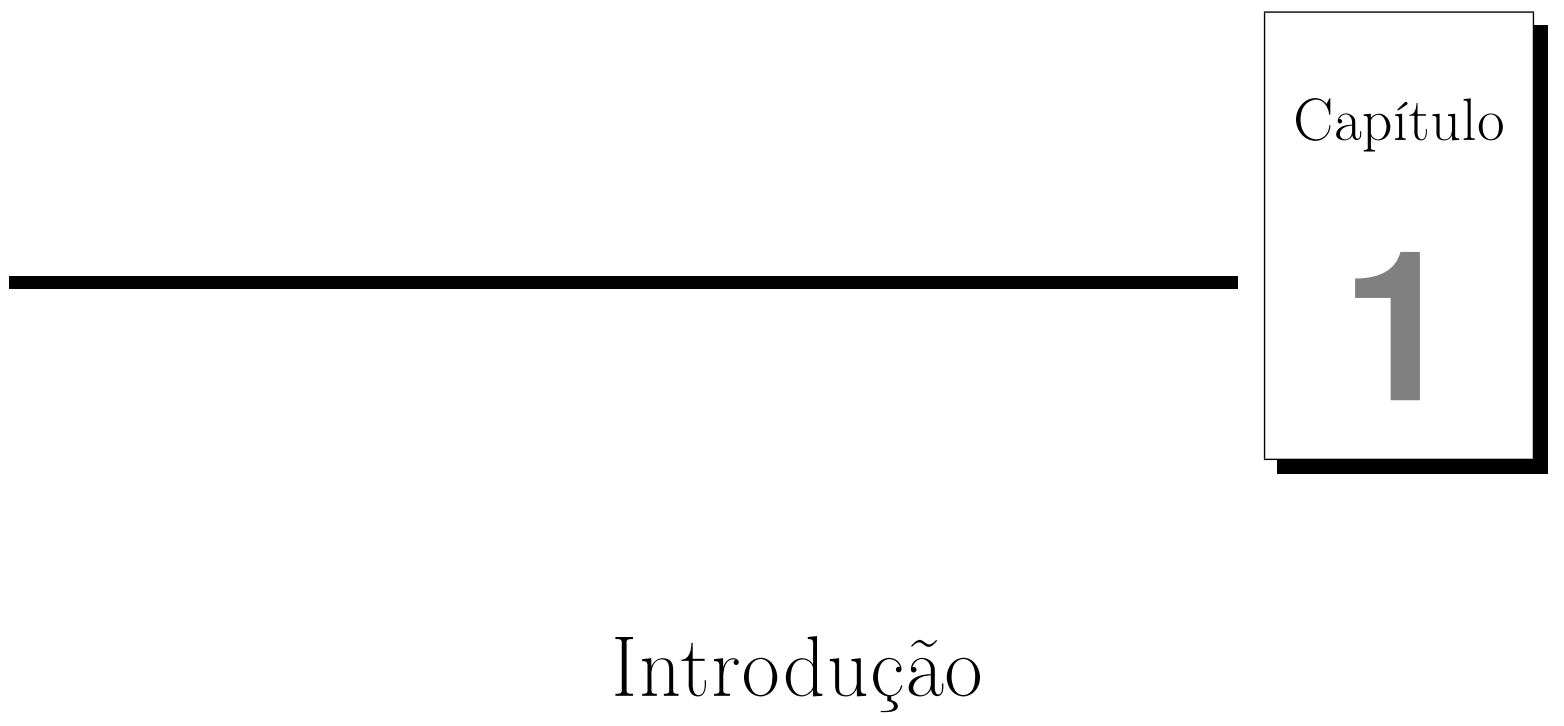

A tradicional abordagem reducionista adotada pela pesquisa científica considera a divisão de sistemas em partes, que são analisadas individualmente, de modo a entender o comportamento global de tais sistemas. Apesar do enorme avanço obtido por essa metodologia, ela não se mostrou adequada na análise de sistemas ditos complexos, formados por componentes individuais que se influenciam mutuamente (A.-L. Barabási, 2003; M. E. J. Newman, 2010). Essa limitação do tratamento reducionista ocorre, por exemplo, em neurociência, já que fenômenos emergentes como a consciência e processos cognitivos não podem ser explicados pela análise de um simples neurônio (Bullmore e Sporns, 2009). Sendo assim, o estudo de sistemas complexos exige uma abordagem holística, que tem como princípio o fato de que o comportamento desses sistemas não pode ser explicado apenas pela soma de seus componentes individuais (Amaral e Ottino, 2004).

Sistemas complexos são formados por elementos individuais que interagem de forma nãolinear. Logo, tais sistemas podem ser representados por grafos. Como a organização da maioria desses sistemas apresenta um alto grau de irregularidade na distribuição das conexões, além 
de padrões não triviais, tais como comunidades e motifs (Boccaletti et al., 2006), esses grafos são denominados redes complexas. Sendo assim, para representar a organização e analisar diferentes dinâmicas de sistemas complexos, surgiu no final da década de 90 a teoria das redes complexas (Watts e Strogatz, 1998; Albert, 1999).

Esta teoria, com caráter altamente interdisciplinar, ganhou importância entre a comunidade científica a partir de 1999, quando foram mapeadas as topologias da Internet e da World Wide Web (Faloutsos et al., 1999; A. Barabási et al., 1999). A motivação da modelagem por redes surgiu com a observação de que a organização de muitos sistemas complexos não é puramente aleatória, mas está ligada às características particulares de cada sistema (Faloutsos et al., 1999; Albert, 1999). Por exemplo, no caso da Internet, os roteadores mais importantes, localizados em grandes centros urbanos, tendem a receber um maior de número de conexões ao longo do tempo do que os roteadores localizados em cidades menores. De maneira semelhante há certas pessoas na sociedade que possuem um número elevado de contatos sociais, enquanto a maioria da população se organiza em pequenas comunidades — como se pode observar em comunidades sociais (e.g. Facebook). Nesses dois casos, a topologia da rede se auto-organiza de forma que haverá alguns vértices altamente conectados, denominados hubs, enquanto a maioria deles apresenta poucas conexões. Trabalhos recentes verificaram que tal organização é fundamental para garantir a robustez de um sistema com relação a falhas aleatórias, como mutações genéticas em redes celulares (Albert et al., 2000).

Embora muitos fundamentos e conceitos tenham sido desenvolvidos para caracterização e análise dinâmica de redes complexas, há algumas limitações ainda não resolvidas. Por exemplo, como padrões de conexão influenciam na emergência de processos dinâmicos? Quais medidas mais adequadas para se caracterizar uma rede? Nesta dissertação, utilizamos técnicas de mineração de dados a fim de caracterizar, classificar e analisar a relação entre estrutura e dinâmica de redes complexas. Além disso, a utilização de tais métodos no pré-processamento de redes permite determinar as medidas topológicas mais significativas para serem utilizadas no processo de classificação supervisionada. Tais técnicas incluem extração, seleção e ordenação de atributos (Theodoridis e Koutroumbas, 2003). Ademais, métodos de classificação não-supervisionada são utilizados para determinar como medidas de centralidade influenciam processos de propagação de epidemias. 
A seguir, serão descritos os objetivos desse trabalho e sua justificativa.

\subsection{Objetivos}

Basicamente, este trabalho tem por objetivo analisar a estrutura e dinâmica em redes complexas com o uso de técnicas de mineração de dados. A seguir, serão descritos detalhadamente cada um dos objetivos.

- Identificação dos nós mais influentes em propagação de epidemias: A organização de uma rede complexa influencia diretamente em processos dinâmicos (Boccaletti et al., 2006). Tal influência ocorre a nível local, de modo que cada vértice contribui para a emergência do fenômeno global, como ocorre em propagação de epidemias. Desse modo, objetivamos analisar como padrões de conexões (clusters de vértices) influenciam na evolução de um processo dinâmico específico. Tais padrões serão obtidos a partir dos métodos de agrupamento de dados, tal como expectation maximization (descrito no capítulo 4), que permitem agrupar os vértices de uma rede de acordo com propriedades locais. No caso da dinâmica de propagação de epidemias, vamos determinar o nível de contágio partindo de cada vértice e, consequentemente, a distribuição de tais níveis para cada cluster. Desse modo, é possível identificar os padrões de conexões dos vértices que mais disseminam uma epidemia. Tal estudo permite desenvolver métodos de vacinação que permitam controlar a propagação de uma epidemia.

\section{- Determinação das medidas mais importantes para caracterização de redes comple-} xas: Existem dezenas de medidas para caracterização de redes complexas (Costa et al., 2007). Sendo assim, a escolha de quais medidas devem ser utilizadas no processo de caracterização e classificação de redes é geralmente arbitrária. O que se faz na maioria das vezes é escolher medidas relacionadas a uma dada propriedade que se deseja caracterizar, como a centralidade ou a ocorrência de ciclos em uma rede. Por exemplo, se um pesquisador está interessado em analisar propriedades centrais, ele pode utilizar as medidas grau de intermediação, eigenvector centrality e closeness centrality. No entanto, essa escolha ainda é arbitrária, já que outras medidas de centralidade, como o PageRank, poderiam ser utilizadas. Desse modo, a fim de eliminar essa arbitrariedade na escolha 
das medidas, propomos a utilização de métodos de seleção e ordenação de atributos (ver capítulo 4). Assim, vamos ordenar os atributos por importância, de modo a determinar aqueles que são mais relevantes para descrever a estrutura de uma rede. Tal ordenação permite, por exemplo, verificar quais medidas proporcionam maior discriminação entre classes de redes.

- Análise e classificação de redes corticais de pacientes com esquizofrenia: Uma das aplicações para redes complexas que tem ganhado bastante força é a análise de redes corticais. Com aumento do interesse da comunidade científica na coleta e análise de dados relativos ao padrão de interações entre as diversas regiões corticais por meio de R-fMRI (do inglês, Resting state functional magnetic resonance imaging) houve um aumento na quantidade de dados disponível de pacientes doentes, bem como saudáveis, para formar um grupo de controle. Utilizamos uma base de dados apresentada em (Vértes et al., 2012) ${ }^{1}$, onde os autores avaliam diferenças na distribuição de grau entre redes de pacientes saudáveis e com esquizofrenia infantil, além de proporem um modelo de redes complexas para descreverem tais redes. Nossa proposta neste objetivo foi a aplicação de técnicas de teoria da informação, estatística e mineração de dados para avaliação das medidas mais relevantes para o estudo de tais redes. Realizando uma análise estrutural e dinâmica das mesmas, além da classificação destas redes. Sendo que parte deste é uma aplicação objetivo descrito anteriormente. Ademais, realizamos uma avaliação de processos dinâmicos em tais redes, comparando o comportamento de redes de pacientes saudáveis com aqueles que possuem esquizofrenia.

\subsection{Descrição dos capítulos}

O capítulo 2 apresenta uma breve introdução aos conceitos de redes complexas, desde sua representação até medidas de caracterização e modelos teóricos utilizados durante este trabalho. As medidas abordadas foram separadas por: (i) Medidas relacionadas a conectividade; (ii) medidas relacionadas a ciclos; (iii) menores caminhos e medidas relacionadas; (iv) medidas relacionadas à busca por informação; (v) K-Core; (vi) medidas espectrais e baseadas em caminhadas aleatórias e (vii) modularidade e estrutura de comunidades.

\footnotetext{
${ }^{1}$ Disponível em http://intramural.nimh.nih.gov/chp/matlab.html
} 
No capítulo 3 são abordados processos dinâmicos em redes. Será feita uma breve descrição para propagação de epidemias e sincronização, focando no modelo de Kuramoto.

A seguir, no capítulo 4, são apresentados os conceitos de mineração de dados que serão aplicados neste trabalho. São eles: (i) pré processamento dos dados; (ii) ordenação de atributos utilizando conceitos de teoria da informação; (iii) uma breve introdução sobre os conceitos fundamentais sobre seleção de atributos; (iv) extração de atributos, pelas técnicas Principal Component Analysis e Linear Discriminat Analysis; (v) classificação utilizando árvores de decisão e abordagens Baysianas; (vi) técnicas para avaliação de modelos preditivos, incluindo validação e métricas para avaliação, focando principalmente em problemas de duas classes e (vii) agrupamento de dados.

O capítulo 5 é uma análise em micro escala, ou seja, no nível dos nós e medidas centrais. Aqui, têm-se como principal objetivo obter subconjuntos de vértices que sejam mais influentes e apresentam comportamento dinâmico semelhante utilizando apenas medidas de centralidade. Verificamos como uma metodologia de agrupamento de dados pode ser utilizada para tal identificação. Além disso, a imunização destes nós é mais eficiente que as metodologias tradicionais, reforçando a metodologia utilizada.

No capítulo 6, analisamos as medidas de redes apresentadas no capítulo 2 e medidas de desempenho para processos dinâmicos, visando determinar aqueles que são mais importantes para caracterização e discriminação entre os modelos teóricos. Verificando a necessidade de tal metodologia, pois a escolhas das medidas de caracterização pode ser contra intuitiva. Ademais, observa-se que propriedades relacionadas aos menores caminhos são fundamentais para tarefas de caracterização.

A seguir, no capítulo 7 realizamos uma análise estrutural e dinâmica de redes corticais, utilizando as técnicas de seleção e ordenação de atributos introduzidas no capítulo 6, bem como classificação de redes. De fato, observou-se boa separação entre as redes de pacientes saudáveis e com esquizofrenia, sugerindo que a doença está relacionada com as variações estruturais encontradas. Além disso, foi proposta uma metodologia não invasiva para diagnóstico baseada em descritores de redes complexas. 
Por fim seguem os capítulos com trabalhos futuros e conclusões. Onde serão apresentadas algumas das possibilidades para sequência dos trabalhos, bem como uma discussão sobre possíveis aplicações e consequências dos resultados obtidos aqui. 


\section{Caracterização e modelos de redes complexas}

A teoria das redes complexas representa sistemas complexos por meio de grafos. Estes são formados por um conjunto de vértices (também chamados nós), $\mathcal{N}=\left\{n_{1}, n_{2}, \ldots, n_{N}\right\}$, que são conectados por um conjunto de arestas (links), $\mathcal{L}=\left\{l_{1}, l_{2}, \ldots, l_{M}\right\}$, devido a algum tipo de interação. De maneira geral, redes complexas são grafos com estrutura altamente irregular (Boccaletti et al., 2006). Computacionalmente, pode-se representar uma rede como uma lista de conexões ou como uma matriz de adjacências. No caso de listas, as conexões são armazenadas como pares $(i, j)$, onde $i$ e $j$ são os vértices da aresta. Na representação matricial (ver Figura 2.1), a rede é representada por uma matriz $A$, de dimensão $N \times N$, onde $N$ é o número de vértices, cujos elementos $a_{i j}$ são iguais a 1 se existir uma conexão entre os vértices $i$ e $j$ e iguais a zero, caso contrário. Em redes não-dirigidas, a matriz de adjacências é simétrica, i.e. $a_{i j}=a_{j i}$, enquanto em redes dirigidas, geralmente $a_{i j} \neq a_{j i}$.

Em redes complexas, geralmente não ocorrem mais de uma aresta entre dois vértices, nem autoconexões, isto é, uma aresta que liga um vértice a ele mesmo. 


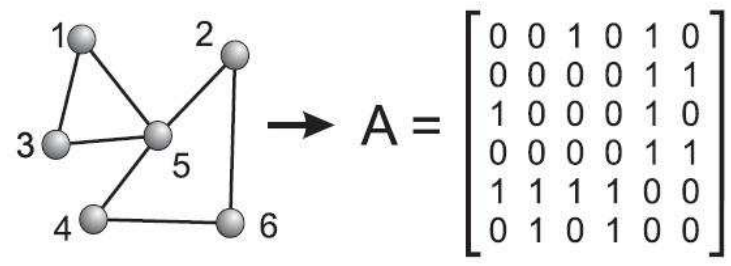

(a)

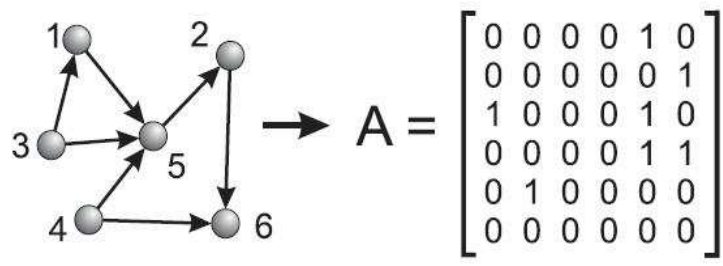

(b)

Figura 2.1: Redes complexas podem ser representadas por matrizes de adjacência. Em (a) temos uma rede não-dirigida e em (b) uma rede dirigida. No caso (a), os elementos $a_{i j}$ da matriz são iguais a 1 se há uma ligação entre os vértices $i$ e $j$ e iguais a zero, caso contrário. Já no caso (b), os elementos da matriz $a_{i j}$ são iguais a 1 se existe uma conexão dirigida do vértice $i$ para o vértice $j$.

\subsection{Caracterização de redes complexas}

Medidas de redes são fundamentais para a sua caracterização, representação, classificação e análise. Nesta seção, descrevemos as medidas consideradas em nosso trabalho.

\subsubsection{Medidas relacionadas a conectividade}

O grau, ou conectividade, de um vértice é igual ao número de arestas incidentes no mesmo, sendo definido em termos da matriz de adjacência A como:

$$
k_{i}=\sum_{j \in \mathcal{N}} a_{i j}
$$

Para redes dirigidas é possível generalizar este conceito, obtendo-se uma grandeza para o número de arestas que "saem" do nó, $k_{i}^{o u t}$ e outra para o número de arestas que "chegam”, ou incidentes ao nó, $k_{i}^{i n}$. Neste caso, o grau total é igual a $k_{i}=k_{i}^{o u t}+k_{i}^{i n}$. Nós que possuem altos valores para o grau são conhecidos como hubs.

Um grande número de redes reais é correlacionada no sentido que a probabilidade de um nó com grau $k$ estar conectado a um vértice de grau $k^{\prime}$ depende de $k$. Neste caso é necessário considerar a probabilidade condicional $P\left(k^{\prime} \mid k\right)$, isto é, a probabilidade de uma aresta de um nó com grau $k$ incida sobre outro de grau $k^{\prime}$. Assim (Boguñá e Pastor-Satorras, 2002):

$$
P\left(k^{\prime} \mid k\right)=\frac{\langle k\rangle P\left(k, k^{\prime}\right)}{k P(k)}
$$


onde $\langle k\rangle$ é o grau médio da rede.

Observe que $\sum_{k^{\prime}} P\left(k^{\prime} \mid k\right)=1$. Para redes não-dirigidas, $P\left(k \mid k^{\prime}\right)=P\left(k^{\prime} \mid k\right) \mathrm{e}$ $k^{\prime} P\left(k \mid k^{\prime}\right) P\left(k^{\prime}\right)=k P\left(k^{\prime} \mid k\right) P(k)$. Note que $P\left(k \mid k^{\prime}\right)$ e $P\left(k^{\prime} \mid k\right)$ caracterizam a correlação entre o grau dos vértices (Boccaletti et al., 2006; Costa et al., 2007).

Uma maneira de determinar a correlação do grau é considerando-se o coeficiente de correlação de Pearson do grau dos extremos de cada aresta (M. Newman, 2002):

$$
\rho=\frac{(1 / M) \sum_{j>i} k_{i} k_{j} a_{i j}-\left[(1 / M) \sum_{j>i}(1 / 2)\left(k_{i}+k_{j}\right) a_{i j}\right]^{2}}{(1 / M) \sum_{j>i}\left(k_{i}^{2}+k_{j}^{2}\right) a_{i j}-\left[(1 / M) \sum_{j>i}(1 / 2)\left(k_{i}+k_{j}\right) a_{i j}\right]^{2}}
$$

onde $M$ é o número total de arestas. Caso $\rho>0$ a rede é assortativa, indicando que vértices com altos valores de grau tendem a se conectarem, caso $\rho<0$, a rede é disassortativa, indicando que vértices com altos valores de grau conectam-se a vértices de baixo grau e para $\rho=0$ não há correlação entre o grau dos vértices.

Outra medida relacionada ao grau é a conectividade média dos vizinhos, tendo uma dependência em $i$, no vértice. Tal medida é definida pela expressão:

$$
k n n(i)=\frac{1}{k_{i}} \sum_{j}^{N} a_{i j} k_{j}
$$

onde $a_{i j}$ é o elemento da matriz de adjacência $A$ e $k_{i}$ é a conectividade do vértice $i$.

\subsubsection{Coeficiente de aglomeração}

Clustering coefficient ou coeficiente de aglomeração, em português, caracteriza a presença de ciclos de ordem três. Esta medida também pode ser interpretada como a probabilidade de dois vizinhos de um vértice estarem conectados. Há duas maneiras diferentes para quantificar a presença de tais ciclos. A primeira é conhecida como transitividade (M. Newman, 2001), definida pela seguinte expressão:

$$
C=\frac{3 N_{\triangle}}{N_{3}}
$$

onde $N_{\triangle}$ é o número de triângulos presentes na rede e $N_{3}$ é o número de triplas conectadas. Note que $0 \leq C \leq 1$ 


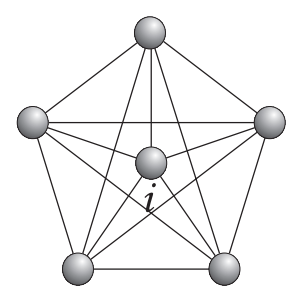

(a)

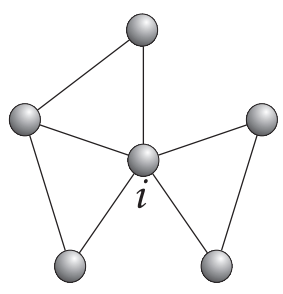

(b)

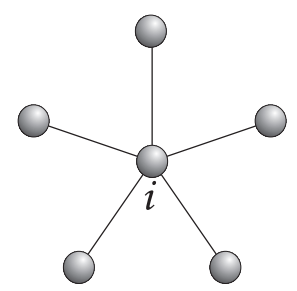

(c)

Figura 2.2: Ilustração esquemática de três situações onde o coeficiente de aglomeração tem diferentes valores. Em (a) é apresentado um exemplo de clique, onde todos os vértices estão conectados entre si. Neste caso, $C_{i}=1$. Na figura (b), $C_{i}=3 / 10$. Já em (c) $C_{i}=0$, pois os vizinhos do vértice $i$ não possuem conexões entre si.

A segunda definição calcula o coeficiente para cada vértice $i$ (Watts e Strogatz, 1998), através de:

$$
C(i)=\frac{3 N_{\triangle}(i)}{N_{3}(i)}
$$

onde $N_{\triangle}(i)$ é o número de triângulos envolvendo o vértice $i$ e $N_{3}(i)$ é o número de trios conectados que possuem o nó $i$ como vértice central. Estas podem ser calculadas pelas expressões a seguir:

$$
\begin{gathered}
N_{\triangle}(i)=\sum_{k>j} a_{i j} a_{i k} a_{j k}, \\
N_{3}(i)=\sum_{k>j} a_{i j} a_{i k} .
\end{gathered}
$$

A figura 2.2 exemplifica o conceito deste índice. Em (a) todos os vértices estão conectados entre si, neste caso, $C_{i}=1$. Em (b), $C_{i}=3 / 10$, já em (c) $C_{i}=0$, pois os vizinhos do vértice $i$ não possuem conexões entre si.

Vale ressaltar que a distribuição de probabilidades do coeficiente de aglomeração é contínua, portanto será necessário utilizar a seguinte expressão para a construção do histograma de $C(i)$ (Sturges, 1926):

$$
k_{s}=\left\lceil\log _{2} n+1\right\rceil,
$$

onde $k_{s}$ é o o número de caixas para um conjunto de dados $x \operatorname{com} n$ amostras. Assim, o tamanho de cada caixa, $h$, é obtido por meio da seguinte relação,

$$
k_{s}=\left\lceil\frac{\max (x)-\min (x)}{h}\right\rceil .
$$


A partir do histograma pode-se extrair seu n-ésimo momento, bem como sua variância e entropia (Shannon e Weaver, 1948), que podem ser consideradas como medidas globais da rede.

\subsubsection{Menores caminhos e medidas relacionadas}

Menores caminhos ou geodésica, representam um importante tópico de estudos em redes, principalmente na análise de transportes e comunicação (Costa et al., 2007). Tais caminhos são obtidos através dos algoritmos de Dijkstra ou uma busca em amplitude (Cormen et al., 2001). Para cada par de vértices, $i$ e $j$, há $n_{i j}$ menores caminhos, sendo que este pode ser igual a zero, caso em que o grafo possuí duas ou mais componentes ${ }^{1}$, neste caso diz-se que o menor caminho entre $i$ e $j$ é infinito.

A partir dos menores caminhos foram propostas diversas medidas (Boccaletti et al., 2006; Costa et al., 2007). A média do comprimento do menor caminho, também chamada de comprimento do caminho característico (Watts e Strogatz, 1998; Watts, 1999) é calculado por:

$$
L=\frac{1}{N(N-1)} \sum_{i, j \in \mathcal{N}, i \neq j} d_{i j},
$$

onde $d_{i j}$ é o comprimento do menor caminho entre $i$ e $j$.

Porém, esta medida diverge quando há mais de um componente conexo. Para eliminar esta limitação da medida $L$ foi proposta a medida de eficiência da rede (Latora e Marchiori, 2001):

$$
E=\frac{1}{N(N-1)} \sum_{i, j \in \mathcal{N}, i \neq j} \frac{1}{d_{i j}} .
$$

Note que o calculo de $E$ difere de $L$ apenas por considerar o inverso da média harmônica ao invés da média aritmética. A medida $E$ é um indicador de capacidade de trafego na rede (Boccaletti et al., 2006).

A partir das distâncias é possível quantificar o grau de centralidade de um vértice. Sendo assim, a medida betweenness centrality (também conhecida como carga do nó), foi originalmente introduzida para quantificar a importância de um individuo em uma rede social (Freeman,

\footnotetext{
${ }^{1}$ Um componente conexo é um sub-grafo onde há pelo menos um caminho entre cada par de vértices.
} 
1977), sendo definida por:

$$
b_{i}=\sum_{j, k \in \mathcal{N}, j \neq k} \frac{n_{j k}(i)}{n_{j k}},
$$

onde $n_{j k}(i)$ é igual ao número de menores caminhos conectando $j$ e $k$ que passam por $i$.

Esta medida pode ser generalizada para as arestas, conhecida como edge betweenness, sendo definida como o número de menores caminhos entre um par de nós que passa por uma determinada aresta. A medida de betweenness centrality para vértices e arestas pode ser expressa na forma de histogramas, sendo possível extrair seus momentos, variância e entropia.

Outra medida relacionada à betweenness centrality é a dominância do ponto central, ou CPD, do inglês, central point dominance (Freeman, 1977), sendo definida como:

$$
C P D=\frac{1}{N(N-1)} \sum_{i}\left(b_{\max }-b_{i}\right)
$$

onde $b_{\max }$ é o maior valor de betweenness centrality na rede e $b_{i}$ é o valor de betweenness centrality do nó $i$. A $C P D$ será zero para um grafo completo e 1 para um grafo em estrela, onde todos os caminhos passam pelo vértice central.

Outra medida de centralidade importante é conhecida como closeness centrality, que é muito utilizada em redes sociais. Sua definição é dada por:

$$
C_{i}=\frac{N}{\sum_{j} d_{i j}}
$$

\subsubsection{Medidas relacionadas à busca por informação}

Uma caminhada aleatória é caracterizada por um passeio onde não há nenhum tipo de preferencia quanto ao próximo passo. Desta maneira, um andarilho no vértice $i$ caminha para um de seus vizinhos com probabilidade $\frac{1}{k_{i}}$.

Considerando $l(i, b)$ um menor caminho entre os vértices $i$ e $b$, a probabilidade de seguir este caminho em uma caminhada aleatória é dada por (Rosvall et al., 2005):

$$
\mathcal{P}[l(i, b)]=\frac{1}{k_{i}} \prod_{j \in l(i, b)} \frac{1}{k_{j}-1}
$$


onde $k_{j}$ é o grau do vértice $j$ e o produto inclui todos os vértices $j$ no caminho, excluindo-se os vértices $i$ e $b$.

Assim, a informação necessária para identificar um dos menores caminhos entre $i$ e $b$ é dada por:

$$
\mathcal{S}(i, b)=\log _{2} \sum_{\{l(i, b)\}} \mathcal{P}[l(i, b)]
$$

onde a somatória é feita sobre todos o menores caminhos entre os vértices $i$ e $b$.

A busca média por informação (Rosvall et al., 2005) caracteriza a facilidade ou dificuldade de navegação em uma rede, sendo dada por (Rosvall et al., 2005):

$$
\mathcal{S}=\frac{1}{N^{2}} \sum_{i b} \mathcal{S}(i, b)
$$

Para quantificar a dificuldade de encontrar-se vértices partindo de um vértice $i$, foi proposta a medida chamada acesso à informação, que é dada por (Rosvall et al., 2005):

$$
\mathcal{A}_{i}=\frac{1}{N} \sum_{b} \mathcal{S}(i, b)
$$

Para medir a dificuldade de se encontrar o vértice $b$ a partir de qualquer outro vértice utilizase a informação escondida (Rosvall et al., 2005):

$$
\mathcal{H}_{b}=\frac{1}{N} \sum_{i} \mathcal{S}(i, b)
$$

Note que: $\sum_{i} \mathcal{A}_{i}=\sum_{b} \mathcal{H}_{b}=\mathcal{S} N$.

\subsubsection{K-Core}

A estrutura de grafos muito grandes pode ser estudada a partir da segmentação em partes menores, que são mais simples de serem manipuladas. Uma decomposição possível é baseada em $k$-cores, proposta por Seidman (Seidman, 1983).

O subgrafo induzido $H_{k}$ é um $k$-core, ou núcleo de ordem $k$, se todo vértice de $H_{k}$ possui grau maior ou igual à $k$ e $H_{k}$ for o maior grafo com esta propriedade. O core de maior ordem é chamado de core principal e o número de core de um vértice, $v$, é a maior ordem de core que contêm este vértice, denotado por $k_{S}(v)$. 

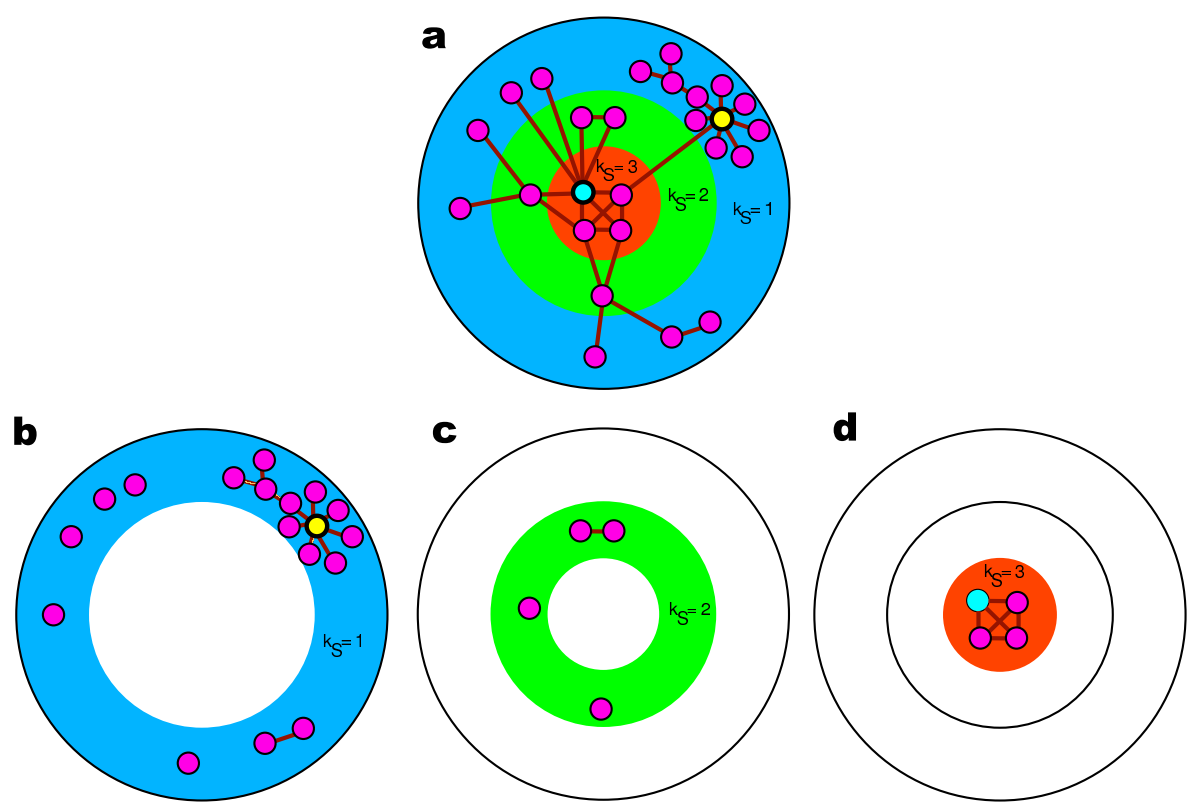

Figura 2.3: Exemplo do algoritmo de decomposição em núcleos. Em (a) a rede original com a respectiva divisão em núcleos; em (b), (c) e (d) os subgrafos induzidos que compõe os núcleos de $k_{S}=1, k_{S}=2$ e $k_{S}=3$ respectivamente. Figura adaptada de (Kitsak et al., 2011)

Um algoritmo rápido para realizar a decomposição em k-cores foi proposto em (Batagelj e Zaversnik, 2003), que tem ordem de complexidade $O(M)$. Este é baseado na remoção dos nós de acordo com seu grau. Na primeira etapa excluí-se aqueles vértices com grau $k=1$, assim, novos vértices com grau $k=1$ irão surgir. Continua-se eliminando tais nós, até que não haja mais nós com grau $k=1$. Os vértices removidos, bem como as arestas que conectam os mesmos formam o núcleo $k_{S}=1$. A seguir, repete-se o mesmo procedimento para os demais valores de grau presentes na rede. A figura 2.3 exemplifica o algoritmo de decomposição em núcleos.

É importante observar que este procedimento associa um índice $k_{S}$ único para cada nó da rede, sendo que $k \geq k_{S}$.

\subsubsection{Medidas espectrais e baseadas em caminhadas aleatórias}

O espectro de uma rede é dado pelo conjunto de autovalores $\lambda_{i}$ da matriz de adjacências. A densidade espectral é definida por (Farkas et al., 2001; Goh et al., 2001):

$$
\rho(\lambda)=\frac{1}{N} \sum_{i} \delta\left(\lambda-\lambda_{i}\right)
$$


onde $\delta(x)$ é a função delta de Dirac e $\rho$ tende à uma função contínua se $N$ tende ao infinito. Os autovalores podem ser usados para calcular o l-ésimo momento espectral:

$$
M_{l}=\frac{1}{N} \sum_{i_{1}, i_{2}, \ldots, i_{l}} a_{i_{1} i_{2}} a_{i_{2} i_{3}} \ldots a_{i_{l} i_{1}}=\frac{1}{N} \sum_{i}\left(\lambda_{i}\right)^{l}
$$

Os autovalores e autovetores da matriz de adjacências estão relacionados ao diâmetro, número de ciclos e conectividade da rede (Farkas et al., 2001; Goh et al., 2001). A expressão $D_{l}=N M_{l}$ é o número de caminhadas retornando ao mesmo vértice passando por $l$ vértices, sendo que estes podem conter vértices já visitados.

A acessibilidade é uma medida que está associada a facilidade de se encontrar um determinado vértice. Esta foi inicialmente definida em (Travençolo et al., 2008), de maneira multiescala, como:

$$
A c c_{h}(i)=e^{-\sum_{j} P_{h}(i, j) \log P_{h}(i, j)}
$$

onde $P_{h}(i, j)$ é a probabilidade de ir do nó $i$ ao nó $j$ em $h$ passos e $P_{h}=P^{h}$. A matriz $P$ é chamada de matriz de probabilidade de transição. Esta é definida como:

$$
P(i, j)=\frac{a_{i, j}}{\sum_{j} a_{i, j}}=\frac{a_{i, j}}{k_{i}} .
$$

Para evitar a dependência do parâmetro $h$ e considerar todas as escalas possíveis foi proposta a seguinte formulação (Barbieri, 2010):

$$
\mathbf{P}=\sum_{k=0}^{\infty} \frac{1}{k !} P^{k}=e^{P}
$$

onde $\mathbf{P}$ é conhecida como matriz de probabilidade de comunicação e considera todos os caminhos possíveis ponderando cada um deles pelo fatorial do seu comprimento. Assim, a medida de acessibilidade total é dada por,

$$
A c c(i)=e^{-\sum_{j} \mathbf{P}(i, j) \log \mathbf{P}(i, j)} .
$$

Essa medida resulta em valores altos para vértices cujas localizações permitem que se comuniquem com vértices de mesma probabilidade (Barbieri, 2010), como é exemplificado na 


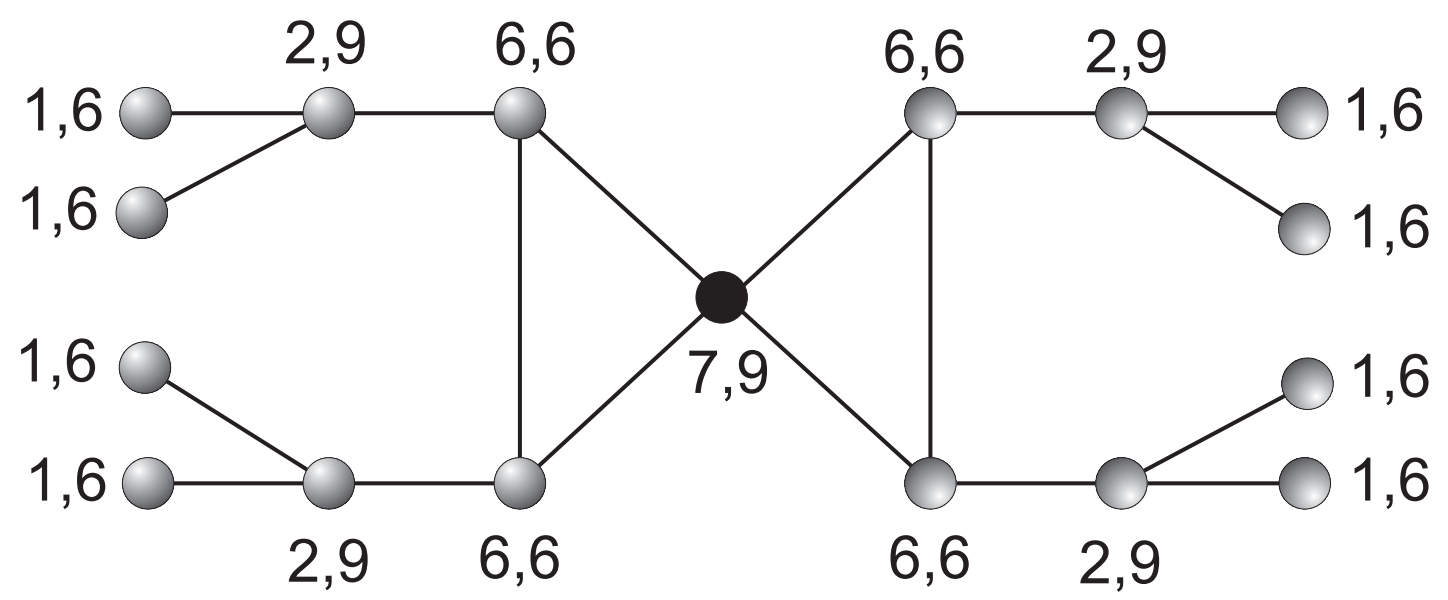

Figura 2.4: Visualização do conceito de acessibilidade. Figura adaptada de (Barbieri, 2010)

figura 2.4. Como esta característica está associada a cada vértice, é possível extrair seu histograma e demais medidas associadas. Assim obtêm-se medidas globais de acessibilidade da rede.

Ainda utilizando o conceito de caminhadas aleatórias, outra medida que foi definida na literatura é a comunicabilidade (Ernesto e Hatano, 2008), que toma por base o principio da dispersão de partículas. Assim,

$$
\mathcal{C}=e^{A}=\sum_{k=0}^{\infty} \frac{1}{k !} A^{k},
$$

onde $A$ é a matriz de adjacência e $\mathcal{C}$ é chamada de matriz de comunicabilidade, onde o elemento $\mathcal{C}(i, j)$ é o número de caminhos entre os vértices $i$ e $j$ ponderados por $\frac{1}{k !}$, onde $k$ é o comprimento do caminho.

Esta medida pode ser considerada como uma generalização dos menores caminhos, descritos anteriormente, pois nem toda informação caminha pelas geodésicas, parte dela utiliza caminhos alternativos (Ernesto e Hatano, 2008).

Para se obter medidas globais associadas à comunicabilidade, extrai-se o histograma da matriz de comunicabilidade, equação 2.27, e a partir dele seus momentos, variância e entropia.

Outra medida de caracterização baseada em caminhadas aleatórias é o PageRank, que define a importância de um vértice como sendo proporcional à centralidade dividida pelo grau de saída do nó. Desta maneira, vértices que apontam para muitos outros contribuem com apenas uma pequena quantidade para a centralidade de seus vizinhos. Esta medida é definida por:

$$
P R_{i}=\alpha_{P R} \sum_{j} a_{i j} \frac{P R_{j}}{k_{j}},
$$


onde $\alpha_{P R}=0.85$ como originalmente definida em (Brin e Page, 1998).

A centralidade de redes também pode ser caracterizada por uma medida denominada $e i$ genvector centrality. Diferentemente do grau, esta medida não considera que todas as conexões possuem mesma importância. Neste caso a conexão com nós mais “influentes” irá garantir mais peso do que com vértices de "menor importância". Sendo $V_{i}$ a centralidade do vértice $i$, tem-se que esta é proporcional a centralidade dos seus vizinhos:

$$
V_{i}=\frac{1}{\lambda} \sum_{j=1}^{N} a_{i j} V_{j}
$$

onde $\lambda$ é uma constante. Definindo o vetor de centralidades $\vec{V}=\left[V_{1}, V_{2}, \ldots, V_{N}\right]$ é possível reescrever a equação 2.29 na forma matricial:

$$
\lambda \vec{V}=\mathbf{A} \vec{V}
$$

onde $\vec{V}$ é o autovetor da matriz de adjacências com autovalor $\lambda$. Como se deseja valores de centralidade positivos — que pode ser mostrado pelo teorema de Perron-Frobenius $-\lambda$ deve ser o maior autovalor e $\vec{V}$ seu autovetor correspondente (M. E. J. Newman, 2010).

\subsubsection{Modularidade e estrutura de comunidades}

A estrutura das comunidades em redes complexas é caracterizada pela presença de módulos na rede. Isto é, são formadas por conjuntos de nós mais fortemente conectados dentro de suas comunidades do que à nós de outras. De maneira semelhante a definição utilizada em sociologia. O problema de reconhecimento de comunidades em redes complexas é do tipo NP-difícil, sendo necessária a aplicação de alguma heurística para guiar a busca pelo espaço de soluções. A solução mais aceita atualmente pela comunidade cientifica consiste na otimização da função de modularidade, que compara uma partição com uma rede aleatória. Formalmente definida por:

$$
Q=\frac{1}{2 M} \sum_{i \neq j}\left(A_{i j}-\frac{k_{i} k_{j}}{2 M}\right) \delta\left(c_{i}, c_{j}\right),
$$

onde $k_{i} k_{j} / 2 M$ é a probabilidade de que exista uma aresta entre os vértices $i$ e $j$ se as conexões forem realizadas de maneira aleatória, sendo que $M$ é o número de arestas presente no grafo 


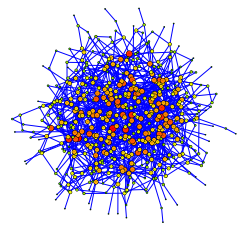

(a) Modelo aleatório de Erdös Renyi.

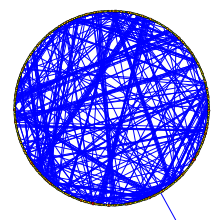

(b) Modelo de pequeno mundo de Watts - Strogatz.

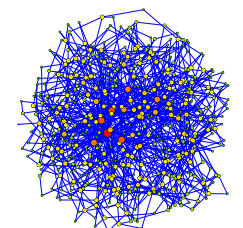

(c) Modelo livre de escala de Barabási - Albert.

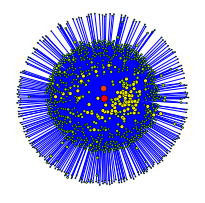

(d) Modelo livre de escala com conexão preferencial não linear, $\alpha=3$.

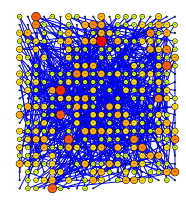

(e) Modelo geográfico.

Figura 2.5: Exemplos de redes complexas gerada por diferentes modelos. Todas as redes possuem grau médio $\langle k\rangle=2$ e $N=500$ nós. Em todas as figuras o tamanho do nó e a cor do nó representam o grau, ou seja, quanto maior e mais próxima do vermelho maior o grau do nó e quanto menor e mais próximo da cor verde menor é o grau.

e $\delta\left(\sigma_{i}, \sigma_{j}\right)$ é igual a 1 se $c_{i}=c_{j}$ e igual a 0 caso contrário, onde $c_{i}$ é a comunidade a qual o vértice pertence. Se a fração de arestas entre comunidades não é diferente do que se espera de uma versão aleatória da rede, o valor de $Q$ será próximo de 0 e caso este valor seja próximo de 1 a rede é bastante modular, ou seja, possui uma forte estrutura de comunidades.

Em (Fortunato, 2010) é feita uma revisão de diversos métodos utilizados para obtenção de comunidades baseados na otimização da modularidade, equação 2.31 .

\subsection{Modelos de redes complexas}

Afim de modelar a topologia e evolução de sistemas complexos, diversos modelos de redes complexas foram propostos na literatura (Boccaletti et al., 2006). A figura 2.5 (a) é uma representação gráfica de uma rede aleatória e (b) é um modelo de pequeno mundo, proposto por Watts - Strogatz, que se situa entre a aleatoriedade e a regularidade, como será descrito a seguir. As figuras 2.5 (c) e (d) são redes livres de escala, construídas por meio de processos de conexão preferencial, linear para o item (c) e não-linear para o item (d). Por fim, a figura 2.5 (e) é um modelo geográfico, onde a construção é feita baseando-se na posição dos vértices que estão distribuídos em um espaço euclidiano. Todos estes modelos serão descritos em detalhes nas subseções a seguir. 


\subsubsection{Modelo Aleatório: Erdös - Renyi}

Inicialmente proposto pelos matemáticos Paul Erdös e Alfred Renyi em 1959 (Erdös e Rényi, 1959), o modelo que gera grafos aleatórios foi muito estudado teoricamente (Bollobás, 2001). No entanto, tal modelo não é adequado para gerar estruturas representativas de redes reais (M. Newman, 2003).

Para gerar redes segundo esse modelo, inicia-se com um conjunto de $N$ vértices totalmente desconectados e a cada passo, dois vértices são escolhidos aleatoriamente e conectados com uma probabilidade fixa $p$, sendo cada par de vértices considerado apenas uma vez. Dessa forma, todas as ligações possuem a mesma probabilidade de ocorrerem, fazendo com que a rede gerada tenha uma estrutura altamente homogênea.

O número médio de conexões para cada vértice é dado por $k=p(N-1)$. A distribuição da conectividade para essas redes segue uma distribuição binomial, uma vez que o processo de geração das redes é um processo de Bernoulli homogêneo. No entanto, quando $N$ é grande e a conectividade média é mantida constante, a distribuição do número de conexões tende à uma distribuição de Poisson, segundo a lei dos eventos raros (Bollobás, 2001).

\subsubsection{Modelo de pequeno mundo: Watts - Strogatz}

Em 1998, analisando dados empíricos, pesquisadores das Universidade de Columbia e Cornell observaram em algumas redes reais, tais como a rede de neurônios do Caenorhabditis elegans e a rede de distribuição de energia dos Estados Unidos, a presença de ciclos (caminhos fechados) de ordem três é muito maior do que nas redes aleatórias com mesmo número de vértices e arestas (Watts e Strogatz, 1998). Esse foi o primeiro indício de que as redes reais não são completamente aleatórias, mas possuem uma determinada lei de formação.

Baseados nesta descoberta, Watts e Strogatz sugeriram um modelo alternativo aos grafos aleatórios, chamado modelo small world de Watts-Strogatz (em analogia ao fenômeno descoberto por Stanley Milgram), que apresenta o efeito small world e a presença de um grande número de ciclos de ordem três. Nesse modelo, para a construção de uma rede, inicia-se com uma rede regular formada por $N$ vértices ligados aos $\kappa$ vizinhos mais próximos em cada direção, totalizando $2 \kappa$ conexões iniciais, sendo $N \gg \kappa \gg \log (N) \gg 1$. A seguir, cada aresta é aleatoriamente reconectada com uma probabilidade fixa $p$, que introduz o caráter aleatório à 
rede. Quando $p=0$ a rede é completamente regular, apresentando alta quantidade de loops e caminho médio alto, e quando $p=1$, a rede é aleatória, apresentando baixa quantidade de ciclos de ordem três, mas pequeno caminho médio. Portanto, tal modelo se situa entre a completa regularidade e a aleatoriedade.

\subsubsection{Modelo Geográfico}

Este modelo baseia-se fundamentalmente em duas ideias: distribuição aleatória no espaço e probabilidade de conexões que decai exponencialmente com a distância dos vértices. Os vértices são distribuídos aleatoriamente em um quadrado unitário e são conectados com uma probabilidade $P_{i j}=\beta \exp \left(-\beta d_{i j}\right)$, onde $\beta$ é uma constante que regulará o grau médio da rede e $d_{i j}$ é a distância euclidiana entre os vértices $i$ e $j$. Este modelo também é conhecido por modelo de Waxman e foi proposto inicialmente para modelar a estrutura da Internet (Waxman, 1988).

\subsubsection{Modelo Livre de escala: Barabási - Albert}

Em 1999, dois pesquisadores da Universidade de Notre Dame, Estados Unidos, Albert-László Barabási e Reka Albert (Albert, 1999), decidiram verificar se o fenômeno small world estava presente na Teia Mundial (World Wide Web). Eles verificaram que a distribuição de conexões na web não é aleatória, mas do tipo livre de escala (scale-free), que é da forma $P(k) \sim k^{-\gamma}$ (A. Barabási et al., 1999). Naquele mesmo ano, o mesmo tipo de distribuição já havia sido encontrada na Internet pelos irmãos Faloutsos (Faloutsos et al., 1999), embora tal trabalho não tivesse despertado forte impacto. A distribuição livre de escala é um tipo de distribuição de probabilidades que reflete invariância de escala. Leis de potência também são conhecidas como lei de Zipf ou distribuição de Pareto.

Inspirados por essas descobertas, Barabási e Albert propuseram um modelo de crescimento, que gera redes livres de escala (Albert, 1999), que é baseado em dois passos:

1. Crescimento: Iniciando-se com um pequeno número de vértices $N_{0}$, a cada passo é adicionado um vértice com $m\left(m \leq N_{0}\right)$ arestas que se conectam com vértices já presentes na rede. 
2. Ligação preferencial: O novo vértice, que vai ser adicionado à rede, tende a se conectar com os vértices mais conectados, ou seja, a probabilidade de um vértice $j$, presente na rede, ser escolhido é proporcional a sua conectividade,

$$
\mathcal{P}_{i \rightarrow j}(n+1)=\frac{k_{j}(n)}{\sum_{u=N_{0}+1}^{N} k_{u}(n)}
$$

onde $n$ representa o tempo e o número de vértices adicionados à rede.

\subsubsection{Barabási não-linear}

Além do modelo de Barabási e Albert, muitos outros foram propostos para aperfeiçoá-lo, de forma a permitir maior flexibilidade no valor de $\gamma$, que é igual a três quando $N \rightarrow \infty$ no modelo de Barabási e Albert.

Um deles é a generalização para ligação preferencial não-linear (Krapivsky et al., 2000; Onody e Castro, 2004), ou seja, a equação 2.32 é substituída por:

$$
\mathcal{P}_{i \rightarrow j}(n+1)=\frac{k_{j}(n)^{\alpha}}{\sum_{u=-N_{0}+1}^{N} k_{u}(n)^{\alpha}}
$$

caso $\alpha=1$, recupera-se o modelo tradicional. Para $\alpha \rightarrow-\infty$ este modelo gera redes homogêneas com conectividade igual a $m$. Caso $\alpha>1$ surgem $m$ vértices superconectados e a probabilidade de que estes vértices estejam conectados a todos os demais vértices na rede é não nula para $\alpha \geq 2$.

Além disto, a generalização não-linear apresenta como propriedades interessantes o fato de ser disassortativa para $\alpha>1$, observa-se, também, que o clusterig coefficient cresce para valores de $\alpha>1$, chegando a valores próximos à unidade. 



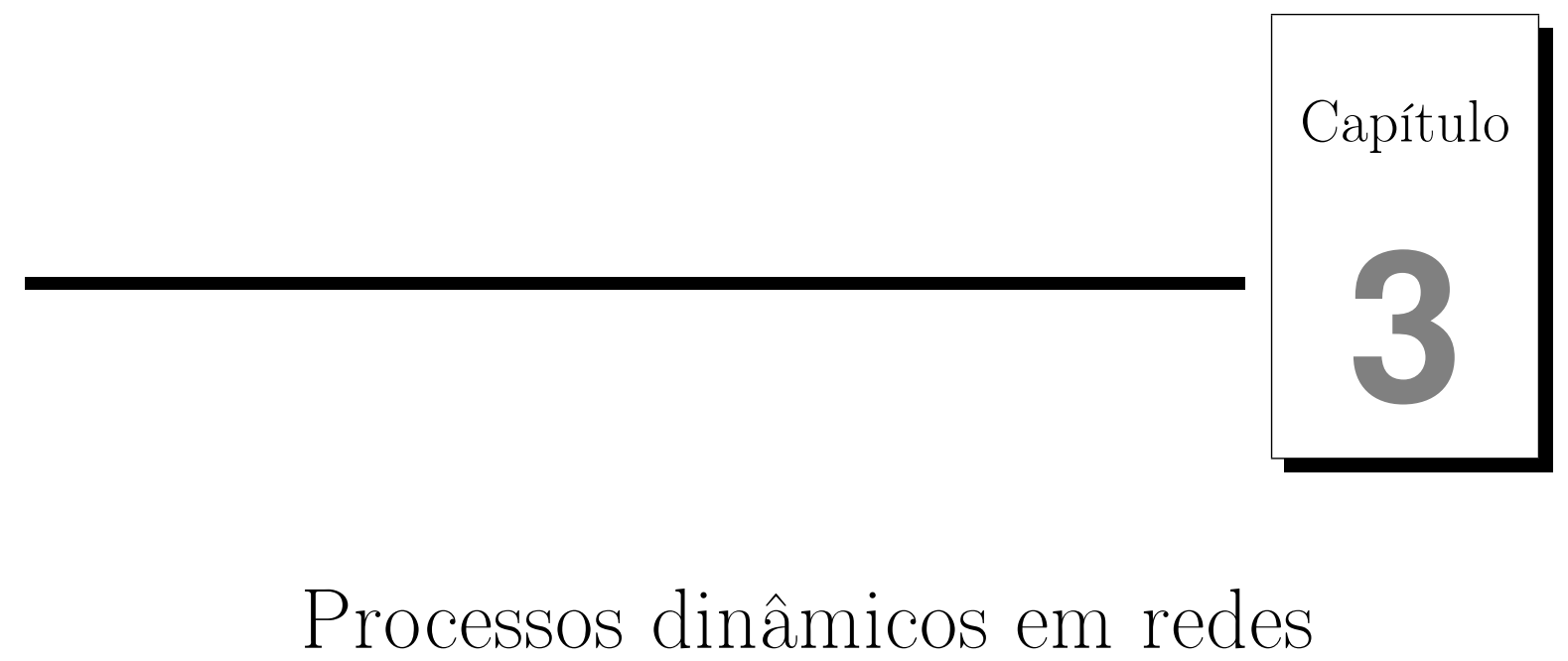

Muitos processos dinâmicos não-lineares e simulações estocásticas podem ser analisados em redes complexas. Aqui serão descritas aqueles que têm despertado maior interesse da comunidade científica. O primeiro a ser descrito é a propagação de epidemias. Nesta há um conjunto finito de estados e possuem probabilidades relacionadas à transição entre estes estados. Outro processo que será descrito é a sincronização de osciladores acoplados. Neste caso, cada nó da rede é considerado um oscilador e por meio da interação entre osciladores a rede apresenta um comportamento coletivo e os nós podem oscilar em coerência de fase. Por fim, serão descritas análises relativas à robustez de redes complexas em relação à falhas aleatórias, ataques e também será apresentada uma medida que quantifica tais dinâmicas.

\subsection{Propagação de epidemias}

Uma das dinâmicas mais importantes em redes é a propagação de epidemias. Para entendê-la será feita uma introdução aos modelos tradicionais para redes regulares, ou homogêneas, onde o grau decai exponencialmente ao distanciar-se da média, e posteriormente serão inseridos dentro 
do contexto de redes complexas com padrão de conexão heterogêneo, ou seja, para qualquer distribuição de grau. Aqui, porém, desconsidera-se que haja qualquer tipo de correlação de grau, apesar desta estar presente em redes reais. Ao final será deixada como referência tal avaliação.

Dentre os modelos tradicionais serão descritos o SI (susceptível - infectado), SIR (susceptível - infectado - recuperado) e SIS (susceptível - infectado - susceptível). Nesta abordagem a probabilidade de que haja um contato é igual entre todos os indivíduos da população, considerando apenas as taxas de propagação, recuperação e o grau médio da rede.

O primeiro a ser descrito é o modelo SI. Suponha que um indivíduo infectado transmite uma determinada doença com probabilidade $\beta\langle k\rangle d t$, significando que cada indivíduo tem, na média, $\langle k\rangle$ contatos com outros indivíduos por unidade de tempo e transmite a doença à uma taxa $\beta$. Definindo $S$ e $I$ como o número médio de indivíduos susceptíveis e infectados, respectivamente, e considerando uma população de $N$ indivíduos, define-se $s=\frac{S}{N}$ e $i=\frac{I}{N}$. Assim, uma pessoa infectada tem contato com em média $\beta\langle k\rangle s$ indivíduos susceptíveis por unidade de tempo. Uma vez que há na média uma fração de $i$ indivíduos infectados no total, isto implica que a média global da taxa de novas infecções será $\beta\langle k\rangle$ si, assim é possível expressar este modelo pela seguinte equação diferencial (Barrat et al., 2008),

$$
\frac{d i(t)}{d t}=\beta\langle k\rangle i(t)[1-i(t)]
$$

onde se utilizou a relação $s+i=1$. Sua solução exata é dada por (Barrat et al., 2008),

$$
i(t)=\frac{i_{0} e^{t / \tau}}{1+i_{0}\left(e^{t / \tau}-1\right)}
$$

onde $i_{0}$ é a densidade inicial de indivíduos infectados e $\tau=(\beta\langle k\rangle)^{-1}$.

O modelo SIS é guiado por uma equação semelhante a equação 3.1, incluindo apenas um termo de transição espontânea com taxa $\mu$, onde esta é a taxa de recuperação do indivíduo. Desta maneira, a probabilidade com que um indivíduo infectado se recupera é de $\mu d t$. Assim, a equação é dada por (Barrat et al., 2008),

$$
\frac{d i(t)}{d t}=-\mu i(t)+\beta\langle k\rangle i(t)[1-i(t)]
$$




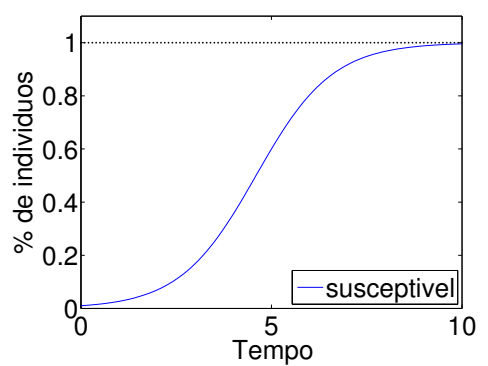

(a) Modelo SI

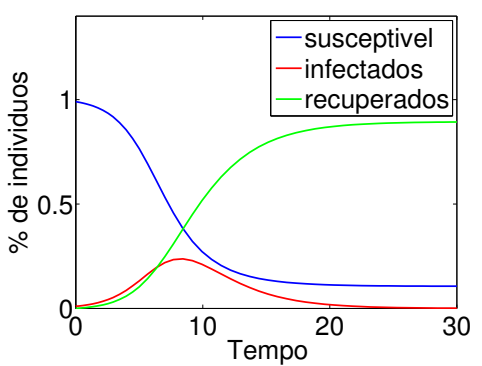

(b) Modelo SIR

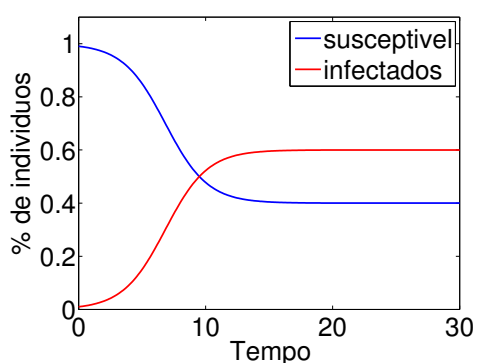

(c) Modelo SIS

Figura 3.1: Resposta temporal dos modelos para propagação de epidemias. (a) Modelo SI: um pequeno número de indivíduos infectados inicialmente (1\% neste exemplo), apresentará um crescimento exponencial no inicio, chegando a saturação em 1 no estado estacionário; (b)

Modelo SIR: mostra as frações da população susceptíveis, infectadas e recuperadas. Os parâmetros desta simulação foram $\beta=1, \gamma=0.2, s_{0}=0.99, x_{0}=0.01$ e $r_{0}=0$; (c) Modelo SIS: a fração dos indivíduos infectados neste modelo cresce de acordo com a curva logística, de maneira semelhante ao modelo SI, entretanto, a fração de infectados nunca chega a 1.

É interessante notar que o termo " $-\mu i(t)$ " não depende do grau médio da rede, pois trata-se de um processo espontâneo, onde o individuo passa de infectado à susceptível novamente. O modelo SIR (Anderson e May, 1992) é semelhante, porém, após este processo de recuperação o individuo passa à um terceiro estado, no qual ele está recuperado e não participa de qualquer interação. Esta dinâmica é regida pelo seguinte sistema de equações diferenciais (Barrat et al., 2008),

$$
\left\{\begin{array}{l}
\frac{d s(t)}{d t}=-\beta\langle k\rangle i(t)[1-r(t)-i(t)], \\
\frac{d i(t)}{d t}=-\mu i(t)+\beta\langle k\rangle i(t)[1-r(t)-i(t)], \\
\frac{d r(t)}{d t}=\mu i(t),
\end{array}\right.
$$

onde $r(t)$ são os indivíduos recuperados e esta recuperação ocorre com uma taxa $\mu$.

A figura 3.1 exemplifica o comportamento destas três dinâmicas considerando uma rede totalmente conectada para os modelos SI, em (a), SIR em (b) e SIS em (c).

Tanto o modelo SIS quanto o modelo SIR apresentam comportamento semelhantes para a fração de indivíduos infectados para valores pequenos de $t$. Isto ocorre, pois a equação de variação do número de infectados, $\frac{d i(t)}{d t}$ (equação 3.3), é a mesma para ambas dinâmicas (Barrat et al., 2008). A solução desta equação pode ser obtida utilizando-se uma aproximação linear, isto é, negligenciando-se os termos $O\left(i^{2}\right)$. Para valores pequenos de $t$, têm-se,

$$
\frac{d i(t)}{d t}=-\mu i(t)+\beta\langle k\rangle i(t),
$$


para o modelo SIR deve-se considerar que o termo $r(t)$ pode ser considerado de mesma ordem de grandeza de $i(t)$ para valores próximos de $t=0$. Desta maneira, a solução têm a forma

$$
i(t) \simeq i_{0} e^{t / \tau}
$$

onde $i_{0}$ é a densidade inicial de indivíduos infectados e

$$
\tau^{-1}=\beta\langle k\rangle-\mu \text {. }
$$

A partir desta expressão obtêm-se o chamado limiar epidêmico. Para valores inferiores a este limiar a doença tende a ser eliminada em tempo finito, não atingindo toda a rede. Formalmente, este é dado por,

$$
\frac{\beta}{\mu}>\langle k\rangle
$$

As equações apresentadas até aqui consideraram apenas redes homogêneas, isto é, regulares. Tais modelos também podem ser aplicados à redes onde o grau decai exponencialmente ao distanciar-se do grau médio, $\langle k\rangle$, que ocorre em redes de modelos aleatório de Erdös - Renyi (Ver seção 2.2) e de pequeno mundo de Watts - Strogatz(Ver seção 2.2). Assim, para se realizar uma análise mais geral, uma distribuição arbitrária, é conveniente considerar a fração de vértices susceptíveis e infectados que possuem grau $k$, dado por

$$
i_{k}=\frac{I_{k}}{N_{k}} ; \quad s_{k}=\frac{S_{k}}{N_{k}}
$$

onde $N_{k}$ é o número de vértices com grau $k, I_{k}$ e $S_{k}$ são os números de vértices com grau $k$ que estão infectados e susceptíveis respectivamente. Desta maneira, as médias globais são recuperadas por

$$
i=\sum_{k} P(k) i_{k} ; \quad s=\sum_{k} P(k) s_{k} ;
$$

onde $P(k)$ é a distribuição de grau da rede.

A situação mais simples para esta análise considera que não haverá correlação de grau, logo (Boccaletti et al., 2006; Costa et al., 2007; Barrat et al., 2008),

$$
P\left(k^{\prime} \mid k\right)=\frac{k^{\prime} P\left(k^{\prime}\right)}{\langle k\rangle}
$$


Esta relação apenas diz que a probabilidade de uma aresta apontar para um nó de grau $k^{\prime}$ é proporcional à $k^{\prime}$. Assim, obtêm-se que a fração de vizinhos infectados para um vértice de grau $k$ é dada por

$$
\Theta_{k}(t)=\Theta(t)=\sum_{k^{\prime}} \frac{\left(k^{\prime}-1\right) P\left(k^{\prime}\right)}{\langle k\rangle} i_{k^{\prime}}(t)
$$

onde o termo $\left(k^{\prime}-1\right)$ aparece, pois a doença chega até o nó em questão por meio de um de seus vizinhos e este certamente não é mais susceptível à doença. Assim a dinâmica SI é regida por (Barrat et al., 2008)

$$
\left\{\begin{array}{l}
\frac{d i_{k}(t)}{d t}=\beta k \Theta(t), \\
\frac{d \Theta(t)}{d t}=\beta\left(\frac{\left\langle k^{2}\right\rangle}{\langle k\rangle}-1\right) \Theta(t) .
\end{array}\right.
$$

Conduzindo, assim, para um limiar epidêmico dado por

$$
\tau=\frac{\langle k\rangle}{\beta\left(\left\langle k^{2}\right\rangle-\langle k\rangle\right)}
$$

Para os modelos SIR e SIS a fração de infectados com grau $k$ é dada por,

$$
\left\{\begin{array}{l}
\frac{d i_{k}(t)}{d t}=\beta k \Theta(t)-\mu i_{k}(t) \\
\frac{d \Theta(t)}{d t}=\beta\left(\frac{\left\langle k^{2}\right\rangle}{\langle k\rangle}-1\right) \Theta(t) .
\end{array}\right.
$$

Obtendo, assim, um limiar epidêmico para a dinâmica SIR (Barrat et al., 2008) de

$$
\frac{\beta}{\mu} \geq \frac{\langle k\rangle}{\left\langle k^{2}\right\rangle-\langle k\rangle}
$$

e, para a dinâmica SIS (Barrat et al., 2008) de

$$
\frac{\beta}{\mu} \geq \frac{\langle k\rangle}{\left\langle k^{2}\right\rangle}
$$

Esta diferença ocorre, pois um vértice infectado não tem que necessariamente apontar para outro vértice infectado, desde que o vértice passa espontaneamente para o estado susceptível novamente, fazendo com que o termo $\left(k^{\prime}-1\right)$ em 3.12 seja substituído por $k^{\prime}$. 
A análise destes valores de limiar, equações 3.16 e 3.17, indica que em redes livres de escala, onde $\left\langle k^{2}\right\rangle \rightarrow \infty$, este limiar tende a zero, fazendo com que a propagação de epidemias neste tipo de redes seja muito fácil (Barrat et al., 2008).

Além dos resultados apresentados aqui é possível avaliar estas dinâmicas em redes com correlação de grau, como realizado em (Barrat et al., 2008). Entretanto estas consideram apenas estatísticas de primeira ordem, desconsiderando a estrutura global da rede, como por exemplo comunidades. Tais considerações são problemas abertos para a comunidade científica, como exposto em (Barrat et al., 2008).

\subsection{Sincronização}

Sincronização é um dos fenômenos presente na natureza. O coração humano bate devido a sincronização na atividade de milhares de células, assim como milhares de neurônios no córtex visual sincronizam suas atividades para atender a um determinado estimulo externo. A sincronização está intimamente ligada à vida, desde reações químicas do metabolismo das células até tarefas cognitivas. Sendo assim, sincronização possui aplicações em diversos ramos da ciência como física, biologia, tecnologias, etc (Arenas et al., 2008).

Uma das mais bem sucedidas tentativas de modelar este tipo de fenômeno foi realizada por Kuramoto (Kuramoto, 2003), que analisou um modelo de osciladores acoplados por diferenças de fases. Este modelo consiste em um conjunto de $N$ osciladores acoplados, onde a fase do i-ésimo oscilador, denotada por $\theta_{i}(t)$ evolui de acordo com a seguinte equação diferencial:

$$
\frac{d \theta_{i}}{d t}=\omega_{i}+\frac{K}{N} \sum_{j=1}^{N} \sin \left(\theta_{j}-\theta_{i}\right) \quad(i=1, \ldots, N)
$$

onde o fator $1 / N$ é incorporado para garantir o bom comportamento do modelo no limite termodinâmico, $N \rightarrow \infty, \omega_{i}$ é a frequência natural do oscilador $i$, e $K$ é a constante de acoplamento. As frequências $\omega_{i}$ são distribuídas de acordo com alguma distribuição de probabilidade $g(\omega)$, dependendo do sistema. 


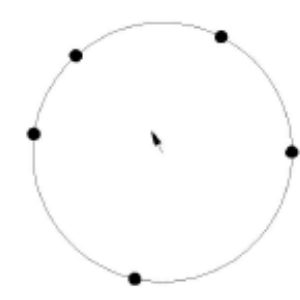

(a) $|r|=0.18$

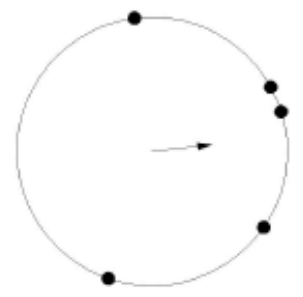

(b) $|r|=0.44$

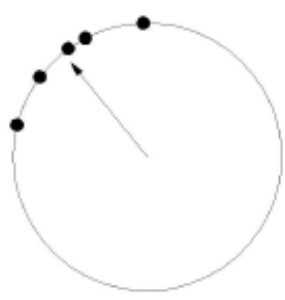

(c) $|r|=0.91$

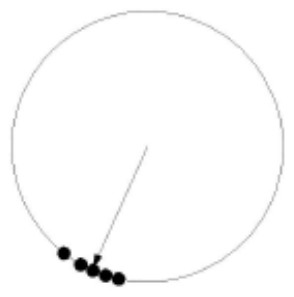

(d) $|r|=0.99$

Figura 3.2: Representação esquemática do parâmetro de ordem do sistema, $r$. O módulo deste é dado pelo comprimento deste vetor, enquanto a fase de cada oscilador é dada pela posição de cada um deles pelo círculo. Os itens de (a) - (b) mostram a variação deste parâmetro desde uma oscilação de maneira incoerente em (a), $|r|=0.18$, até uma oscilação onde todos os osciladores oscilam de maneira coerente, $|r|=0.99$, em (d).

A dinâmica coletiva de toda a população de osciladores é medida a partir do parâmetro de ordem macroscópico (Kuramoto, 2003),

$$
r(t) e^{i \phi(t)}=\frac{1}{N} \sum_{j=1}^{N} e^{i \theta_{j}(t)}, \quad 0 \leq r(t) \leq 1
$$

onde o módulo $0 \leq r(t) \leq 1$ irá medir a fase de coerência do conjunto de osciladores e $\phi(t)$ é a fase média. Os valores em que $r \simeq 1$ e $r \simeq 0$ descrevem os limites em que todos os osciladores estão em fase ou estão se movendo de forma incoerente, respectivamente. Multiplicando a eq. 3.19 por $e^{-i \theta_{i}}$ temos:

$$
r \sin \left(\phi-\theta_{i}\right)=\frac{1}{N} \sum_{j=1}^{N} \sin \left(\theta_{j}-\theta_{i}\right),
$$

de modo que podemos reescrever a eq. 3.18 na forma:

$$
\frac{d \theta_{i}}{d t}=\omega_{i}+K r \sin \left(\phi-\theta_{i}\right) \quad(i=1, \ldots, N)
$$

A eq. 3.21 mostra que cada oscilador interage com os outros osciladores apenas através das quantias de campo médio $r$ e $\phi$. Através de $r$ é observado o comportamento macroscópico do acoplamento dos osciladores A medida que $r$ aumenta, mais coerente o movimento destes se torna. A figura 3.2 é uma representação esquemática de tal conceito. 


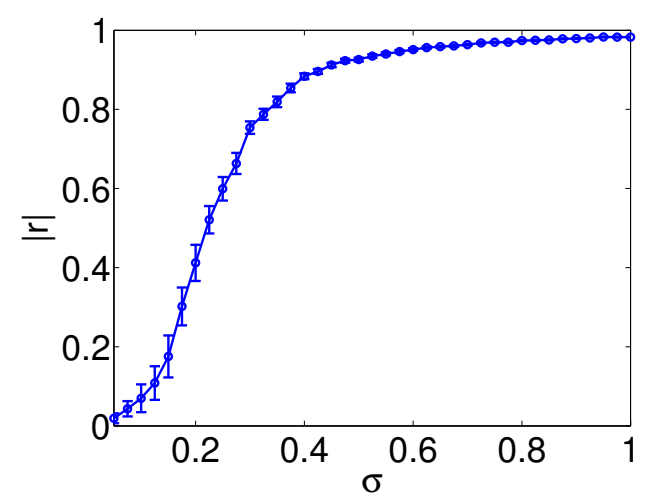

(a) Sincronização de um conjunto de 50 redes do modelo Barabási e Albert. Figura reproduzida, de (Moreno e Pacheco, 2004)

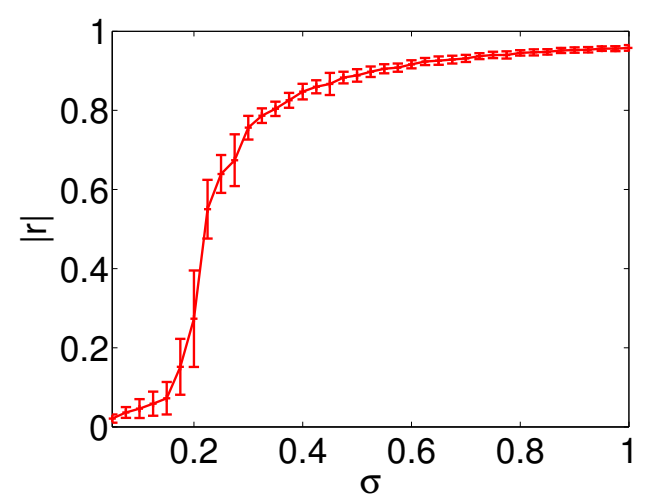

(b) Sincronização de um conjunto de 50 redes do modelo Erdös-Renyi.

Figura 3.3: Coerência de fases, $|r|$, em função da força de acoplamento, $\sigma$. Sincronização para 50 redes dos modelos Barabási e Albert em (a) e Erdös-Renyi em (b). Ambas com grau médio $\langle k\rangle=4$ e $N=1000$ nós.

O nível de sincronização de uma rede é determinado pela coerência entre os osciladores, a qual é calculada por

$$
r(t)=\left|\frac{1}{N} \sum_{j=1}^{N} e^{i \theta_{j}(t)}\right|
$$

onde $0 \leq r(t) \leq 1$. No caso em que $r(t)=1$, todos os vértices oscilam com a mesma fase.

Um resultado importante obtido a partir da equação 3.21 é o acoplamento critico (Arenas et al., 2008), que consiste no valor de acoplamento a partir do qual há a emergência de um comportamento coletivo. Este é dado por:

$$
K_{c}=\frac{2}{\pi g(0)}
$$

onde $g(\cdot)$ é a função de distribuição das frequências naturais. Um fato interessante é que ao considerar uma estrutura não trivial de conexões o valor do acoplamento crítico é dado por (Arenas et al., 2008)

$$
\sigma_{c}=\frac{2}{\pi g(0)} \frac{\langle k\rangle}{\left\langle k^{2}\right\rangle}=K_{c} \frac{\langle k\rangle}{\left\langle k^{2}\right\rangle},
$$

ou seja, é apenas um produto entre o fator de acoplamento crítico com um termo relacionado a heterogeneidade da rede, isto é, $\frac{\langle k\rangle}{\left\langle k^{2}\right\rangle}$. 
Para formular o problema em topologias complexas, é necessário reformular (Arenas et al., 2008) a eq. 3.18 para incluir a conectividade da rede:

$$
\frac{d \theta_{i}}{d t}=\omega_{i}+\sum_{j} \sigma_{i j} a_{i j} \sin \left(\theta_{j}-\theta_{i}\right)
$$

onde $w_{i}$ é a frequência natural do oscilador $i, \sigma_{i j}$ é a força do acoplamento entre dois osciladores e $a_{i j}$ são os elementos da matriz de adjacência. A partir da eq. 3.25 pode-se calcular o parâmetro de ordem macroscópico para diferentes topologias (Arenas et al., 2008). O modelo original de Kuramoto é recuperado quando temos $a_{i j}=1, \forall i \neq j$ e $\sigma_{i j}=K / N \forall i, j$.

A Figura 3.3 apresenta o comportamento de duas redes com estrutura não trivial: em (a) o modelo de Barabási e Albert, que possui uma distribuição livre de escala; em (b) uma rede aleatória, segundo o modelo de Erdös-Renyi. Ambas são uma média de 50 redes com grau médio $\langle k\rangle=4$ e $N=1000$ nós.

\subsection{Robustez de redes complexas}

Outro processo importante dentro deste contexto de redes complexas é a robustez destas à falhas aleatórias e ataques. Diversos tipos de informação podem se propagar por meio de redes, como troca de pacotes pela Internet, doenças ou vírus em uma rede social, sinais em redes corticais ou neuronais. Assim é importante quantificar de maneira sistemática a robustez de redes em relação à falhas e ataques, para melhor compreender a propagação destas é importante conhecer a robustez das redes analisadas, já que esta pode ser interrompida devido à remoção de alguns vértices deste sistema.

Dentro deste contexto, Albert et al. propuseram duas dinâmicas distintas para simular falhas aleatórias e ataques (Albert et al., 2000). Outra maneira de se quantificar a resiliência de redes complexas, também em relação à falhas aleatórias, é por meio de uma medida chamada entropia dinâmica, proposta em (Demetrius e Manke, 2005). A seguir serão descritas e discutidos os conceitos de falhas e ataques e, por fim, será apresentada a medida de entropia dinâmica.

Tais dinâmicas serão utilizadas para a análise de redes corticais no capítulo 6 . 

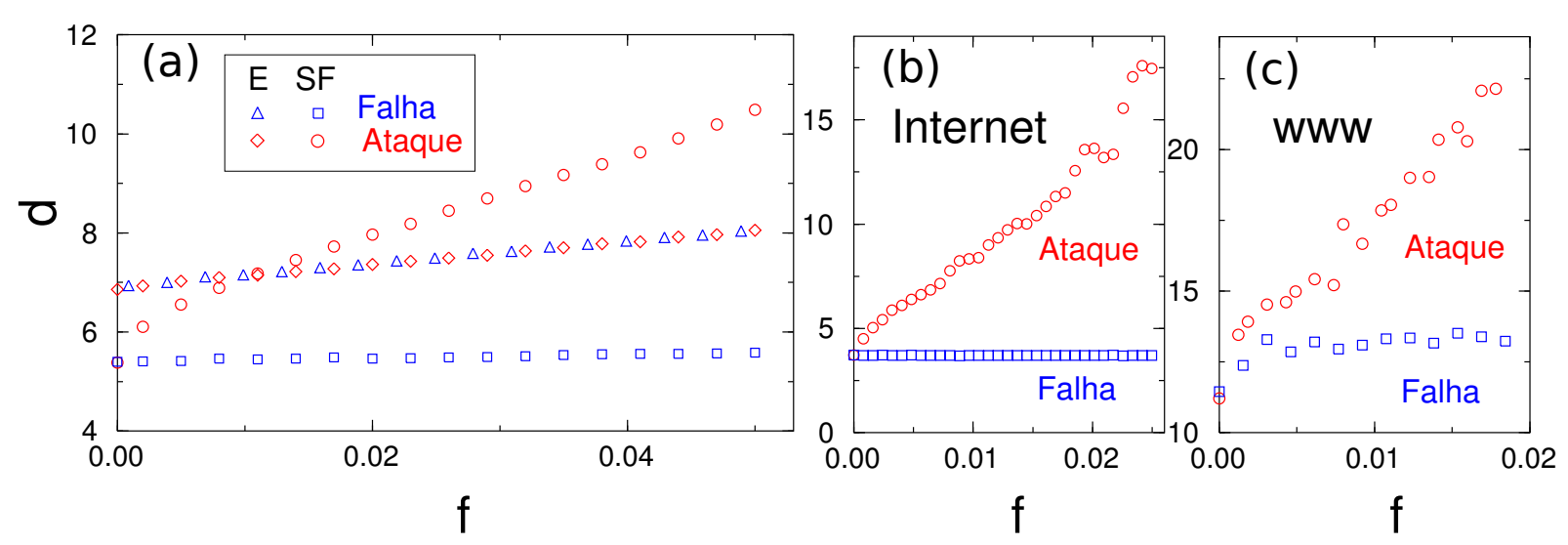

Figura 3.4: Variação do diâmetro, $d$ em função da fração de nós removidos da rede, $f$. Em (a) é feita a comparação entre as dinâmicas de falhas e ataques para redes livres de escala $S F$ (modelo Barabási - Albert) e redes exponenciais (por meio do modelo de Erdös - Renyi). Cada rede possui $N=10000 \mathrm{e}\langle k\rangle=4$. Em (b) foi avaliada a rede da uma amostra da Internet com $N=6209$ e $\langle k\rangle=3.4$. Por fim, em (c), a rede World - Wide Web, sendo uma amostra com $N=325729$ e $\langle k\rangle=4.59$. Figura adaptada do artigo de Albert et al. (Albert et al., 2000)

\subsubsection{Falhas e ataques}

Uma das maneiras de analisar a robustez de redes complexas é por meio da simulação de falhas aleatórias e ataques. No primeiro caso uma fração de nós é removida de maneira aleatória, sem qualquer preferência associada ao processo de remoção. Já para a segunda dinâmica, tal remoção é feita de acordo com a conectividade do nó, ou seja, os nós que são removidos segundo uma ordenação decrescente de acordo com seu grau, assim aqueles que possuem maior grau são removidos antes daqueles que têm menor grau.

O trabalho que avaliou tais dinâmicas em redes complexas foi proposto por Albert et al. em (Albert et al., 2000). Neste, a relação entre a estrutura e estas dinâmicas é analisada. A figura 3.4 apresenta alguns dos principais resultados de (Albert et al., 2000). Observa-se que modelos livres de escala são altamente robustos à falhas aleatórias, porém muito bastante vulneráveis à ataques. A robustez de tais redes à falhas aleatórias ocorre devido a inexistência de preferência na remoção dos nós, assim há uma grande probabilidade de se remover nós de baixa conectividade e uma probabilidade muito baixa de se remover hubs. Entretanto, para o caso de ataques inicia-se o processo pela remoção dos $h u b s$, ocasionando, assim, um aumento significativo do diâmetro da rede, pois estes são responsáveis pelo efeito de pequeno mundo. Por outro lado, redes aleatórias, apresentam comportamento distinto, sendo tão robustas à ataques 
quanto à falhas, já que o grau dos vértices deste modelo decai exponencialmente ao se afastar de $\langle k\rangle$.

Ademais, Albert et al. quantificaram tais efeitos em duas redes reais, uma amostra da Internet e uma amostra da teia mundial, WWW. Estas redes reais são livres de escala, ou seja, ambas têm uma distribuição de conectividade da forma $P(k) \sim k^{\gamma}$. Para a rede de Internet, tal valor foi estimado por Faloutsos et al. em (Faloutsos et al., 1999) como $\gamma=2$, 48. Já para a rede rede WWW como sendo $\gamma_{i n}=2,1$ e $\gamma_{\text {out }}=2,45$ (A. Barabási et al., 1999). Os resultados desta análise são mostrados nas figuras 3.4 (b) e (c) respectivamente. Verifica-se que tais redes tem comportamento semelhante às redes do modelo Barabási - Albert.

Em linhas gerais, o trabalho de Albert et al. (Albert et al., 2000) mostra que redes livres de escala são robustas em relação à falhas, porém bastante vulneráveis à ataques. Em contrapartida modelos exponenciais (i.e. redes aleatórias do modelo de Erdös - Renyi, bem como o modelo de Watts - Strogatz) são robustos em relação à ataques e suscetíveis à falhas.

\subsubsection{Entropia dinâmica}

A robustez pode ser definida como a insensibilidade observável de uma rede em relação a alterações estruturais, como por exemplo falhas (Demetrius e Manke, 2005). Baseado em mecânica estatística e teoria ergódica foi proposta uma medida que quantifica tal processo. O principal conceito da medida proposta nesta seção é que características macroscópicas são mantidas por um longo tempo, entretanto isto não significa que microestados sejam estáticos. A incerteza de processos microscópicos determina a resiliência de estados macroscópicos . No contexto de sistemas dinâmicos e teoria ergódica tal incerteza é mensurada pela entropia de Kolmogorov Sinai. De acordo com o teorema de flutuações, no contexto de redes complexas (Demetrius e Manke, 2005), mudanças nesta entropia estão relacionadas à mudanças de resiliência do sistema macroscópico em relação a perturbações microscópicas.

Assim, a robustez de redes à falhas aleatórias é definida por uma medida chamada entropia dinâmica (Demetrius e Manke, 2005). Assumindo um processo estocástico Markoviano, as componentes da distribuição estacionária $\pi$ são definidas como o autovetor à esquerda associado ao maior autovalor, 1 , da matriz estocástica $P_{d}$, isto é, $\pi P_{d}=\pi$. Desta forma a entropia 
dinâmica é definida como,

$$
H_{d}=-\sum_{i j} \pi_{i} p_{d}(i, j) \log p_{d}(i, j)
$$

onde $p_{d}(i, j)$ é a probabilidade de um andarilho sair de $i$ para $j$ de forma aleatória em apenas uma etapa. Esta é definida por

$$
p_{d}(i, j)=\frac{a_{i j} v_{j}}{\lambda v_{i}}
$$

onde $v_{j}$ é o principal autovetor e $\lambda$ é o principal autovalor. Esta medida associa valores maiores para redes mais robustas e valores menores para redes mais vulneráveis.

Além disso, é possível obter a contribuição individual de cada nó por meio da decomposição da entropia, assim têm-se

$$
H_{d}(i)=-\pi_{i} \sum_{j} p_{d}(i, j) \log p_{d}(i, j)
$$

Tal decomposição sugere que aqueles vértices da rede que mais contribuem para a medida global têm grande efeito para a estrutura e funcionalidade da rede.

Em (Demetrius e Manke, 2005),é demonstrado que esta medida apresenta valores elevados para redes livres de escala e valores menores para redes aleatórias e regulares. Confirmando os resultados esperados e mostrando como esta medida pode ser aplicada na análise de robustez a falhas em redes complexas. 


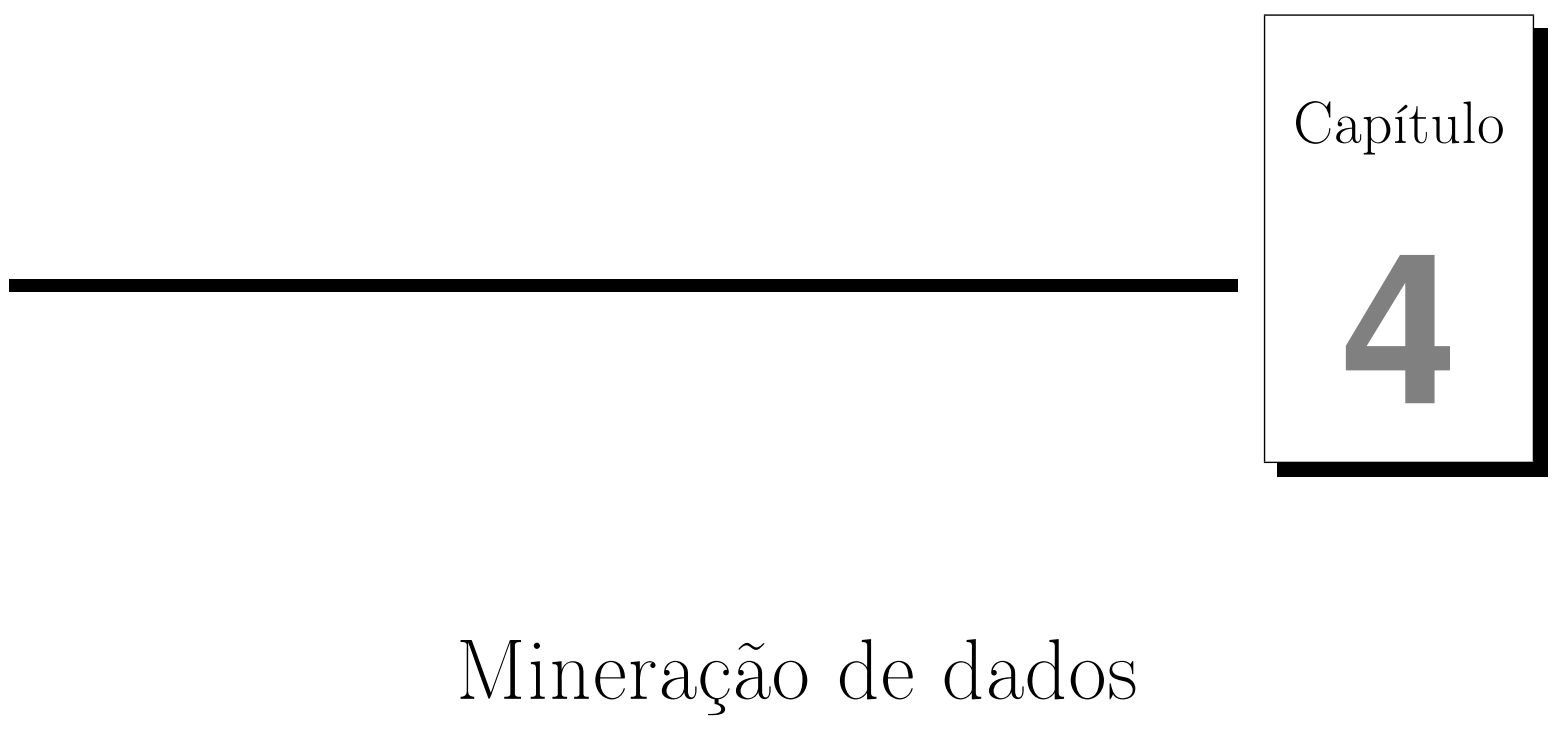

Mineração de dados é um campo altamente interdisciplinar e apresenta grande intersecção com diversos outros, como aprendizado de máquinas e reconhecimento de padrões, além de fazer uso de diversos conceitos de computação e estatística. Este processo consiste em extrair padrões de grandes quantidades de dados. Isto pode ser feito por meio de métodos supervisionados como classificação e também por métodos não-supervisionados, como por exemplo, agrupamento de dados.

Neste capítulo será feita uma introdução sobre o pré-processamento de dados, focando em métodos de normalização, seleção, ordenação e extração de dados. É importante ressaltar que, ainda na etapa de pré-processamento há diversas outras tarefas como: detecção de outliers, tratamentos de atributos ausentes, entre muitos outros, porém estes não serão utilizados ao decorrer deste trabalho devido à natureza dos dados utilizados. A seguir, serão apresentadas técnicas de classificação baseadas em árvores de decisão e métodos para avaliação de modelos preditivos. Por fim, será apresentada uma metodologia para agrupamento de dados baseada em estimação de densidades. 
É importante verificar que as escolhas dos modelos utilizados neste trabalho estão fundamentalmente baseadas em conceitos de teoria da informação, estatística e probabilidades. Desta maneira, é possível extrair informações tanto dos modelos induzidos, quanto dos dados classificados.

\subsection{Normalização de dados}

As medidas de caracterização de redes apresentam resultados em escalas distintas, como por exemplo o coeficiente de aglomeração (clustering coefficient), que varia em uma faixa de 0 à 1, enquanto o grau será sempre um inteiro positivo. A fim de eliminar as tendências que estas diferenças de escala podem acarretar ao método de agrupamento realiza-se a normalização dos dados como uma etapa de pré-processamento. Comumente utiliza-se a normalização segundo:

$$
x_{i}^{\prime}=\frac{x_{i}-\mu}{\sigma}
$$

onde $\mu$ e $\sigma$ são respectivamente, a média e desvio padrão do atributo a ser normalizado. O atributo normalizado, $x_{i}^{\prime}$, apresenta média zero e desvio padrão unitário.

Outra maneira de eliminar as tendências que as diferenças de escala podem acarretar ao método de agrupamento ou classificação é a normalização softmax (Theodoridis e Koutroumbas, 2003). Esta é expressa por:

$$
y_{i}=\frac{1}{1+e^{x_{i}^{\prime}}}
$$

onde $x_{i}^{\prime}$ é dado pela expressão 4.1 .

Esta expressão transforma a faixa $[-\infty, \infty]$ em um intervalo fechado $[0,1]$.

\subsection{Extração de atributos}

A extração de características consiste em combinar os atributos para se obter um novo espaço com dimensão menor. Existem várias técnicas utilizadas para esta finalidade, aqui serão descritas duas delas, as variáveis canônicas, também chamadas de análise discriminante linear (LDA, do inglês Linear Discriminant Analysis) e a técnica de análise das componentes principais (PCA, do inglês Principal Component Analysis). A primeira apresenta como principal 
característica o favorecimento da separação entre as classes. Já a segunda é uma técnica que não utiliza informações relativas às classes e tem como propriedades fundamentais a maximização da variância sobre os eixos projetados e minimização da distorção sobre o novo espaço gerado pela projeção.

\subsubsection{Linear Discriminant Analysis (LDA)}

A análise de variáveis canônicas, também chamada LDA (Linear Discriminant Analysis) (McLachlan e Wiley, 1992), tem como principal objetivo maximizar a distância interclasses, a distância entre elementos de classes distintas e minimizar a distância intraclasses, a distância entre elementos de mesma classe. Antes de introduzir este método é necessário apresentar as matrizes de dispersão (scatter matrix).

Para $N_{c}$ classes cada uma com $N_{i}$ elementos e identificadas por $C_{i}\left(i=1,2, \ldots, N_{c}\right)$, sendo que cada elemento é representado por seu vetor de características $\overrightarrow{x_{\xi}}=\left(x_{1}, x_{2}, \ldots, x_{p}\right)^{T}$, onde $p$ é o número de atributos.

A scatter matrix para cada classe $C_{i}$ é dada por:

$$
S_{i}=\sum_{\xi \in C_{i}}\left(\overrightarrow{x_{\xi}}-\langle\vec{x}\rangle_{i}\right)\left(\overrightarrow{x_{\xi}}-\langle\vec{x}\rangle_{i}\right)^{T}
$$

Onde $\langle\vec{x}\rangle_{i}$ é o vetor médio de características para a classe $C_{i}$.

A intraclass scatter matrix, que quantifica a dispersão dentro de cada classe, é definida como:

$$
S_{\text {intra }}=\sum_{i=1}^{N_{c}} S_{i}
$$

Por fim, a interclass scatter matrix que quantifica a dispersão entre cada par de classes é dada por:

$$
S_{\text {inter }}=\sum_{i=1}^{N_{c}} N_{i}\left(\langle\vec{x}\rangle_{i}-\langle\vec{x}\rangle\right)\left(\langle\vec{x}\rangle_{i}-\langle\vec{x}\rangle\right)^{T}
$$

O método LDA consiste em projetar a matriz de características sobre os maiores autovetores da matriz $S_{\text {intra }}^{-1} S_{\text {inter }}$, o que favorece a separação dos grupos. 


\subsubsection{Principal Component Analysis (PCA)}

Outra projeção de interesse é a chamada análise de componentes principais, PCA (do inglês, Principal Component Analysis). Esta é uma técnica não supervisionada, pois não utiliza qualquer informação relativa às classes, diferentemente da técnica apresentada anteriormente. A principal característica desta metodologia é maximizar a variância nos eixos projetados, além de apresentar mínima distorção do espaço projetado em relação ao espaço original. A formulação por maximização da variância é a ideia mais tradicional do PCA. Seja o novo espaço definido pela direção $u_{1}$. Sem perder generalidade, $u_{1}^{T} u_{1}=1$, pois estamos interessados na direção de $u_{1}$ e não em sua norma. Cada ponto projetado é dado por $u_{1}^{T} x_{n}$ e a média projetada é $u_{1}^{T} \bar{x}$, onde a média é dada por

$$
\langle x\rangle=\frac{1}{N} \sum_{n=1}^{N} x_{n}
$$

e a variância é dada por

$$
\frac{1}{N} \sum_{n=1}^{N}\left(u_{1}^{T} x_{n}-u_{1}^{T} \bar{x}\right)^{2}=u_{1}^{T} S u_{1}
$$

sendo $S$, dada por

$$
S=\frac{1}{N} \sum_{n=1}^{N}\left(x_{n}-\bar{x}\right)\left(x_{n}-\bar{x}\right)^{T}
$$

Desejamos maximizar a variância projetada $u_{1}^{T} S u_{1}$ em relação a $u_{1}$. Utilizando multiplicadores de Lagrange temos:

$$
u_{1}^{T} S u_{1}+\lambda_{1}\left(1-u_{1}^{T} u_{1}\right)
$$

Derivando em relação a $u_{1}$, têm-se um ponto estacionário em:

$$
S u_{1}=\lambda_{1} u_{1}
$$

Desta maneira $u_{1}$ é o eixo de máxima variância. $u_{1}$ é, também, autovetor de $S$. Multiplicando por $u_{1}^{T}$ nos dois lados, temos:

$$
u_{1}^{T} S u_{1}=\lambda_{1}
$$

Logo, a máxima variância é obtida quando $\lambda_{1}$ é o maior autovalor de $S$, assim $u_{1}$ será o autovetor associado a este. Este autovetor é chamado de primeira componente principal. 
Além da ideia exposta anteriormente, pode-se mostrar que a técnica PCA minimiza a distorção do espaço gerado, considerando o erro quadrático médio (Bishop, 2006). O principal resultado obtido desta analise é que a distorção do espaço gerado, considerando tal erro é dado por:

$$
J=\sum_{i=M+1}^{D} \lambda_{i}
$$

onde $M$ será a dimensão do novo espaço gerado, $D$ a dimensão do espaço de características original e $\lambda_{i}$ são os autovalores de $S$, considerando que estes estão ordenados de forma crescente, ou seja, a distorção é medida como a somatória dos autovalores desprezados durante a projeção.

\subsection{Ordenação de atributos}

A maior desvantagem de processos de extração de atributos, discutidos na seção anterior, é que as novas características são combinações dos atributos originais, sendo assim, há uma dificuldade maior para se analisá-los. Os novos descritores não possuem um significado físico e sua interpretação muitas vezes é bastante difícil. Ademais, em um conjunto de dados onde há um número de atributos grande, muitas vezes é importante verificar a relevância de cada um dos atributos. Dentro deste contexto, há interesse apenas em ordenar os atributos segundo sua capacidade de reproduzir as classes às quais as amostras do conjunto de dados pertencem.

Assim, visando analisar cada característica individualmente e, desta maneira, criando uma ordenação sistemática, relaciona-se a cada atributo um valor segundo uma função critério. Várias funções podem ser utilizadas, optou-se pela incerteza simétrica (Witten e Frank, 2005), dada por:

$$
U(C, A)=\frac{2(H(C)-H(C \mid A))}{H(C)+H(A)}
$$

onde $C$ é uma classe e $A$ um atributo e

$$
\begin{gathered}
H(x)=-\sum_{i} p_{x}(i) \ln \left(p_{x}(i)\right), \\
H(y \mid x)=-\sum_{i, j} p_{x y}(i, j) \ln \left(\frac{p_{x y}(i, j)}{p_{x}(i)}\right) .
\end{gathered}
$$




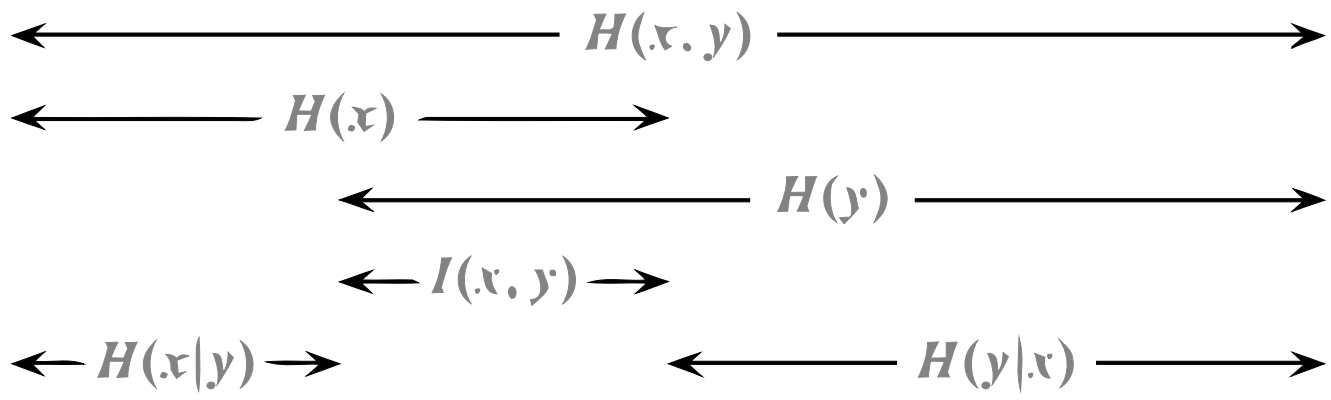

Figura 4.1: Diagrama esquemático para representação da entropia, entropia condicionada e informação mútua. Figura adaptada de Press et al. (Press et al., 1992).

onde $p_{x}$ e $p_{y}$ são as probabilidades das variáveis aleatórias $X$ e $Y$ e $p_{x y}$ é a probabilidade conjunta destas duas variáveis aleatórias.

A incerteza simétrica é obtida da ponderação entre os coeficientes de incerteza (Prass, 2007). As equações 4.16 e 4.17, a seguir, são os coeficientes de incerteza em relação a $y$ e $x$ respectivamente:

$$
\begin{aligned}
& U(y \mid x)=\frac{H(x)-H(x \mid y)}{H(y)}, \\
& U(x \mid y)=\frac{H(y)-H(y \mid x)}{H(x)} .
\end{aligned}
$$

Estes coeficientes variam na faixa entre zero e a unidade, sendo que zero indica que não há associação entre as variáveis $x$ e $y$ e um indica que ao se conhecer uma das variáveis é possível prever completamente a outra.

Como se deseja uma medida que seja simétrica, a combinação a seguir é bastante conveniente:

$$
U(x, y)=2\left[\frac{H(x)+H(y)-H(x, y)}{H(x)+H(y)}\right]=\frac{H(x) U(x \mid y)+H(y) U(y \mid x)}{H(x)+H(y)}
$$

onde,

$$
H(x, y)=H(x)+H(y \mid x)=H(y)+H(x \mid y) .
$$

Ao observar-se a equação 4.18, nota-se que a medida simétrica é apenas uma média ponderada das médias assimétricas 4.17 e 4.16 ponderadas pela entropia de cada variável separadamente. A figura 4.1 é um diagrama esquemático que exemplifica de maneira gráfica os conceitos da teoria da informação os conceitos presentes na construção de tal função critério. 
A equação 4.13 foi exposta dentro do contexto de mineração de dados, ou seja, as variáveis $x$ e $y$ correspondem às variáveis $A$ e $C$. Além disso, pode-se verificar que (Press et al., 1992):

$$
\begin{aligned}
U(x, y)=\frac{H(x) U(x \mid y)+H(y) U(y \mid x)}{H(x)+H(y)}= & \frac{H(y)-H(y \mid x)+H(x)-H(x \mid y)}{H(x)+H(y)}= \\
& 2 \frac{I(x, y)}{H(x)+H(y)}=2 \frac{H(x)-H(y \mid x)}{H(x)+H(y)}
\end{aligned}
$$

onde,

$$
I(x, y)=H(x)-H(y \mid x)=H(y)-H(x \mid y)=\sum_{i, j} p_{i j} \ln \left(\frac{p_{i j}}{p_{i} p_{j}}\right)
$$

sendo que $I(x, y)$ é chamada de informação mútua entre as variáveis $x$ e $y$. É importante observar que $I(x, y)=I(y, x)$. Assim fica clara a igualdade entre as equações 4.13, 4.18 e 4.20. Desta maneira a incerteza simétrica nada mais é que a informação mútua entre a distribuição de uma determinada medida e seu vetor de classes normalizado para valores entre zero e a unidade. Observando o diagrama da figura 4.1 nota-se que caso $I(C, A)=H(C)$ têm-se que $H(C)=H(A), \operatorname{logo}, U(C, A)=1$, como esperado para tal função, já que o atributo reproduz perfeitamente o vetor de classes. Por outro lado, caso $I(C, A) \rightarrow 0$ pouca informação sobre o vetor de classes está presente no atributo $C$, fazendo assim $I S(C, A) \rightarrow 0$. Portanto, tal função critério responde de maneira esperada e pode ser utilizada para ordenação dos atributos.

Outra possibilidade é a utilização do conhecido teste estatístico $\chi^{2}$. Neste caso, a importância de cada atributo é mensurada por meio de uma ordenação da estatística $\chi^{2}$ em relação à classe (Press et al., 1992).

\subsection{Seleção de atributos}

O principal objetivo da seleção de atributos é a identificação das características mais importantes de um conjunto de dados, de forma a eliminar as características que pouco contribuem para a discriminação das classes em estudo. Além disso, a seleção é necessária devido a um problema conhecido por maldição da dimensionalidade (Theodoridis e Koutroumbas, 2003; Bishop, 2006), que se refere ao problema causado pelo aumento exponencial no volume associado com a adição de dimensões extras a um espaço matemático. Na prática, tal limitação significa que para um tamanho de amostras, existe um número máximo de atributos a partir 
do qual o desempenho do classificador irá piorar ao invés de melhorar. De fato, a informação perdida ao se descartar algumas características é compensada por uma melhor classificação em um espaço de atributos com uma dimensão menor. Sendo assim, a aplicação dessas técnicas na análise de redes complexas permitirá a identificação de quais medidas de redes oferecem maior discriminação entre redes geradas por diferentes modelos e que são, consequentemente, mais importantes para análise da estrutura de redes complexas.

A seleção requer uma estratégia de busca e uma função critério. Apesar de computacionalmente caro, é possível utilizar um método ótimo, o Branch \& Bound (Narendra e Fukunaga, 1977), este fornecerá o melhor subconjunto dentre todos os possíveis dentro do espaço de busca. Como função critério há uma vasta gama de possibilidades (Molina et al., 2002) , dentre elas, a função $\operatorname{traço}\left(S_{\text {intra }}^{-1} S_{\text {inter }}\right)$ (equações 4.4 e 4.5), baseado nas matrizes de dispersão utilizadas durante o desenvolvimento da análise LDA. Para utilização deste método é necessário informar a dimensão do novo espaço. A determinação deste pode ser feita por meio de um método baseado nos autovalores do PCA (Principal Component Analisys) (Fukunaga e Olsen, 1971). Este método fornece a dimensionalidade intrínseca do espaço. Outra possibilidade é utilizar um número arbitrário ou realizar diversos experimentos e optar pelo subconjunto que fornecer o maior valor para a função critério.

É importante mencionar que a seleção de atributos pode ser executada como uma combinação de um método de busca dentro do espaço de atributos e uma função critério. Esta busca pode levar ou não ao valor ótimo segundo a função objetivo escolhida. Há uma ampla gama de combinações. Em (Molina et al., 2002) os autores discutem diversas destas possibilidades.

Uma maneira interessante de se criar uma função critério é utilizar alguns dos conceitos de teoria da informação apresentados na seção anterior. A metodologia CFS (do inglês, Correlation Feature Selection) baseai-se na seguinte hipótese: "Bons subconjuntos de atributos é composto por atributos que possuem alta discriminação em relação à classe e, também, pouco correlacionados entre si” (Ghiselli, 1964; Hall e Smith, 1999). A equação que formaliza este conceito é dada por,

$$
\text { Merit }_{S_{k}}=\frac{k \overline{r_{c f}}}{\sqrt{k+k(k-1) \overline{r_{f f}}}}
$$

onde $S_{k}$ é um subconjunto com $k$ atributos, $\overline{r_{c f}}$ é a correlação média entre atributos e o vetor de classes $(f \in S)$ e $\overline{r_{f f}}$ é a correlação média entre atributos. Esta correlação pode ser 
medida por meio da incerteza simétrica, equação 4.13. Tal heurística é baseada na teoria dos jogos (Ghiselli, 1964), onde um principio semelhante é aplicado em um teste composto para uma variável externa de interesse.

\subsection{Classificação}

A classificação supervisionada consiste em induzir um modelo preditivo baseado em um conjunto de dados rotulados. Para isto existem diversos métodos propostos na literatura (Theodoridis e Koutroumbas, 2003; Bishop, 2006). Aqui se optou pela utilização de árvores de decisão e classificadores Bayesianos. Esta escolha foi feita, pois tanto as árvores quanto os modelos Bayesianos fornecem informações sobre o conjunto de dados e a maneira como a busca é realizada dentro do espaço de características. Assim é possível extrair informações e avaliar os melhores resultados obtendo conclusões tanto sobre os dados classificados quanto informações dos modelos induzidos.

\subsection{1 Árvores C4.5}

A indução de árvores de decisão é baseada na estratégia dividir para conquistar. O espaço é dividido em hiper-retângulos, de maneira que todas as possibilidades são cobertas pelo modelo. Sua construção é feita de maneira gulosa, ou seja, durante a indução, quando uma decisão é tomada ela nunca será reconsiderada. Isto gera modelos otimizados localmente. A figura 4.2 é um exemplo da divisão do espaço de características em (a) e uma árvore de decisão em (b).

Formalmente, uma árvore de decisão é um grafo acíclico e direcionado em que cada nó pode ser classificado como folha ou nó de decisão. O primeiro representa o resultado da classificação, ou seja, uma classe. Enquanto os nós de decisão são um teste condicional. Tal teste é obtido por meio de uma heurística. De maneira resumida, o algoritmo gerador da árvore devido o espaço em hiper-retângulos visando uma maximização local desta heurística. Um dos algoritmos mais utilizados atualmente é o C4.5 (Quinlan, 1993). A heurística utilizada para definir qual o melhor atributo para cada nó é o ganho de informação,

$$
I G(C, A)=H(C)-H(C \mid A)
$$




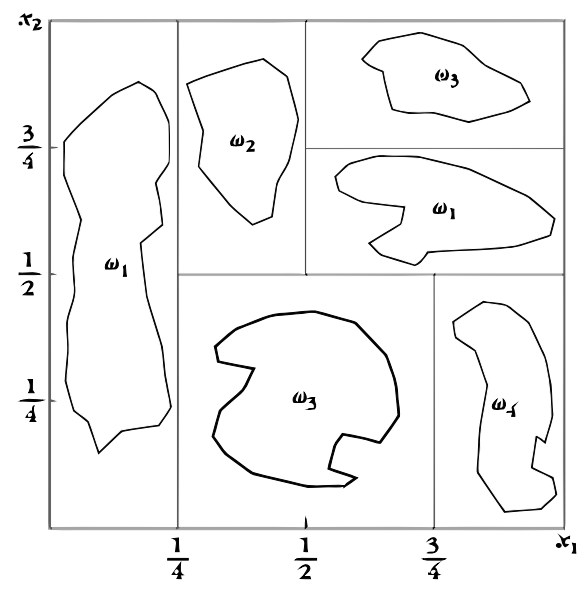

(a) Divisão do espaço de características em hiper-retângulos.

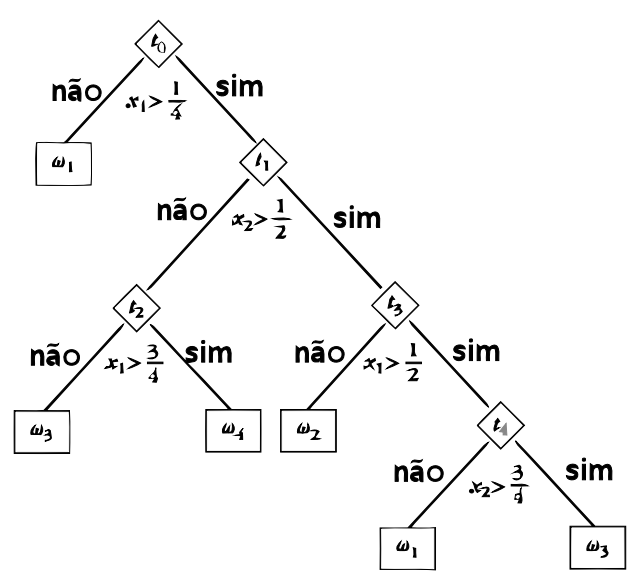

(b) Árvore de decisão induzida.

Figura 4.2: Exemplo de árvore de decisão em (a) para um espaço de características bidimensional com os atributos $x_{1}, x_{2}$ e as classes $w_{1}, w_{2}, w_{3}$ e $w_{4}$ em (b). Figura adaptada de (Theodoridis e Koutroumbas, 2003).

onde $C$ é uma classe, $A$ é um atributo, $H$ é a entropia e $I G$ é o ganho de informação. Este é baseado na entropia de informação e mede a aleatoriedade de uma variável aleatória.

Um ponto negativo desta abordagem é sua alta instabilidade à pequenas variações no conjunto de treinamento. É importante ressaltar que após a indução do modelo o algoritmo C4.5 realiza uma poda na árvore para aumentar o grau de generalização e evitar overfitting.

\subsubsection{Classificação Bayesiana}

Muitas outras metodologias podem ser utilizadas para finalidades de classificação, em especial os modelos Bayesianos ingênuos, chamados Naive Bayes, do inglês, e redes Bayesianas. Assim como as árvores de decisão, estes também fornecem informações interessantes sobre o conjunto de dados, entretanto tem um foco diferente. Enquanto os anteriores que são baseados na teoria da informação estes são baseados em estatística e na teoria de probabilidades.

Além das metodologias que serão expostas nesta seção há outros tipos de classificadores Bayesianos, como exposto em (Duda et al., 2001; Bishop, 2006; Theodoridis e Koutroumbas, 2003). De maneira geral, qualquer função que calcule as probabilidades condicionais $P\left(c_{i} \mid \mathbf{x}\right)$, onde $c_{i}$ é a classe e $\mathbf{x}$ é uma amostra, é chamada função discriminante, pois esta separa os 
exemplos em classes distintas. Uma possibilidade é a utilização do teorema de Bayes,

$$
P\left(c_{i} \mid \mathbf{x}\right)=\frac{P\left(c_{i}\right) P\left(\mathbf{x} \mid c_{i}\right)}{P(\mathbf{x})}
$$

Pode-se desconsiderar o denominador $P(\mathbf{x})$, pois a amostra é a mesma para todas as classes. A função discriminante deve ser associada a uma função custo, que é dada por

$$
C=\arg \max _{i} P\left(c_{i} \mid \mathbf{x}\right)
$$

na qual a função $\arg \max _{i}$ retorna a classe com maior probabilidade de estar associada à amostra $\mathbf{x}$, isto é, aquela que possui maior valor de $P\left(c_{i} \mid \mathbf{x}\right)$.

O classificador Naive Bayes assume que os atributos são independentes entre si, daí a denominação ingênua (naive do inglês), pois, de maneira geral, isto não é real. Seguindo este pressuposto pode-se decompor $P\left(c_{i} \mid \mathbf{x}\right)$ no produto $P\left(x_{1} \mid c_{i}\right) \times P\left(x_{2} \mid c_{i}\right) \times \ldots \times P\left(x_{p} \mid c_{i}\right)$, onde $x_{j}$ é o j-ésimo atributo da amostra $\mathbf{x}$ e $c_{i}$ é a classe. Assim, a probabilidade desta amostra pertencer à classe $c_{i}$ é proporcional à

$$
P\left(c_{i} \mid \mathbf{x}\right) \propto P\left(c_{i}\right) \prod_{j=1}^{p} P\left(x_{j} \mid c_{i}\right) .
$$

Este classificador é composto pela expressão 4.26 e a regra de decisão é dada pela equação 4.25.

Como exposto anteriormente, a suposição quanto a independência dos atributos, na maioria dos casos, não condiz com a realidade. Para superar tal dificuldade utiliza-se redes Bayesianas para fins de classificação. Nesta admite-se que há relação entre os atributos. Formalmente uma rede Bayesiana é um grafo acíclico e direcionado, onde os nós representam variáveis aleatórias e as arestas representam dependências entre estas variáveis. A cada nó está associado um conjunto de probabilidades condicionais, $P\left(x_{i} \mid A_{i}\right)$, onde $x_{i}$ é a variável do nó e $A_{i}$ é o conjunto de pais associados. Além disto, este grafo satisfaz a condição de Markov, onde cada nó depende apenas de seus descendentes. Assim, para uma variável alvo qualquer, todas as demais variáveis serão consideradas como atributos de entrada e o conjunto de variáveis que influenciam tal alvo é designado Markov Blanquet. Este é constituído pelos pais e filhos da variável alvo e pelos pais dos filhos da variável alvo. Um exemplo qualitativo de redes Bayesianas é mostrado 


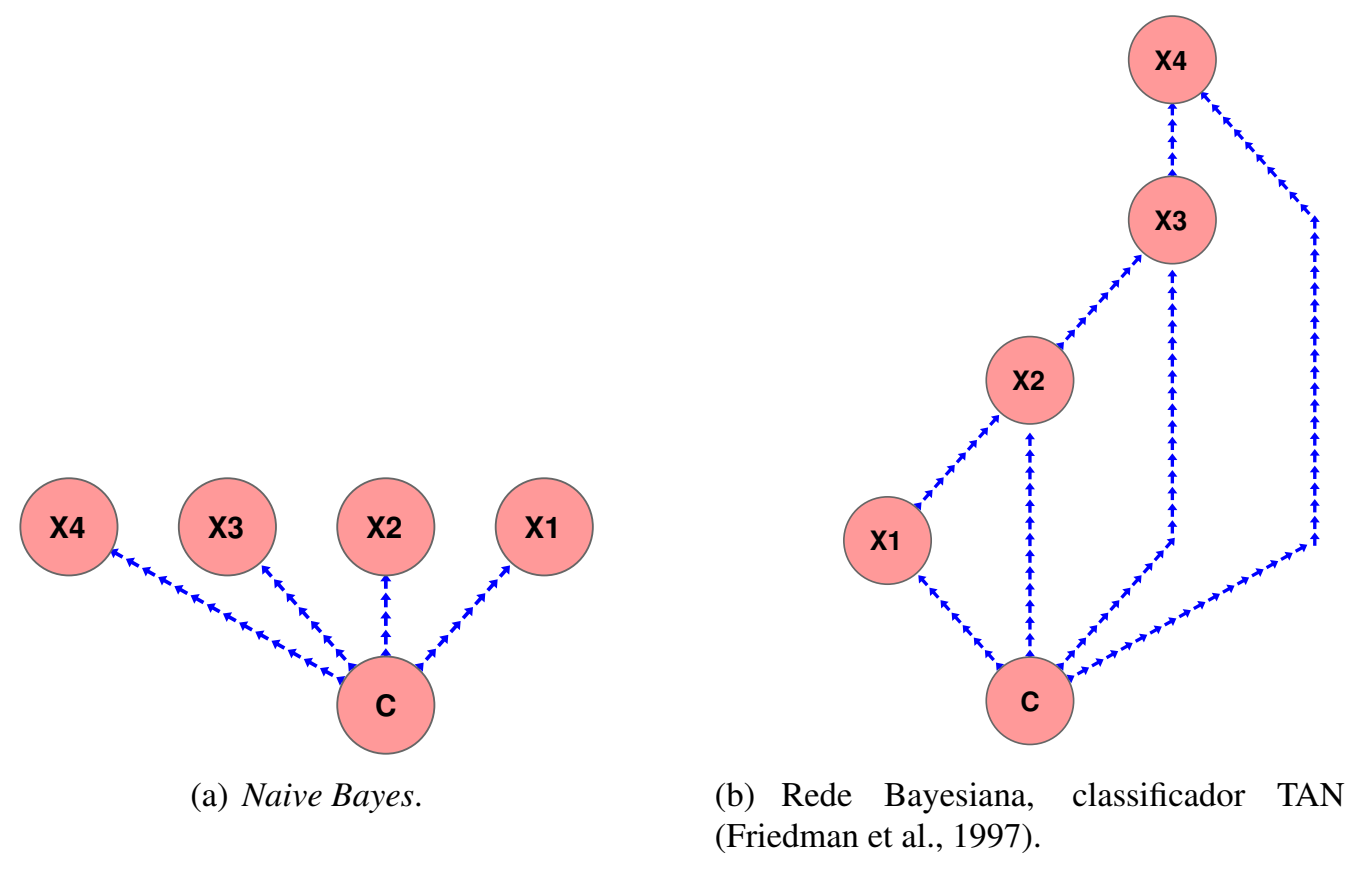

Figura 4.3: Os diagramas mostram de maneira qualitativa a interação entre as variáveis, onde $C$ é a classe e $X_{i}$ são os atributos. Em (a) para o modelo Naive Bayes, onde há apenas a interação entre a classificação e os atributos. Em (b) o modelo de rede Bayesiana, onde considera-se que há interação entre os atributos e estes são considerados durante o processo de classificação.

na figura 4.3, sendo classificadores Naive Bayes, em (a), e uma rede Bayesiana (classificador TAN (Friedman et al., 1997)), em (b).

Por exemplo, a fatoração da probabilidades conjuntas $P\left(C, x_{1}, x_{2}, x_{3}, x_{4}\right)$ das redes apresentadas na figura 4.3 é:

- Naive Bayes:

$$
P\left(C, x_{1}, x_{2}, x_{3}, x_{4}\right)=P(C) P\left(x_{1} \mid C\right) P\left(x_{2} \mid C\right) P\left(x_{3} \mid C\right) P\left(x_{4} \mid C\right)
$$

- Rede Bayesiana (TAN):

$$
P\left(C, x_{1}, x_{2}, x_{3}, x_{4}\right)=P(C) P\left(x_{1} \mid C\right) P\left(x_{2} \mid x_{1}, C\right) P\left(x_{3} \mid x_{2}, C\right) P\left(x_{4} \mid x_{3}, C\right)
$$

O problema da obtenção da melhor topologia para a rede está ligada à área de inferência estatística, que procura o melhor modelo para um determinado problema. Existem várias técnicas para se obter a topologia destas redes (Theodoridis e Koutroumbas, 2003; Bishop, 2006). 
Nesta seção foi feita uma introdução sobre aprendizado Bayesiano, apresentado seus conceitos fundamentais, bem como a função discriminante para o classificador Naive Bayes. Ao final foi exposto o conceito de redes Bayesianas e seu processo de indução foi deixado nas referências devido a vasta quantidade de modelos possíveis.

\subsection{Avaliação de modelos preditivos}

\subsubsection{Validação}

Esta é uma das etapas mais importantes do processo de mineração de dados. É nesta etapa que analisa-se o modelo induzido, verificando se este se ajusta ao problema e se é geral o suficiente para análise de dados de teste.

Uma das metodologias mais utilizadas é a validação cruzada, em inglês $k$-fold cross validation (Theodoridis e Koutroumbas, 2003; Bishop, 2006). Este procedimento consiste em dividir o conjunto de treinamento em $k$ subconjuntos aleatórios de aproximadamente mesmo tamanho. Este processo consiste em induzir o modelo de classificação $k$ vezes, sendo que em cada uma das vezes utiliza-se uma das partições como teste e as $k-1$ restantes como conjunto de treinamento. Em cada uma das execuções um conjunto de testes diferente é utilizado, sendo assim, todas as amostras serão testadas uma única vez. O desempenho final do modelo é dado pela média dos desempenhos em cada um dos subconjuntos testados. Em geral utiliza-se $k=10$.

Uma variação deste método de validação para problemas de classificação é o $k$-fold cross validation estratificado (Theodoridis e Koutroumbas, 2003; Bishop, 2006). Neste, a divisão em $k$ subconjuntos mantêm a proporção de elementos de cada classe semelhante à proporção do conjunto de dados original.

Um caso especial da validação cruzada ocorre quando se utiliza $k=n$, ou seja, o número de subconjuntos é igual ao número de elementos no conjunto de dados. Este é chamado leaveone-out (Theodoridis e Koutroumbas, 2003; Bishop, 2006). Desta maneira utiliza-se apenas um elemento para teste e os demais para treinamento. O desempenho final será dado pela soma dos desempenhos. Este método produz uma estimativa mais fiel do desempenho do modelo, porém apresenta um custo computacional mais elevado. 


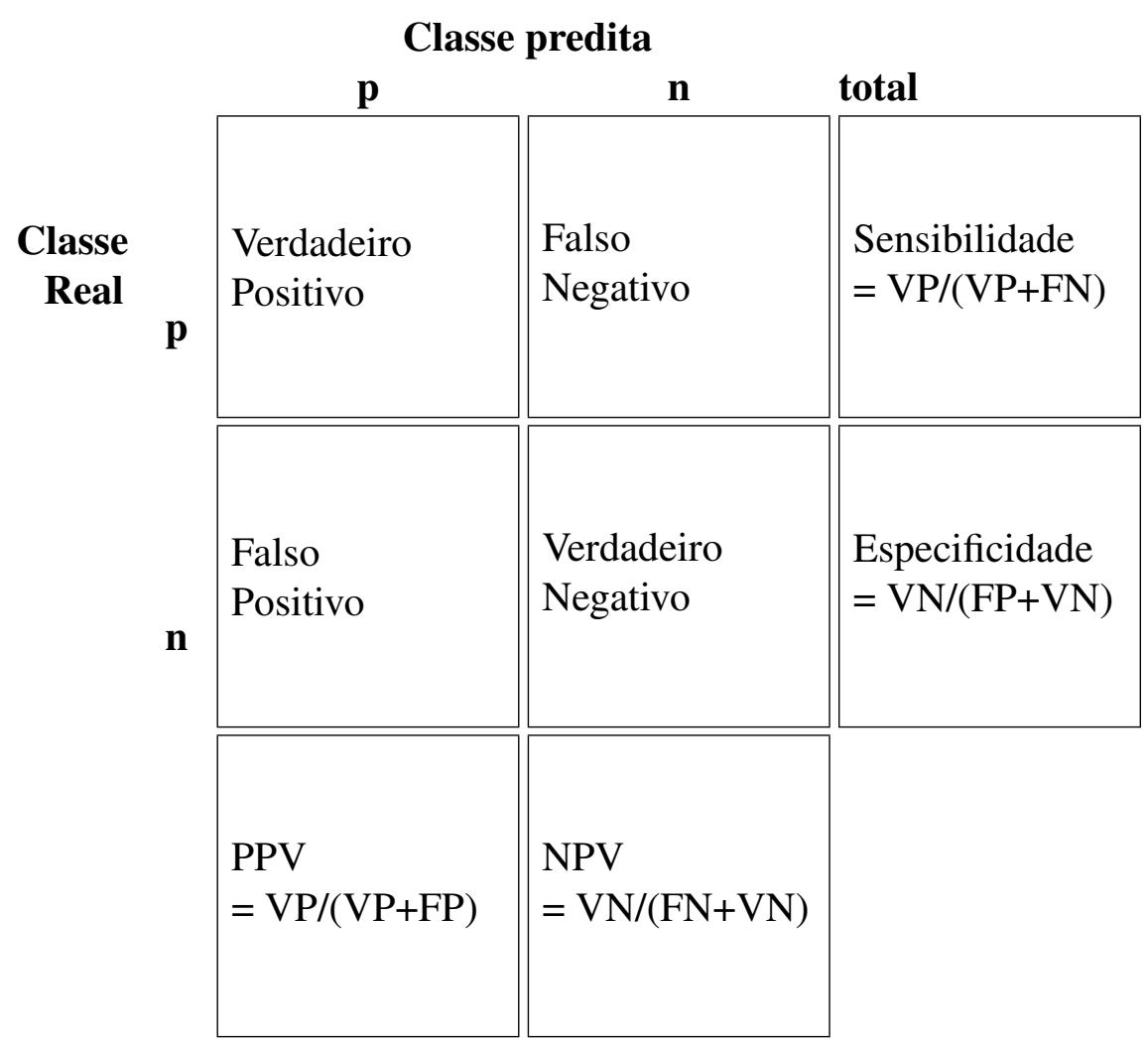

Tabela 4.1: Diagrama para uma matriz de confusão. Onde PPV e NPV correspondem as siglas Positive predictive value e Negative predictive value respectivamente.

\subsubsection{Problemas de duas classes}

Considerando um problema de duas classes, convenciona-se uma delas como positiva, sendo assim a outra como negativa. Assim tem-se: (i) $V P$ o número de verdadeiros positivos, (ii) $V N$ os verdadeiros negativos, (iii) $F P$ os falsos positivos e (iv) $F N$ os falsos negativos. Sendo que $n=F P+F N+V P+V N$, onde $n$ é o número total de amostras. De forma geral, estes dados podem ser representados na forma matricial, onde as linhas representam as classes verdadeiras e as colunas as preditas e cada célula desta matriz contêm um número de amostras de acordo com a resposta do classificador. Esta matriz é conhecida por matriz de confusão, tal matriz é representada na tabela 4.1. A partir desta, é possível extrair uma série de medidas de desempenho, entre elas:

- Erro total, mede o erro do modelo, este é dado por:

$$
\text { erro }=\frac{F P+F N}{n}
$$


- Sensibilidade ou revocação, corresponde a taxa de acerto na classe positiva, esta é dada por:

$$
\text { sensibilidade }=\frac{V P}{V P+F N}
$$

- Precisão, mede a proporção de exemplos positivos classificados corretamente entre aqueles preditos positivos, esta é dada por:

$$
\text { precisao }=P P V=\frac{V P}{V P+F P}
$$

- Medida F, é a média harmônica ponderada da precisão e a revocação, em geral, estas medidas não são discutidas isoladamente, assim utiliza-se a medida F, que é dada por:

$$
F_{1}=\frac{2 \times \text { Precisao } \times \text { sensibilidade }}{\text { Precisao }+ \text { sensibilidade }}
$$

É importante observar que a sensibilidade ao se admitir uma classe positiva é igual a especificidade admitindo-se a outra classe como positiva. De maneira semelhante ocorre para as quantidades Positive predictive value e Negative predictive value.

\subsection{Agrupamento de dados}

Clustering ou agrupamento de dados é uma tarefa de aprendizado não supervisionado que se refere a identificação de informações relevantes nos dados sem a presença de um elemento externo para guiar o aprendizado. A essência desta modalidade de aprendizado é a identificação de propriedades intrínsecas dos dados de entrada de maneira a construir uma representação destes, além de encontrar padrões ou tendência que auxiliem na compreensão destes dados.

Apesar da ideia de cluster ser bastante intuitiva não há uma definição formal, única e precisa para este conceito. Em geral cada algoritmo utiliza uma definição que seja mais conveniente para determinado tipo de aplicação. Algumas das definições presentes na literatura são (Theodoridis e Koutroumbas, 2003): (i) Cluster baseado em centro: um cluster é um conjunto de pontos tal que qualquer ponto em um dado cluster está mais próximo ao centro deste cluster do que qualquer outro cluster; (ii) Cluster contínuo: é um conjunto de pontos tal que 
qualquer ponto em um dado cluster é mais similar a um ou mais pontos nesse cluster do que a qualquer ponto que não pertence a ele; (iii) Cluster baseado em densidade: um cluster é uma região densa de pontos, separada de outras regiões de alta densidade por regiões de baixa densidade; (iv) Cluster baseado em similaridade: um cluster é um conjunto de pontos similares, enquanto pontos de clusters diferentes não são similares.

Para realizar este tipo de aplicação existem diversos algoritmos. Um que vem ganhando bastante destaque é o chamado expectation maximization (EM). Este algoritmo surgiu da unificação de diversos trabalhos apresentados por Dempster et al (Dempster et al., 1977). De maneira geral, se uma variável foi observada algumas vezes e outras não, é possível utilizar os casos observados para aprender e predizer os valores não observados. O algoritmo EM realiza esta tarefa, mas também pode ser utilizado para variáveis cujos valores nunca foram observados, sempre e quando seja conhecida a forma geral da distribuição de probabilidade das variáveis.

Em resumo o algoritmo EM é definido em dois passos: (i) Passo E: Encontram-se os valores esperados das estatísticas suficientes para os dados completos Y, dado os dados incompletos, Z, e as estimativas dos parâmetros; (ii) Passo M: Utilizam-se estas estatísticas suficientes para fazer uma estimativa de máxima verossimilhança. Considere que $X=x_{1}, \ldots, x_{m}$ são os dados observados independentemente e $Z=z_{1}, \ldots, z_{m}$ os dados não observados nestas instâncias,e seja $Y=X \cup Z$. $Z$ pode ser tratado como uma variável aleatória cuja distribuição de probabilidades depende do conjunto de parâmetros desconhecidos $\theta$ e dos dados observados $X$. Analogamente, $Y$ é uma variável aleatória, já que esta é definida em função da variável aleatória $Z$. Para descrever a forma geral do algoritmo EM, denota-se a hipótese dos parâmetros atuais, $\theta$ por $h$ e a hipótese revisada, que é estimada a cada iteração do algoritmo, por $h^{\prime}$

O algoritmo EM consiste na busca pela hipótese $h^{\prime}$ de maximização da verossimilhança, isto é, que maximize $E\left[\log \left(P\left(Y \mid h^{\prime}\right)\right)\right]$. Sendo que este valor esperado é calculado sobre a distribuição de probabilidades de $Y$, que é determinada pelos parâmetros desconhecidos $\theta$. Como os dados $Y$ são uma combinação dos dados observados $X$ e não observados $Z$, obtêm-se o valor de $E\left[\log \left(P\left(Y \mid h^{\prime}\right)\right)\right]$ sobre a distribuição de probabilidades de $Y$, que é determinada pelos valores conhecidos $X$ mais a distribuição de probabilidades de $Z$. Em geral a distribuição de probabilidades de $Y$ não é conhecida, pois ela é determinada pelos parâmetros $\theta$ que se deseja estimar. Entretanto o algoritmo EM usa sua hipótese atual $h$ no lugar do parâmetro $\theta$ atual para 
determinar a distribuição de probabilidades de $Y$. Assim, considere uma função $Q\left(h^{\prime} \mid h\right)$ que dá $E\left[\log \left(P\left(Y \mid h^{\prime}\right)\right)\right]$ como função de $h^{\prime}$, pela suposição que $\theta=h$ e dada a porção dos dados observados $X$ dos dados $Y$, tem-se:

$$
Q\left(h^{\prime} \mid h\right)=E\left[\log \left(P\left(X, Y \mid h^{\prime}\right) \mid X, h\right]\right.
$$

Assim, formalmente, o algoritmo EM repete os dois passos seguintes até a convergência: Passo E (Expectation (E)): Calcula $Q\left(h^{\prime} \mid h\right)$ utilizando a hipótese atual $h$ e os dados observados $X$ para estimar a distribuição de probabilidades de $Y$, equação 4.31. Passo M (Maximization $(\boldsymbol{M}))$ : troca-se a hipótese $h$ pela $h^{\prime}$ que maximize a função $Q$ :

$$
h=\arg \max _{h^{\prime}} Q\left(h^{\prime} \mid h\right) .
$$

Quando há apenas um único máximo o algoritmo convergirá para ele, caso contrário ele poderá convergir para máximos locais.

Quando a metodologia Expectation Maximization utiliza a estimação de uma função de probabilidades multivariada por distribuições Gaussianas. Considerando que

$$
\begin{gathered}
p\left(x, a_{k}, S_{k}, \pi_{k}\right)=\sum_{k=1}^{M} \pi_{k} p_{k}(x), \quad \pi_{k} \geq 0, \quad \sum_{k=1}^{M} \pi_{k}=1 \\
p_{k}(x)=\phi\left(x, a_{k}, S_{k}\right)=\frac{1}{(2 \pi)^{d / 2}\left|S_{k}\right|^{1 / 2}} \exp \left(-\frac{1}{2}\left(x-a_{k}\right)^{T} S_{k}^{-1}\left(x-a_{k}\right)\right)
\end{gathered}
$$

onde $M$ é o número de grupos, $p_{k}$ é uma distribuição normal multivariada com média $a_{k}$ e matriz de covariância $S_{k}$ e $\pi_{k}$ é uma ponderação para a k-ésima distribuição.

Assim, esta metodologia é baseada nas duas etapas descritas a seguir (Bilmes, 1998):

- Etapa E: Esta consiste na estimação da probabilidade $p_{i, k}$, denotada por $\alpha_{i k}$ para a amostra $i$ que pertence a distribuição $k$. Tal estimativa é dada por:

$$
\alpha_{k i}=\frac{\pi_{k} \phi\left(x ; a_{k}, S_{k}\right)}{\sum_{j=1}^{m} \pi_{j} \phi\left(x ; a_{j}, S_{j}\right)}
$$


- Etapa M: Esta é a etapa de maximização, nesta os parâmetros da distribuição são otimizados usando as probabilidades das equações a seguir

$$
\pi_{k}=\frac{1}{N} \sum_{i=1}^{N} \alpha_{k i}
$$

onde,

$$
a_{k}=\frac{\sum_{i=1}^{N} \alpha_{k i} x_{i}}{\sum_{i=1}^{N} \alpha_{k i}}
$$

onde

$$
S_{k} \frac{\sum_{i=1}^{N} \alpha_{k i}\left(x_{i}-a_{k}\right)\left(x_{i}-a_{k}\right)^{T}}{\sum_{i=1}^{N} \alpha_{k i}} .
$$

Este algoritmo pode obter o número de grupos automaticamente por meio da validação cruzada. Inicialmente, assume-se que há apenas um grupo. O grupo de treinamento é dividido em 10 subgrupos obtidos aleatoriamente, sendo que este número de divisões é usualmente utilizado em problemas de validação (Theodoridis e Koutroumbas, 2003). O algoritmo Expectation Maximization é executado em cada um destes dez grupos e calcula-se a média da verossimilhança, equação 4.31. Repete-se esta sequência de passos aumentando gradualmente o número de grupos, enquanto a verossimilhança aumentar. Este procedimento termina quando tal medida não aumentar mais. 


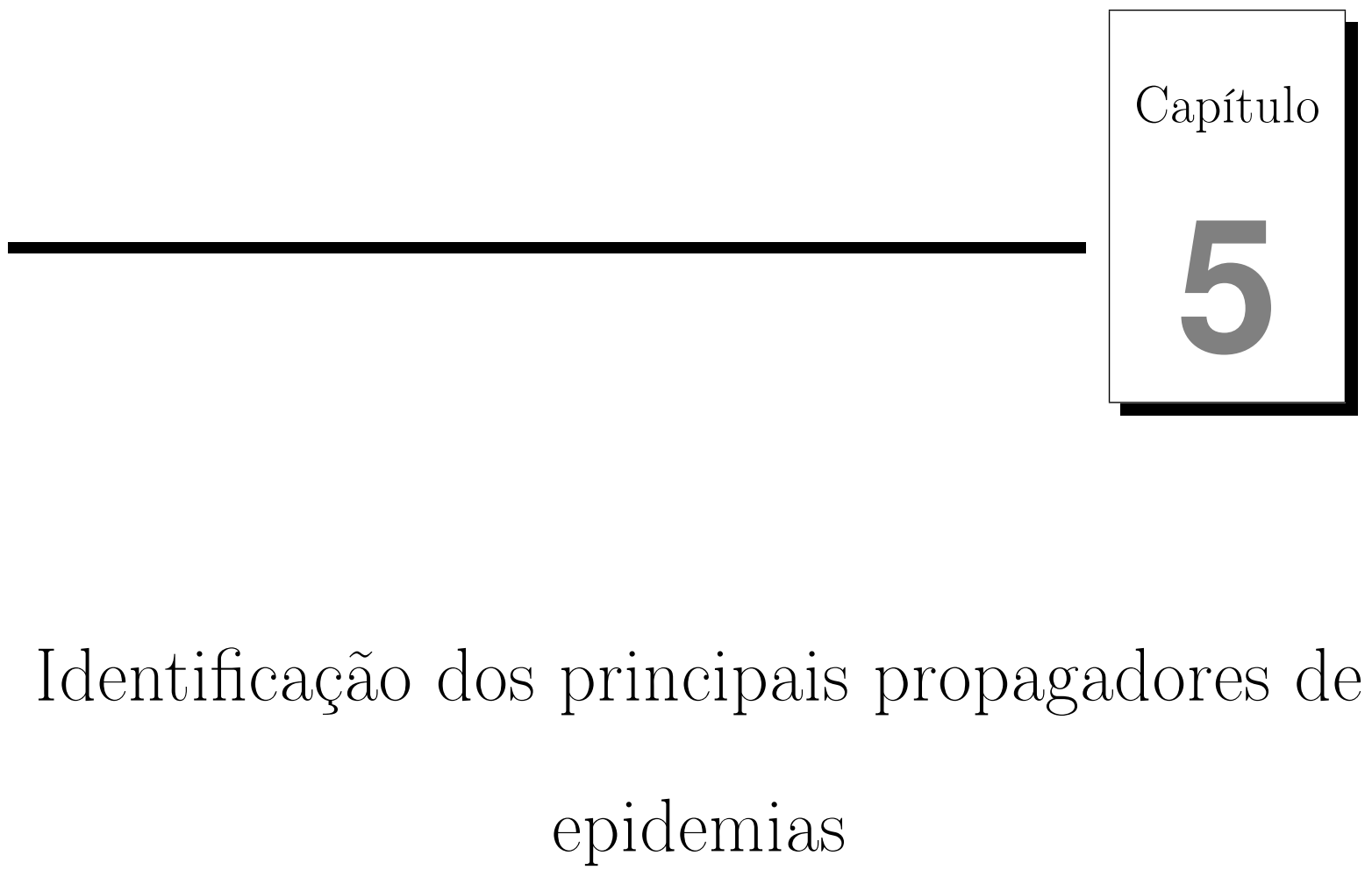

As dinâmicas de propagação são fortemente influenciadas pelos nós centrais e sofrem um menor influência de nós das bordas. Entretanto, não há uma medida de centralidade que seja geral o suficiente e englobe todas as propriedades topológicas da rede. Por exemplo, o grau possui apenas informações locais, enquanto a medida de betweenness e closeness centrality consideram informações globais referentes a menores caminhos e de maneiras diferentes. Assim, cada medida considera nós como centrais ou bordas de maneiras distintas. Além disto, há medidas baseadas em caminhadas aleatórias, espectro da matriz de adjacência, entre outras (Boccaletti et al., 2006; Costa et al., 2007). Neste capítulo será discutida tal arbitrariedade, bem como será proposta uma metodologia para identificar o grupo de nós que mais influência a dinâmica de propagação de epidemias no modelo SIR. 


\subsection{Introdução}

Redes sociais são organizadas de maneira altamente heterogênea (Costa et al., 2007), apresentando propriedades não triviais como distribuições de grau na forma de leis de potência (Liljeros et al., 2001), estruturas de comunidades (Girvan e Newman, 2002), correlação de grau (M. E. J. Newman e Park, 2003), entre outras. Tais propriedades estão intimamente ligadas a maneira como doenças e rumores propagam-se pela rede. Logo, compreender tais propriedades estruturais é fundamental para o desenvolvimento e controle de processos de dinâmicas sociais.

Em processos de propagação de epidemias, as doenças se espalham por meio do contato entre indivíduos em redes sociais. É esperado que os nós mais centrais sejam aqueles que exercem uma maior influência sobre a rede como um todo (Kitsak et al., 2011), pois tais nós espalham sua influência rapidamente pela rede. Entretanto, não há uma única maneira de definir a centralidade de um vértice. Na realidade, esta é uma questão em aberto, já que há varias medidas de centralidade definidas na literatura (ver capítulo 2) e cada uma delas é baseada em uma propriedade estrutural diferente. Uma das medidas mais comuns e mais aceitas é o grau (Costa et al., 2007). Neste caso os nós que apresentam um maior número de conexões são mais centrais do que aqueles que possuem um número menor de conexões. Contudo, trabalhos recentes sugerem que tal medida não é fundamental para o processo de propagação de epidemias (Kitsak et al., 2011). Como é o caso de um nó altamente conectado que esteja na periferia da rede, sendo que sua influência pode não atingir o centro (Kitsak et al., 2011). Por outro lado, observou-se que a medida de $k$-core esta intimamente relacionada com tal processo dinâmico (Kitsak et al., 2011).

De fato, há medidas baseadas na distância entre os nós, como por exemplo betweenness e closeness centrality, medidas de caminhadas aleatórias, espectro da matriz de adjacência, dentre outras. Assim os conceitos de centro e borda de uma rede são distintos para cada uma destas definições. Entretanto, ao se analisar dinâmicas de propagação em epidemias, admite-se que o centro são aqueles nós que exercem maior influência sobre a disseminação da doença, ou mesmo rumores e informações. Tal influência pode ser quantificada de diversas maneiras, como por exemplo o pico da curva de infectados ao longo do tempo, que será utilizada neste trabalho, já que o pico está associado com a velocidade de propagação. Assim, espera-se que 
Tabela 5.1: Propriedades estruturais da base de dados.

\begin{tabular}{|c|c|c|c|c|c|}
\hline Rede & $N$ & $\langle k\rangle$ & $\langle c c\rangle$ & $\rho$ & $\langle L\rangle$ \\
\hline Santa74 & 3578 & 84.82 & 0.263 & 0.070 & 2.486 \\
Smith60 & 2970 & 65.41 & 0.283 & 0.044 & 2.498 \\
Email & 1133 & 9.61 & 0.220 & 0.078 & 3.606 \\
Political blogs & 1222 & 31.24 & 0.320 & -0.221 & 2.738 \\
Árvore artificial & 1000 & 1.998 & 0.0 & -0.897 & 7.238 \\
\hline
\end{tabular}

os nós mais centrais, sejam aqueles que apresentem maior pico, mas que ao serem imunizados, também reduzam ao máximo o impacto da propagação da epidemia pela rede.

\subsection{Base de dados}

Utilizou-se redes reais obtidas por amostras da rede social do Facebook (Traud et al., 2011, 2010). Mais especificamente, as redes dos colégios (segundo a nomenclatura utilizada nos artigos referenciados): Santa74 e Smith60. Utilizou-se também as redes de e-mails (Guimerà et al., 2003) e a rede de blogs de politica (Adamic e Glance, 2005). Esta última é direcionada, porém, foi considerada como não direcionada. Para todas as redes, utilizou-se apenas a maior componente para o caso de grafos desconexos. Além destas, utilizou-se também uma árvore construída artificialmente onde parte-se de um único nó e, a cada passo, adiciona-se para os nós do próximo nível $l+1$ filhos, onde $l$ é o número de níveis, que inicia-se a partir de $l=1$. Desta maneira, têm-se uma árvore onde a raiz tem dois filhos, cada um destes terá três e assim por diante. A tabela 5.1 mostra propriedades estruturais da base de dados: (i) número de nós; (ii)grau médio; (iii) clustering coefficient médio; (iv) assortatividade, $\rho$, e (v) comprimento médio dos menor caminhos entre pares de nós.

\subsection{Metodologia e resultados}

Motivado pela inexistência de uma medida de centralidade que seja geral, deseja-se mostrar que há grupos de vértices que exercem maior ou menor influência sobre as dinâmicas em redes, em especial à propagação de epidemias. Objetivando identificar os principais propagadores de epidemias segundo a dinâmica SIR, agrupou-se, utilizando o algoritmo EM (ver capítulo 4), um 


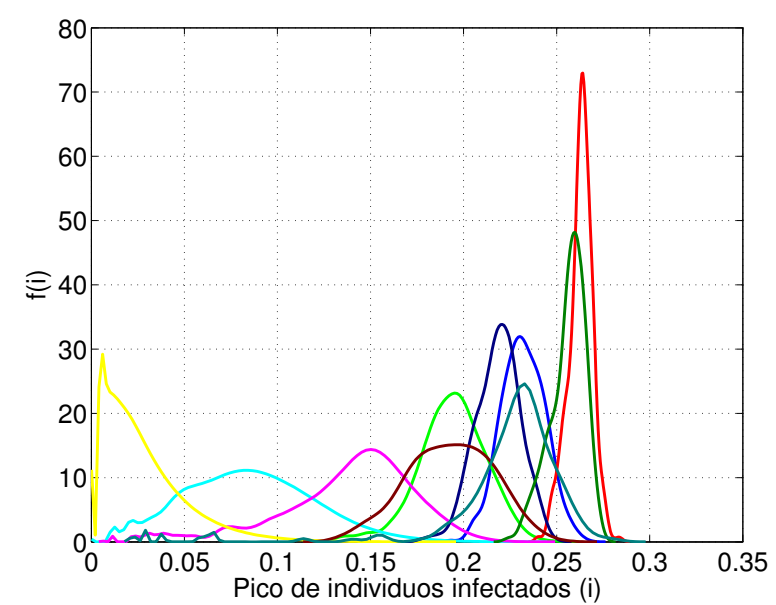

(a)

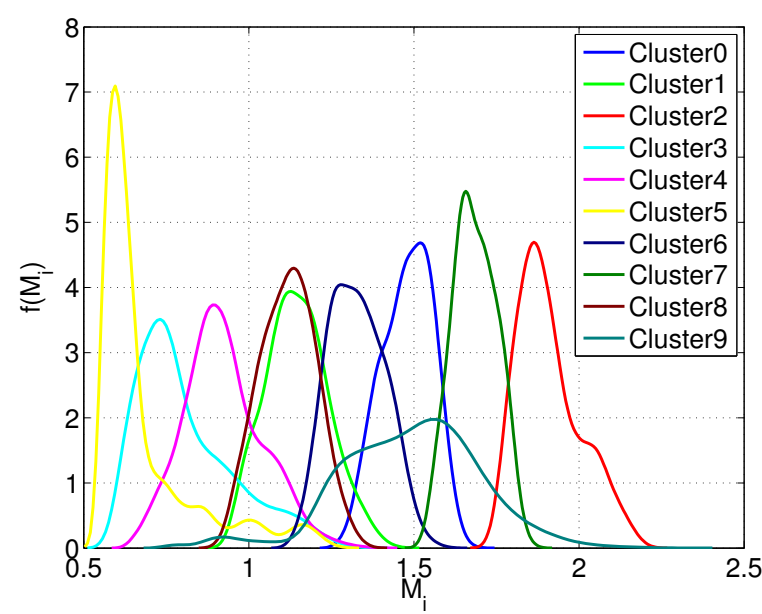

(b)

Figura 5.1: Distribuição de probabilidade para a rede Santa74: (a) pico de infectados para simulação do modelo SIR em cada um dos grupos obtidos, (b) medida $M_{i}$ em cada um dos grupos obtidos.

conjunto de nós de acordo com 6 medidas de centralidade, normalizadas segundo a equação 4.2. Optou-se por esta normalização, pois os resultados ficam restritos ao intervalo fechado $[0,1]$ (ver capítulo 4): (i) Grau; (ii) betweenness; (iii) Closeness; (iv) knn; (v) PageRank; (vi) Kcore. Para cada rede real avaliada, agrupou-se os nós desta em $N_{c}$ clusters, sendo que este valor é obtido automaticamente segundo a técnica exposta no capítulo 4.

Para verificar qual o conjunto de nós apresenta maior potencial de infecção utilizou-se a distância das medidas centrais em relação à origem, porém normalizadas para um intervalo $[0,1]$ pela normalização softmax (ver capítulo 4):

$$
M_{i}=\left\|v_{i}\right\|=\sqrt{k_{i}^{2}+b_{i}^{2}+c_{i}^{2}+n_{i}^{2}+p r_{i}^{2}+k c_{i}^{2}}
$$

esta medida pondera igualmente cada uma das medidas consideradas. O grupo que possuir maior a média de $M_{i}$ deverá, também, exercer uma maior influência sobre a dinâmica, pois terá não apenas um alto valor para uma medida de centralidade, mas sim valores altos de centralidade para todas as medidas.

Por meio desta metodologia o número de grupos é obtido automaticamente através do método de agrupamento, visando a maximização da verossimilhança. Logo, pode-se comparar o principal cluster com os demais, pois o interesse principal é identificar aqueles vértices que exercem papel fundamental para a propagação de epidemias. 


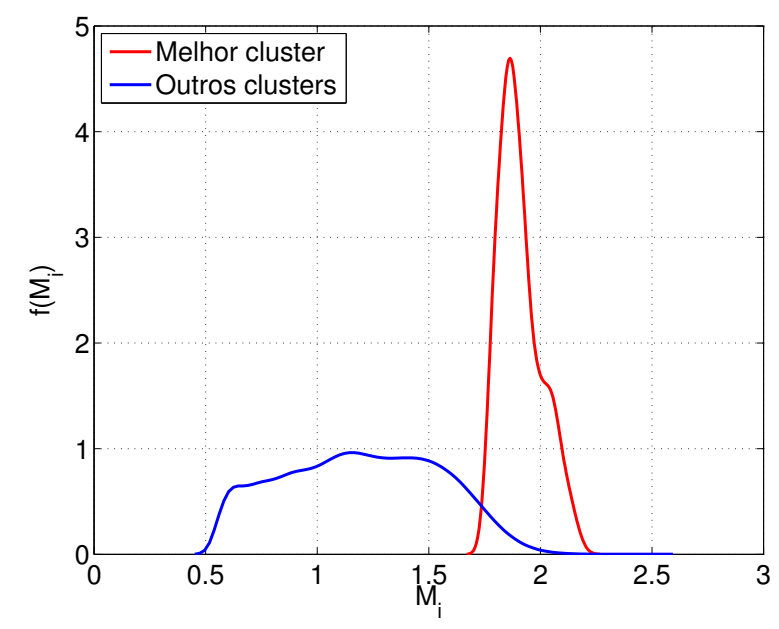

Figura 5.2: Distribuição de probabilidade para a rede Santa74 considerando medida $M_{i}$ para o melhor grupo em comparação com os demais.

A epidemia foi propagada, partindo-se de cada um dos vértices da rede e estimou-se a distribuição do pico de infectados segundo a técnica das janelas de Parzen (Parzen, 1962; Rosenblatt, 1956) utilizando um kernel gaussiano. Formalmente, o pico de infectados é dado por,

$$
S_{v}=\max \left(i_{v}(t)\right)
$$

onde $i_{v}(t)$ é a fração de indivíduos infectados para cada instante de tempo $t$, iniciando-se a propagação a partir do vértice $v$. Assim, espera-se que os grupos de vértices obtidos por meio do agrupamento apresentem comportamento dinâmico semelhante dentro do mesmo grupo e comportamentos distintos em grupos diferentes. A figura 5.1 mostra as distribuições de probabilidade para os picos de infecção em (a) e os índices $M_{i}$ em (b). É importante verificar a correspondência entre estas figuras, nota-se que os grupos apresentam a mesma ordem tanto no item (a) quanto (b). Porém a segunda utiliza apenas propriedades estruturais, enquanto a primeira é uma resposta dinâmica, sugerindo, portanto a relação entre tais grandezas.

Em especial, deseja-se reconhecer o cluster mais influente e verificar seu comportamento dinâmico. Tal grupo possui a maior média de $M_{i}$ e está localizado no extremo direito da figura 5.1 (b). Na figura 5.2 separou-se apenas este grupo de nós, mostrando graficamente a diferença estrutural em relação aos demais vértices em termos da medidas $M_{i}$. Ademais, realizou-se um teste t-Student para comparar as médias de ambas distribuições, verifica-se que estas diferem com um nível e confiança de 0,01 para todas as redes avaliadas. 


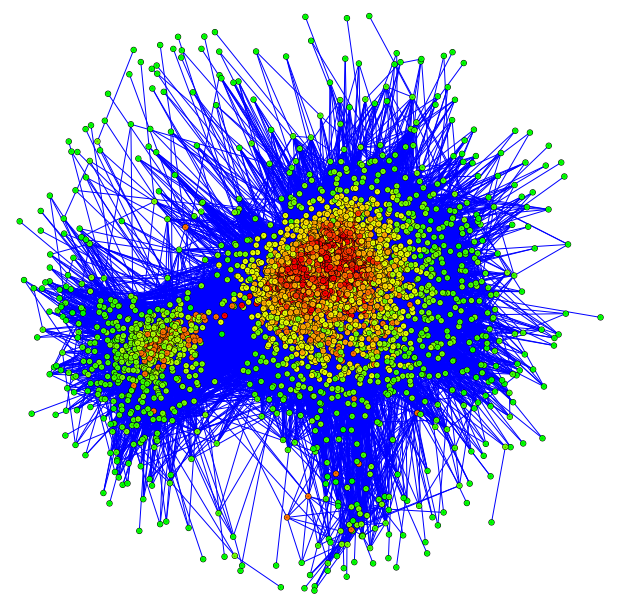

(a)

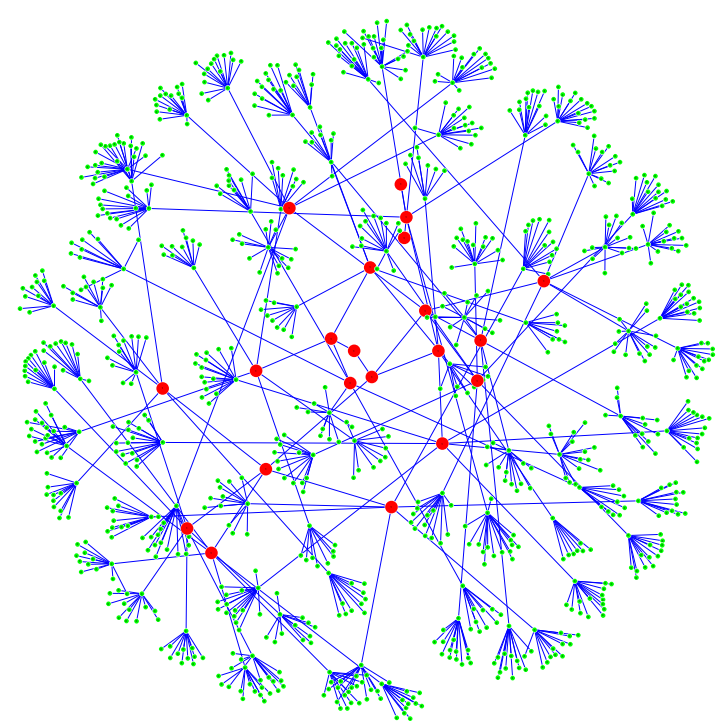

(b)

Figura 5.3: Esta visualização é baseada no algoritmo force-directed proposto por Kamada e Kawai (Kamada e Kawai, 1989). Em (a) os nós com cores mais próximas ao vermelho são aqueles com maiores índices de $M_{i}$, enquanto aqueles com menores valores estão mais próximos da cor verde. Em (b) os nós pertencentes ao cluster mais central estão em vermelho.

Uma observação interessante em relação à este grupo é que para todas as redes avaliadas, o grupo de nós mais influentes forma uma única componente conexa, ou seja, há ao menos um caminho entre todos os pares de nós deste cluster, sugerindo que os nós mais importantes propagam sua influência aos seus vizinhos. Deve-se ressaltar que tal resultado foi obtido sem utilizar diretamente a matriz de adjacências, apenas propriedades centrais dos vértices, que são originadas indiretamente desta.

A análise das figuras 5.1 e 5.2 sugerem que, além da correspondência entre o índice $M_{i}$ e os picos de infecção, o grupo com maior média de $M_{i}$ exerce papel fundamental dentro desta dinâmica, pois este apresenta um conjunto de medidas estruturais com valores altos, não apenas uma medida. Tal fato é uma consequência da metodologia de agrupamento, já que os nós deste grupo possuem propriedades semelhantes. Ademais, ao observar a figura 5.3 (a), nota-se que tal verificação concorda com a noção intuitiva dos conceitos de centro e borda. Entretanto, é importante ressaltar que esta é apenas uma verificação visual, sendo dependente do algoritmo de visualização, force-directed de Kamada e Kawai (Kamada e Kawai, 1989), utilizado aqui apenas como um exemplo. 
Além do que já foi exposto, verificou-se um processo de imunização, onde aqueles nós pertencentes ao cluster mais central são imunizados. Desta maneira, os nós que são imunizados não participam do processo de propagação, não contraindo a doença e assim não transmitindo a mesma. Para efeito de comparação, avaliou-se técnicas baseadas em maior grau ou $k$-core, bem como imunização aleatória. Desde que o número de vértices neste grupo é determinado automaticamente, o mesmo número de nós é imunizado de acordo com cada técnica, possibilitando, assim, uma comparação justa. Todas as simulações foram realizadas 30 vezes, devido a natureza estocástica destas simulações. Tais resultados são expostos nas figuras 5.4 e 5.5 para as redes reais e a rede artificial respectivamente. Para eliminar o efeito causado pela escolha dos parâmetros $\mu$ e $\beta$ foram avaliados vários conjuntos de parâmetros. Verifica-se que a metodologia baseada em $k$-core não obteve resultados superiores às metodologias baseadas em grau e a proposta.

Ademais, para reforçar tal análise, utilizou-se o mesmo procedimento em árvores geradas artificialmente (para mais detalhes ver a seção 5.2). Avaliando a figura 5.3 (b), onde os nós pertencentes ao principal cluster estão em vermelho, verifica-se que a metodologia proposta identifica os vértices de acordo com o que é esperado. Ou seja, aqueles nós mais antigos no processo de construção da árvore são identificados como centro da rede. De fato, a eliminação de tais nós divide a rede em componentes menores e isoladas, sugerindo a imunização destes nós. Os resultados para o processo de imunização nesta rede é mostrado na figura 5.5. Deve-se observar que a metodologia baseada em k-core não foi considerada, pois todos os nós apresentam o mesmo índice. Nota-se que as metodologias aleatória e baseada em grau apresentam resultados bastante inferiores. Para a primeira, aleatória, há uma alta probabilidade de se imunizar nós que tenham grau igual a um, o que causa um impacto desprezível sobre o processo. Isto decorre do fato de que há mais nós folhas do que nós internos. Por outro lado a abordagem baseada em grau imuniza os hubs, entretanto estes estão muito mal localizados, fazendo com que o a imunização seja pequena. Por fim, ao imunizar o cluster mais influente, obtêm-se um isolamento muito mais eficaz.

Em redes reais, a abordagem proposta apresenta resultados superiores (ou iguais para o pior caso) à metodologia baseada em grau. Por sua vez esta é melhor que a técnica baseada em $k$-core e aleatória, sendo que esta última apresenta o pior desempenho. Tal resultado sugere 


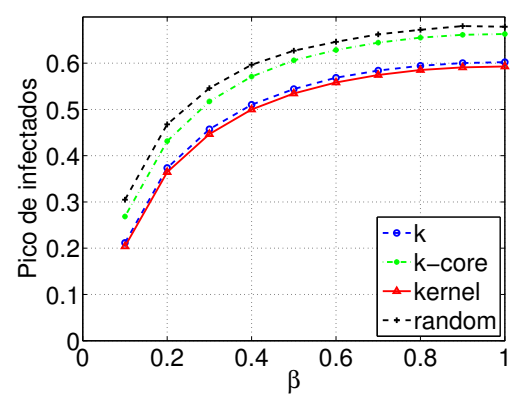

(a) Rede de emails, $\mu=0.3$.

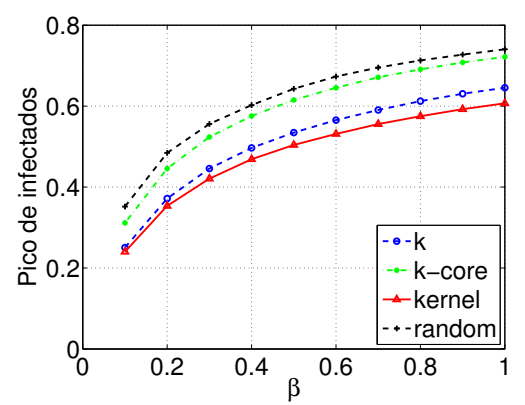

(d) Rede de blogs de politica, $\mu=$ 0.3 .
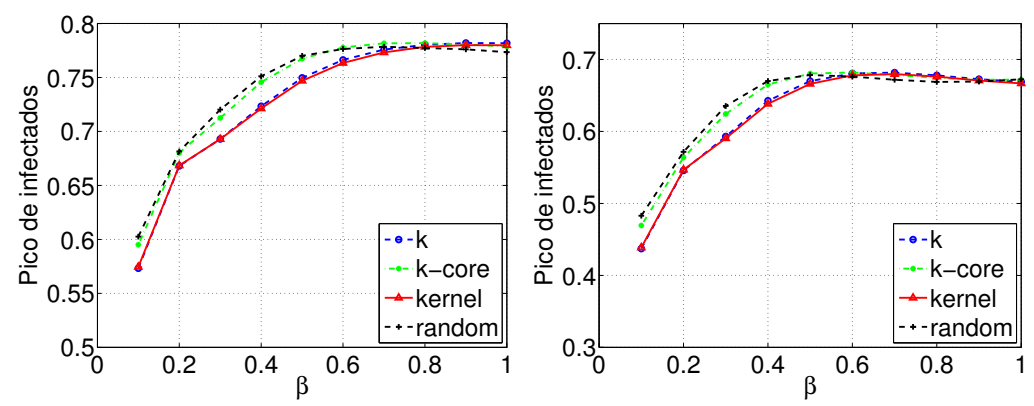

(g) Rede Facebook Smith60, $\mu=$ (h) Rede Facebook Smith60, $\mu=$ 0.3 .

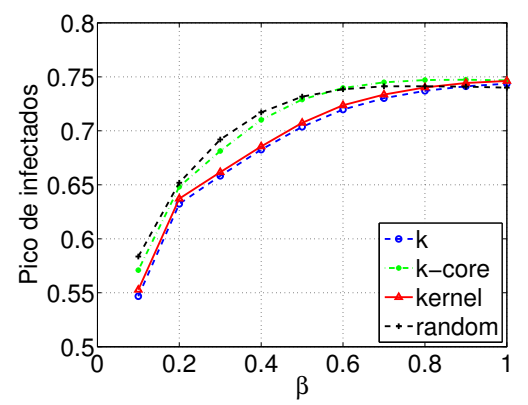

0.6 .
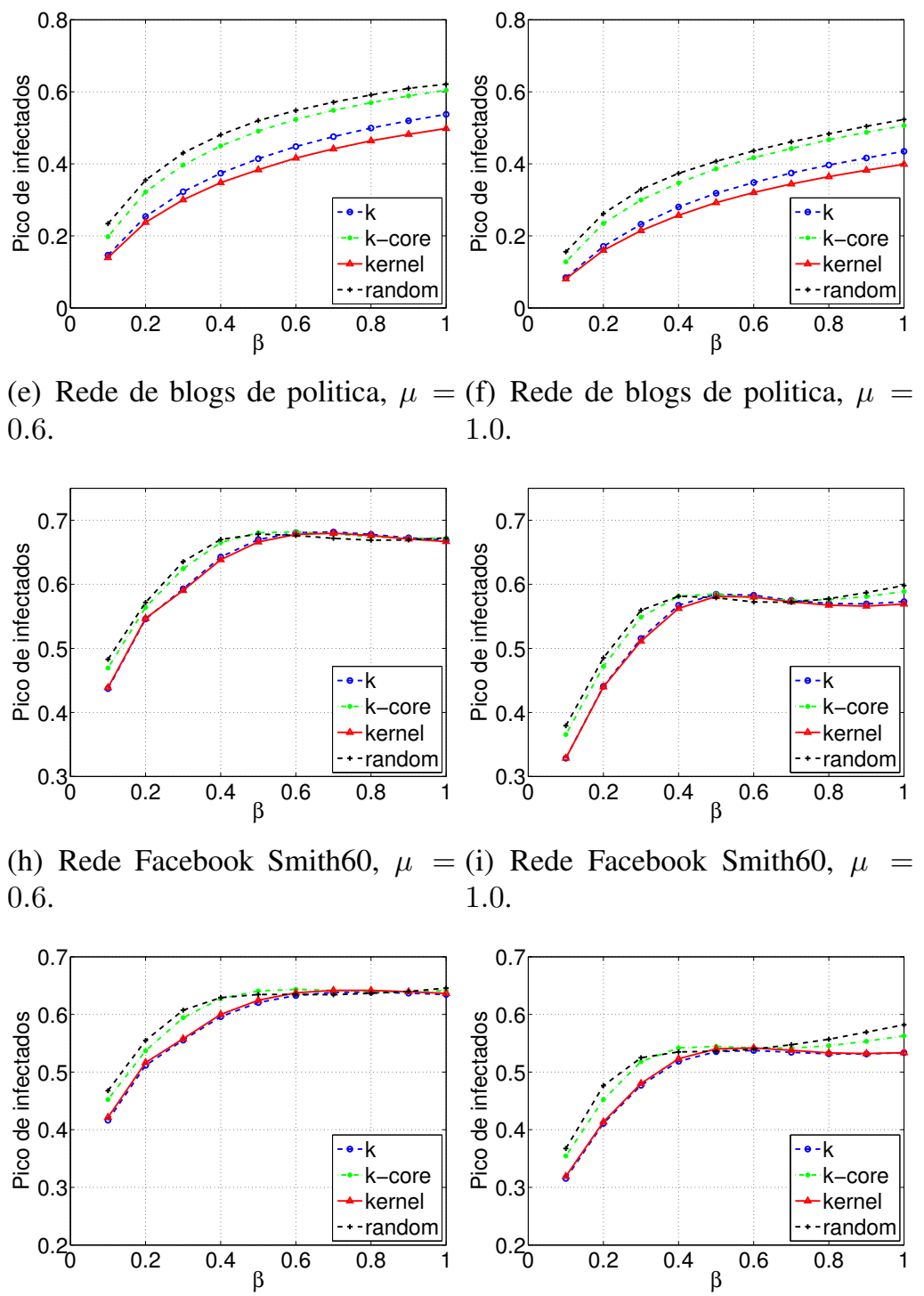

(e) Rede de blogs de politica, $\mu=$ 0.6 .

1.0 .

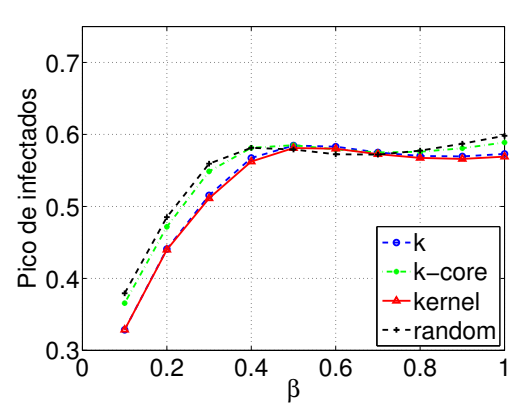

(i) Rede Facebook Smith60, $\mu=$ 1.0 .

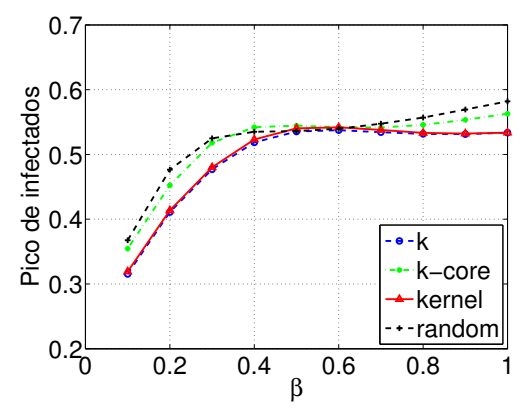

(j) Rede Facebook Santa74, $\mu=(\mathrm{k})$ Rede Facebook Santa74, $\mu=(1)$ Rede Facebook Santa74, $\mu=$ 0.3 . 0.6 .

1.0 .

Figura 5.4: Pico de indivíduos infectados após os processos de imunização discutidos: grau, k-core, aleatória e a metodologia proposta (chamada aqui por kernel). Para quatro redes reais: rede de emails (a) - (c), rede de blogs de politica (d) - (f), rede Smith60 do Facebook (g) - (i) e rede Santa74 do Facebook (j) - (1).

que os vértices que possuem maior grau apresentam importância fundamental dentro do pro- 


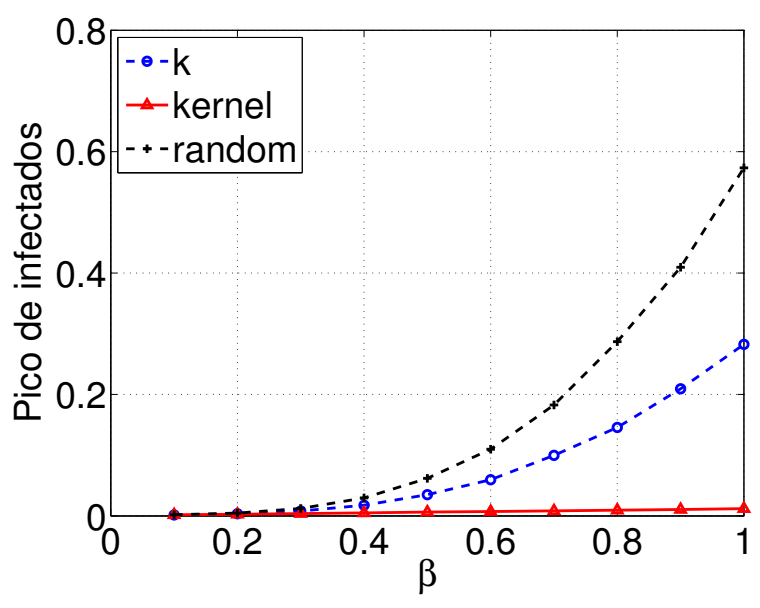

(a) Árvore artificial, $\mu=0.3$.

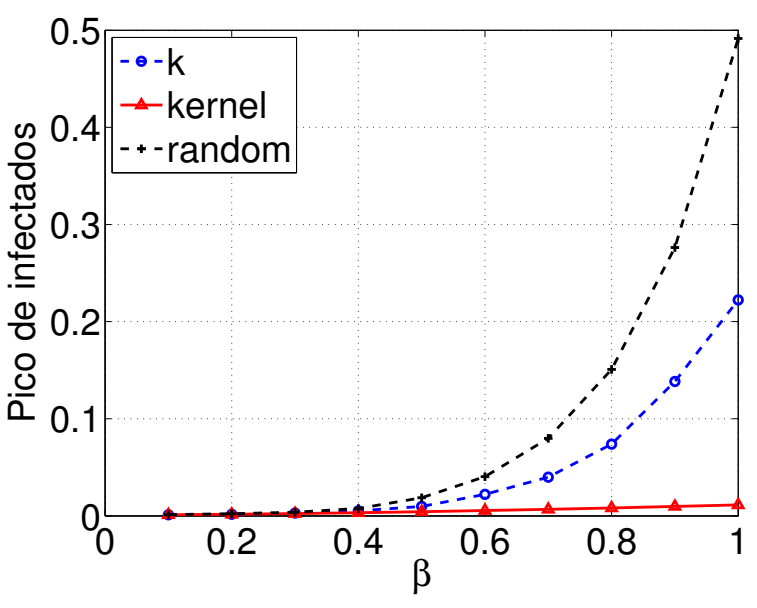

(b) Árvore artificial, $\mu=0.6$.

Figura 5.5: Pico de indivíduos infectados para a árvore artificial após os processos de imunização discutidos: grau, k-core, aleatória e a metodologia proposta (chamada aqui por kernel).

cesso de propagação de epidemias, entretanto outras propriedades centrais também devem ser consideradas.

Uma propriedade importante é o comprimento dos caminhos entre pares de indivíduos. Dentre as metodologias avaliadas, apenas a baseada em agrupamento leva em consideração tal propriedade estrutural. Logo, em redes com maiores distâncias entre pares deve-se obter melhores resultados para a metodologia proposta em relação àquelas baseadas em grau e $k$-core. Isto pode ser observado pela comparação dos resultados das figuras 5.4 e 5.5 com os dados da tabela 5.1. Entretanto, deve-se lembrar também que a assortatividade e as distâncias estão relacionadas, pois o aumento das distâncias na rede produzem redes mais assortativas (Xulvi-Brunet e Sokolov, 2004).

\subsection{Conclusões}

Neste capítulo foi apresentada uma metodologia para identificação dos nós mais influentes em dinâmicas de propagação, especialmente a dinâmica SIR. Tais resultados foram verificados por meio de técnicas de imunização, bem como uma verificação das distribuições dos picos de infecção.

Processos de propagação, de um modo geral, são dependentes das características central dos indivíduos, pois iniciar uma epidemia em um vértice central causa uma propagação muito 
maior que inicia-la em a partir de um nó da borda. Desta maneira, para se identificar aqueles indivíduos mais influentes deve-se considerar diversas propriedades estruturais, tanto locais quanto globais. Entretanto, as definições de centralidade são baseadas em diferentes conceitos, como conectividade, caminhadas aleatórias, distâncias entre pares entre outras. Desta maneira, não há uma única definição que leve em consideração todas estas características estruturais. Logo, foi proposta uma metodologia para identificação destes nós baseada em agrupamento de dados, considerando diversas medidas, sendo estas baseadas em várias propriedades distintas.

Como exposto anteriormente, os principais propagadores são aqueles nós em que a doença propaga-se mais rapidamente que os demais, mas também mais reduzem o efeito global da propagação quando são imunizados. De acordo com os resultados obtidos pelo agrupamento e imunização, figuras 5.1, 5.2, 5.5 e 5.4, sendo as dua primeiras relativas ao agrupamento e as duas últimas à imunização, conclui-se que o grupo identificado como mais influente é de fato fundamental para o processo de propagação da epidemia. Assim, é possível afirmar que as propriedades estruturais deste grupo de nós reflete, diretamente, no modo como tal dinâmica evolui na rede. Sendo que, apenas uma propriedade estrutural não é suficiente para caracterizar este grupo, mas sim um conjunto delas.

De fato, os nós identificados apresentam um conjunto de medidas centrais com altos valores em relação aos demais. Excluindo, assim, hubs mal localizados, ou seja, nas bordas, como é desejado. Os resultados obtidos aqui sugerem que a abordagem utilizada na identificação deste conjunto de nós é eficiente, sendo superior às metodologias tradicionais, baseadas no grau e $k$ core. Deve-se ressaltar que a metodologia de imunização apresentada é bastante robusta, sendo aplicável a um conjunto grande de tipos de redes, como observado ao longo desta análise. 


\section{Seleção e ordenação de propriedades}

\section{estruturais e dinâmicas de redes complexas}

Uma tarefa fundamental em análise, modelagem, validação e classificação de redes é a extração de um conjunto de medidas e uma escolha correta destas. Assim, deseja-se obter o número mínimo de descritores, porém que contenha a maior quantidade de informação possível, reduzindo também a correlação entre as medidas extraídas.

Neste capítulo será descrita a metodologia utilizada para análise de redes por meio de conceitos de redes complexas e mineração de dados, expostos nos capítulos anteriores. Primeiramente, utilizou-se métodos de ordenação de atributos a fim de identificar as medidas que permitem a melhor discriminação entre os diferentes tipos de topologias de redes. Em seguida, foi aplicada tal técnica no estudo de propagação de epidemias e análise de redes reais. A utilização de métodos de seleção de atributos permitirá a escolha de medidas para classificação de redes de forma quantitativa, eliminando a arbitrariedade na escolha dos atributos utilizados, como foi discutido e verificado em (Costa et al., 2007). 


\subsection{Introdução}

Para se descrever a estrutura de redes complexas há uma grande quantidade de medidas de caracterização (ver capítulo 2), sendo que cada medida captura uma determinada propriedade, como por exemplo conectividade, heterogeneidade, distâncias entre pares de nós, presença ou ausência de módulos, entre muitas outras. Entretanto, parte destas medidas apresentam correlação entre si, desde que todas as medidas dependem do número de nós e grau, por exemplo (Costa et al., 2007; M. E. J. Newman, 2010) ${ }^{1}$. Além disto, algumas medidas são pouco influenciadas pela organização da rede, apresentando resultados semelhantes para diferentes tipos de redes (Costa et al., 2007).

Tais limitações das medidas de caracterização podem conduzir análises enviesadas e tendenciosas. Por exemplo, ao avaliar a influência de uma propriedade estrutural em um dado processo dinâmico. Ao considerar um descritor que apresenta valores similares para diferentes topologias de redes, pode-se induzir a conclusão de que a propriedade quantificada por este descritor não exerce influência sobre o processo que esta sendo estudado. Isto pode ser verificado pela comparação de grafos aleatórios com redes de pequeno mundo. Ambas possuem distribuições de grau comparáveis (Costa et al., 2007), entretanto comportamento distinto em relação à dinâmica de sincronização (Arenas et al., 2008). Logo, isto sugere que tal propriedade não exerce influência sobre o grau de sincronização, porém isto não é verdade, como foi exemplificado por Nishikawa, Motter, Lai e Hoppensteadt em (Nishikawa et al., 2003).

Ademais, caso duas medidas, $\mu_{1}$ e $\mu_{2}$, são correlacionadas e apenas uma delas exerce influência sobre a dinâmica, supondo que seja a medida $\mu_{1}$. Neste caso, é possível concluir que a medida $\mu_{2}$ influencia o processo, o que é um resultado enviesado. Um exemplo para tal análise é a observação da influência da assortatividade na dinâmica de sincronização. Porém, observouse que esta é uma consequência do menor caminho médio da rede (Arenas et al., 2008), pois o aumento das distâncias na rede produzem redes mais assortativas (Xulvi-Brunet e Sokolov, 2004).

Além da relação entre a estrutura e dinâmica a seleção de um subconjunto de medidas também é importante para modelagem, análise e classificação de redes complexas. De fato,

\footnotetext{
${ }^{1}$ É importante observar que esta consideração é feita para redes reais, onde o limite termodinâmico não é considerado, ou seja, utiliza-se apenas redes de tamanho finito.
} 
deseja-se obter o menor número de descritores possível que contenha o máximo de informação. Desta maneira, obtêm-se apenas as características que são realmente relevantes para se descrever o sistema em estudo. Sendo assim, estas medidas produzem modelos mais simples, precisos e com interpretação mais fácil. Especialmente para o caso de classificação de redes para validação de um modelo (Costa et al., 2007), é adequado considerar o menor conjunto de atributos possível (Theodoridis e Koutroumbas, 2003). Desta maneira, os modelos de mineração de dados e aprendizado de máquina serão mais robustos (Theodoridis e Koutroumbas, 2003).

Quanto a relação entre estrutura e dinâmica, além de possuir um conjunto de descritores que seja capaz de discriminar entre diferentes classes de redes, é importante também, utilizar uma dinâmica que seja sensível a organização estrutural. Logo, é fundamental compreender como o processo dinâmico estudado evolui em diferentes classes de redes, já que isto permite determinar quais propriedades de redes estão mais relacionadas à dinâmica. Desta forma, é possível controlar o processo dinâmico por meio de características estruturais. Entretanto, vários processos dinâmicos dependem de um conjunto de parâmetros, como por exemplo o coeficiente de acoplamento para sincronização ou as taxas de propagação e recuperação em dinâmicas de propagação de epidemias (Barrat et al., 2008). Dependendo da configuração destes parâmetros, o processo será mais ou menos influenciado pela dinâmica. De fato, com uma alta taxa de infecção o processo de propagação pode atingir toda a rede de maneira muito rápida, fazendo com que a importância do nó seja reduzida (M. E. J. Newman, 2010; Kitsak et al., 2011). Assim, a importância da estrutura da rede é também reduzida. Logo, uma escolha adequada dos parâmetros que regem a dinâmica também é fundamental, fazendo com que a dinâmica tenha comportamentos distintos em diferentes classes de redes.

\subsection{Base de dados}

O processo de construção das bases de dados considerou 50 amostras para cada modelo. Durante a análise dos modelos utilizou-se redes com $N=1000$ vértices e $\langle k\rangle=4$, com uma tolerância de 5\% para este parâmetro.

As classes foram definidas de três maneiras, constituindo três bases distintas: 
1. Redes de pequeno mundo: (i) Small-World com probabilidade de conexão $p=0,01$ (WS001); (ii) Small-World com probabilidade de reconexão $p=0,1$ (WS01); (iii) SmallWorld com probabilidade de reconexão $p=0,2$ (WS02); (iv) Small-World com probabilidade de reconexão $p=0,3$ (WS03);

2. Redes livres de escala: (i) Livre de escala de Barabási - Albert (BA); (ii) Barabási nãolinear $\alpha=2$ (NLB2); (iii) Barabási não-linear $\alpha=1.5$ (NLB1.5); (iv) Barabási nãolinear $\alpha=3$ (NLB3);

3. 10 classes: (i) grafos aleatórios (ER); (ii) Small-World com probabilidade de conexão $p=0,01$ (WS001); (iii) Small-World com probabilidade de reconexão $p=0,1$ (WS01); (iv) Small-World com probabilidade de reconexão $p=0,2$ (WS02); (v) Small-World com probabilidade de reconexão $p=0,3$ (WS03); (vi) Livre de escala de Barabási Albert (BA); (vii) Barabási não-linear $\alpha=2$ (NLB2); (viii) Barabási não-linear $\alpha=1.5$ (NLB1.5); (ix) Livre de escala não-linear $\alpha=3$ (NLB3); (x) Modelo geográfico (GN).

Sendo que as bases de redes de pequeno mundo e redes livres de escala serão utilizadas para validação da metodologia proposta.

É importante observar que as redes geradas pelo modelo Barabási não-linear não necessariamente são livres de escala, entretanto isto ocorre apenas se o coeficiente de conexão preferencial, $\alpha$, for menor que a unidade, porém, nestas bases foram adotados apenas valores de $\alpha \geq 1$ (Ver capítulo 2).

\subsection{Metodologia e resultados}

Nas seções seguintes será exposta a metodologia utilizada bem como os resultados obtidos considerando-se propriedades topológicas e dinâmicas. As subseções a seguir respeitam esta classificação, ou seja, a primeira considera apenas propriedades estruturais das redes, enquanto a segunda apenas propriedades relativas à dinâmica de propagação de epidemias segundo o modelo SIR. 


\subsubsection{Estrutura}

As bases usadas para classificação segundo a estrutura de redes são matrizes compostas pelas seguintes características: primeiro e segundo momento, variância e entropia do: (i) grau ${ }^{2}$, (ii) clustering coefficient, (iii) comprimento dos menores caminhos, (iv) betweenness centrality, (v) edge betweenness centrality, (vi) closeness centrality, (vii) comunicabilidade, (viii) access information e (ix) hiden information. Além das medidas globais de: (i) assortatividade, (ii) dominância do ponto central, (iii) eficiência e (iv) average search information (Ver capítulo refcap:caracterizacao). Essas medidas definem um conjunto com 39 atributos para cada rede.

É importante observar que em redes livres de escala o segundo momento estatístico da distribuição de grau pode divergir quando $N \rightarrow \infty$, porém estamos interessados em redes de tamanho finito. Ademais, esta medida apresenta forte correlação com a variância, também chamada de segundo momento central. De fato, a variância é uma combinação do segundo momento com o quadrado do primeiro momento estatístico. Entretanto, como esta combinação não é linear é possível que haja diferenças durante a análise de tais atributos.

Deve-se observar que alguns parâmetros necessários para construção dos modelos ficaram restritos, pois cada base deve ter o mesmo número de vértices e um grau médio semelhante à rede que deseja-se analisar. Exemplos disto são a probabilidade de conexão da rede aleatória e o valor de $\beta$ para as redes geográficas, já que esses definem o grau médio da rede. Desta forma, varia-se apenas a organização das conexões, possibilitando diferenciar as redes de acordo com suas características topológicas, sem a influência exercida pelo tamanho ou densidade das redes estudadas.

Um procedimento necessário antes da classificação é a normalização dos dados, pois algumas medidas apresentam pequenas variações de escala, enquanto outras tem grandes variações. Adotou-se a normalização segundo média zero e variância unitária, dada pela expressão 4.1, pois esta trata melhor os outliers (Theodoridis e Koutroumbas, 2003).

A partir das medidas calculadas e normalizadas, foi feita a ordenação dos atributos, considerando-se a incerteza simétrica. Esta tem a finalidade de medir qual o poder de discriminação de determinado atributo em relação às classes. Porém, é importante observar que

\footnotetext{
${ }^{2} \mathrm{O}$ primeiro momento do grau é excluído, pois este é fixado de acordo com a rede que deseja-se analisar
} 
Tabela 6.1: Ordenação das 15 melhores medidas considerando a incerteza simétrica para duas classes de problemas: (i) modelo de Watts - Strogatz com probabilidades de reconexão de $p=0,01, p=0,1, p=0,2$ e $p=0,3$; (ii) modelos livres de escala: Barabási - Albert e

Barabási não linear com $\alpha=3, \alpha=2, \alpha=1.5$.

\begin{tabular}{|c|c|c|c|c|c|}
\hline \multicolumn{3}{|c|}{ Modelos de pequeno mundo de Watts - Strogatz } & \multicolumn{3}{|r|}{ Modelos livres de escala } \\
\hline Rank & $U(C, A)$ & Medida & Rank & $U(C, A)$ & Medida \\
\hline 1 & 1 & Comprimento dos menores caminhos: $1^{\circ}$ momento & 1 & 0.959 & Access Information: entropia \\
\hline 1 & 1 & Comprimento dos menores caminhos: $2^{\circ}$ momento & 2 & 0.867 & Clustering Coefficient: entropia \\
\hline 1 & 1 & Comprimento dos menores caminhos: entropia & 3 & 0.826 & Closeness Centrality: $1^{\circ}$ momento \\
\hline 1 & 1 & Comprimento dos menores caminhos: variância & 4 & 0.826 & Closeness Centrality: $2^{\circ}$ momento \\
\hline 1 & 1 & Clustering Coefficient: $1^{\circ}$ momento & 5 & 0.817 & Comunicabilidade: $1^{\circ}$ momento \\
\hline 1 & 1 & Clustering Coefficient: $2^{\circ}$ momento & 6 & 0.817 & Comunicabilidade: $2^{\circ}$ momento \\
\hline 1 & 1 & Grau: $2^{\circ}$ momento & 7 & 0.817 & Comunicabilidade: variância \\
\hline 1 & 1 & Grau: entropia & 8 & 0.804 & Assortatividade \\
\hline 1 & 1 & Grau: variância & 9 & 0.801 & Grau: variância \\
\hline 1 & 1 & Eficiência & 10 & 0.792 & Comprimento dos menores caminhos: $1^{\circ}$ momento \\
\hline 1 & 1 & Average Search Information & 11 & 0.792 & Comprimento dos menores caminhos: $2^{\circ}$ momento \\
\hline 1 & 1 & Betweenness centrality: $2^{\circ}$ momento & 12 & 0.792 & Comprimento dos menores caminhos: entropia \\
\hline 1 & 1 & Edge Betweenness centrality: $2^{\circ}$ momento & 13 & 0.792 & Comprimento dos menores caminhos: variância \\
\hline 1 & 1 & Edge Betweenness centrality: variância & 14 & 0.792 & Eficiência \\
\hline 2 & 0.982 & Comunicabilidade: variância & 15 & 0.792 & Grau: $2^{\circ}$ momento \\
\hline
\end{tabular}

essa técnica de ordenação considera apenas a discriminação feita por um determinado atributo em relação às classes, desconsiderando a correlação entre atributos. (Ver capítulo 4)

Primeiramente, foi feita a validação dos métodos propostos, analisando apenas redes de pequeno mundo de Watts - Strogatz, bem como apenas redes livres de escala em uma segunda análise. A ordenação obtida para tais classe de redes é exposta na tabela 6.1. Em redes de pequeno mundo, fica claro que propriedades relacionadas à menores caminhos e ciclos são as mais importantes de acordo com a ordenação. Sendo assim, confirma-se um resultado esperado, validando-se assim a proposta deste trabalho.

Ademais, com a finalidade de visualizar a importância de tal procedimento, utilizou-se a técnica PCA (ver capítulo 4) para projetar as redes em duas dimensões. Como exposto anteriormente, esta técnica desconsidera a informação das classes e projeta os dados de acordo com a variância dos dados. Esta abordagem fornece uma interpretação visual dos dados em questão.

A figura 6.1 (a) apresenta uma projeção para os quatro melhores atributos segundo a ordenação para as redes de pequeno mundo. Desde que os 14 primeiros atributos dividem a primeira posição da ordenação, pois todos apresentam $U(C, A)=1$, a escolha entre tais atributos é arbitrária. Optou-se por utilizar os dois primeiros momentos da distribuição de menores caminhos e clustering coefficient. Todavia, outras escolhas também foram avaliadas e apresentam resultados semelhantes. Já a figura 6.1 (b) apresenta uma projeção com as quatro piores posições desta mesma ordenação, ou seja, as medidas: (i) comunicabilidade: entropia $(U(C, A)=0.427)$, 


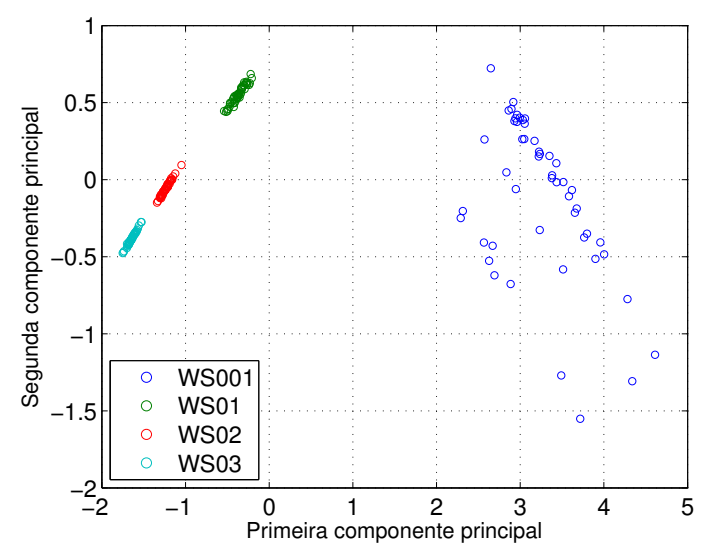

(a) Projeções segundo a técnica PCA considerando os (b) Projeções segundo a técnica PCA considerando os quatro melhores atributos segundo a ordenação para os quatro piores atributos segundo a ordenação para os modelos de Watts - Strogatz. Ver Tabela 6.1

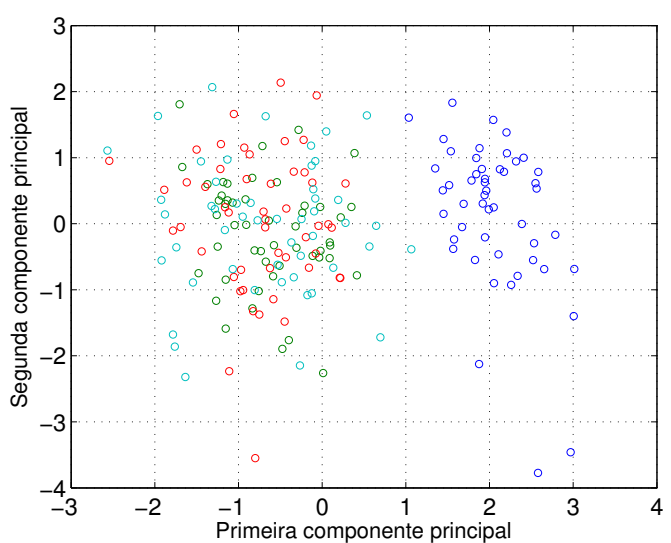

modelos de Watts - Strogatz.

Figura 6.1: Projeções segundo a técnica PCA considerando apenas propriedades estruturais e modelos de Watts - Strogatz.

(ii) Betweenness centrality: entropia $(U(C, A)=0.389)$, (iii) Closeness centrality: variância $(U(C, A)=0.269)$ e (iv) assortatividade $U(C, A)=0)$. Contudo, verifica-se que algumas das medidas que apresentam pior desempenho segundo a ordenação estão relacionadas aos menores caminhos, que é uma propriedades fundamental para esta classe de modelos, reforçando a necessidade da metodologia proposta.

Pela análise comparativa das figuras 6.1 (a) e (b) observa-se que é necessária uma escolha adequada das medidas utilizadas durante o processo de caracterização. Além disso, verificase que propriedades estruturais das redes de pequeno mundo de Watts - Strogatz são bastante evidentes, pois, tal modelo apresenta uma alta sensibilidade à probabilidade de reconexão. Entretanto, os modelos gerados com $p=0,01$ apresentam um comportamento distinto dos demais, já que em ambas projeções este grupo está bem separado dos demais grupos. Porém, este resultado não é uma surpresa, pois redes com baixa probabilidade de reconexão estão muito próximas de estruturas regulares.

De mameira semelhante à realizada anteriormente em redes de pequeno mundo, avaliou-se também as redes livres de escala. Neste caso, altera-se o coeficiente de conexão preferencial, $\alpha$, da equação 2.33 (ver capítulo 2). Utilizando apenas $\alpha \geq 1$ obtêm-se sempre redes livres de escala. O resultado da ordenação é mostrado na tabela 6.1. A interpretação de algumas das medidas obtidas é bastante direta, como por exemplo, assortatividade, clustering coefficient e comprimento dos menores caminhos. Como exposto anteriormente (ver capítulo 2), ao 
aumentar o valor de $\alpha$ o modelo apresenta como propriedade interessante o fato de ser disassortativa. Observa-se, também, que o clustering coefficient cresce para $\alpha>1$, chegando a valores próximos à unidade. Este modelo apresenta este tipo de comportamento, porque um pequeno conjunto de nós apresentará altos valores de conectividade e estará conectado a grande parte dos nós da rede. Assim, os menores caminhos serão drasticamente reduzidos, além do aumento no número de ciclos.

Para esta classe de problemas, a melhor medida segundo a ordenação foi a entropia da distribuição de Access Information, que está intimamente ligada à distribuição de menores caminhos pela rede. Outras três propriedades verificadas observadas na tabela 6.1 são relativas as distribuições de grau e clustering coefficient, além da assortatividade. É importante observar que nestas distribuições o segundo momento do grau diverge para redes de tamanho infinito. Contudo, ao considerar redes de tamanhos finito esta propriedade apresenta boa discriminação. Ademais, outra medida presente nesta tabela é a comunicabilidade, que está relacionada à caminhadas aleatórias, logo também estará relacionada à distribuição de menores caminhos, porém indiretamente.

As projeções para a base de redes livres de escala estão na figura 6.2. Em (a) têm-se a projeção das quatro melhores medidas, enquanto em (b), das quatro piores. Nota-se que em (b) a discriminação é muito baixa, sendo que apenas as redes Barabási - Albert, isto é, com coeficiente de conexão preferencial linear, $\alpha=1$, apresentam alguma distinção das demais. Por outro lado, em (a) os grupos são bem definidos, mas ao aumentar os valores de $\alpha$ a separação diminui.

Os resultados obtidos para as bases de pequeno mundo e livres de escala mostram a validade da metodologia proposta, bem como exemplificam a necessidade de tal procedimento. O que é facilmente visualizado nas figuras 6.1 e 6.2. Além disto, medidas que podem ser consideradas adequadas podem apresentar resultados insatisfatórios. Por exemplo, como foi verificado em redes de pequeno mundo, onde as medidas de entropia para Betweenness centrality e variância de Closeness centrality, que apresentam baixa discriminação se comparadas às outra medidas mesmo sendo baseadas em menores caminhos, reforçando a necessidade da metodologia proposta. 


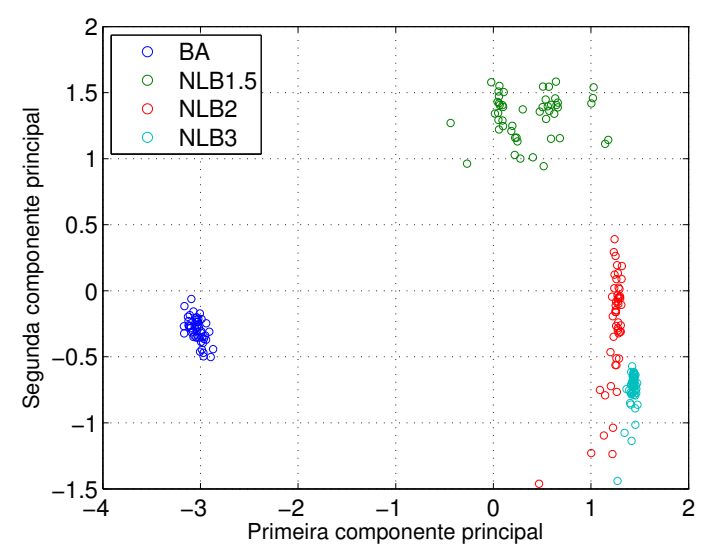

(a) Projeções segundo a técnica PCA considerando os (b) Projeções segundo a técnica PCA considerando os quatro melhores atributos segundo a ordenação para os quatro piores atributos segundo a ordenação para os modelos livres de escala. Ver Tabela 6.1

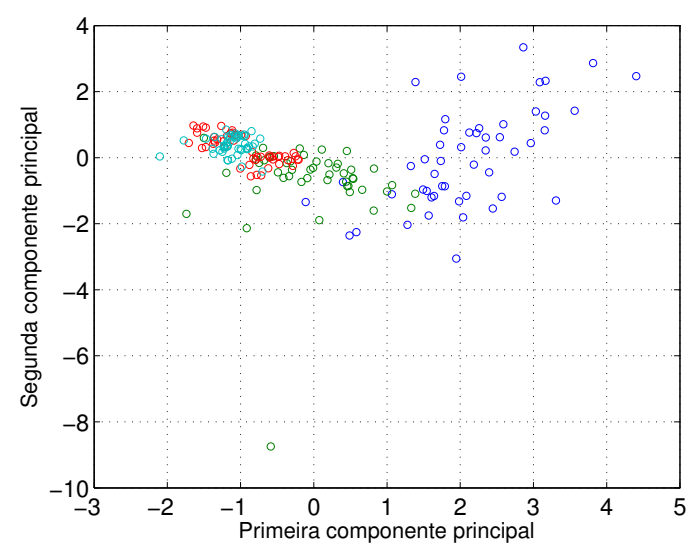

modelos livres de escala.

Figura 6.2: Projeções segundo a técnica PCA considerando apenas propriedades estruturais e modelos livres de escala.

Desta maneira, será realizado o mesmo procedimento, porém analisando uma base com todos os modelos de redes. O resultado para a ordenação deste conjunto de dados é mostrado na tabela 6.2. Por meio da análise desta tabela é possível afirmar que a distribuição de menores caminhos é uma propriedade fundamental para compreensão e caracterização de sistemas representados por redes complexas. Contudo, sua importância não é restrita apenas ao valor médio, mas sim a maneira como esta propriedade se distribui dentro da estrutura da rede. Isto pode ser afirmado, pois as cinco primeiras posições da ordenação são baseadas nesta propriedade, além de mais quatro dentre as 15 primeiras.

Em redes livres de escala a presença de hubs faz com que as distâncias entre os nós da rede diminua. Esta propriedade é ainda mais evidente em redes do modelo Barabási não-linear, já que tais nós fazem com que o caminho médio reduza drasticamente. Assim, as redes desse modelo favorecem o aparecimento de um pequeno conjunto de nós com grande importância e um grande número de nós localizados na periferia da rede. Por outro lado, em redes de pequeno mundo de Watts - Strogatz o menor caminho médio é uma de suas características fundamentais, juntamente com o clustering coefficient. Entretanto, não há hubs e sua distribuição de menores caminhos é fortemente influenciada pelo método de geração destas redes, ou seja, a rede regular ao qual toda rede deste modelo se origina. Além delas, utilizou-se também o modelo de Waxman, para redes geográficas, e o modelo aleatório de Erdös - Renyi. Na primeira classe de redes a distribuição de menores caminhos é extremamente dependente da distância, sendo com- 
Tabela 6.2: Ordenação das 15 melhores medidas considerando a incerteza simétrica e a base com todos os modelos: aleatório de Erdös - Renyi; pequeno mundo de Watts - Strogatz com probabilidades de reconexão de $p=0,01, p=0,1, p=0,2$ e $p=0,3$; Barabási - Albert; Barabási não linear com $\alpha=3, \alpha=2, \alpha=1.5$ e redes geográficas segundo o modelo de

\begin{tabular}{|c|c|c|}
\hline \multicolumn{3}{|r|}{ Waxman. } \\
\hline Rank & $U(C, A)$ & Medida \\
\hline 1 & 0.955 & Comprimento dos menores caminhos: $2^{\circ}$ momento \\
\hline 2 & 0.955 & Comprimento dos menores caminhos: $1^{\circ}$ momento \\
\hline 3 & 0.945 & Eficiência \\
\hline 4 & 0.937 & Comprimento dos menores caminhos: variância \\
\hline 5 & 0.916 & Comprimento dos menores caminhos: entropia \\
\hline 6 & 0.91 & Grau: variância \\
\hline 7 & 0.903 & Grau: $2^{\circ}$ momento \\
\hline 8 & 0.899 & Comunicabilidade: variância \\
\hline 9 & 0.899 & Comunicabilidade: $2^{\circ}$ momento \\
\hline 10 & 0.89 & Average Search Information \\
\hline 11 & 0.871 & Edge Betweenness centrality: variância \\
\hline 12 & 0.837 & Edge Betweenness centrality: $2^{\circ}$ momento \\
\hline 13 & 0.836 & Clustering Coefficient: $2^{\circ}$ momento \\
\hline 14 & 0.829 & Betweenness centrality: $2^{\circ}$ momento \\
\hline 15 & 0.825 & Clustering Coefficient: $1^{\circ}$ momento \\
\hline
\end{tabular}

pletamente diferente dos demais modelos, tendo inclusive um valor médio mais elevado que as demais. Já a segunda classe, redes aleatórias, apresenta um comportamento semelhante as redes de pequeno mundo com alta probabilidade de reconexão, porém, ainda assim diferentes, já que estas não possuem mesmo processo de construção e não sofrem influência da rede regular.

Desta maneira, tal distribuição é influenciada de diversas maneiras distintas, fazendo com que tal propriedade seja fundamental e possibilite, também uma boa discriminação por diversos tipos de medidas. Como por exemplo, medidas de centralidade que são definidas através desta propriedade, além dos descritores estatísticos relacionados a sua distribuição de probabilidades.

As projeções dos quatro melhores e piores descritores é feita na figura 6.3 (a) e (b) respectivamente. A partir desta figura é possível constatar algumas propriedades relativas à estes modelos. Como por verifica-se pela proximidade das nuvens de pontos que representam as redes de pequeno mundo e como elas se aproximam de redes aleatórias de Erdös - Renyi ao se aumentar a probabilidade de reconexão. Outra observação fundamental é que as redes de Watts - Strogatz com $p=0,01$ ficam visualmente separadas das demais, isto ocorre devido a sua proximidade com a rede regular. Ademais, verifica-se também, que as redes geográficas são 


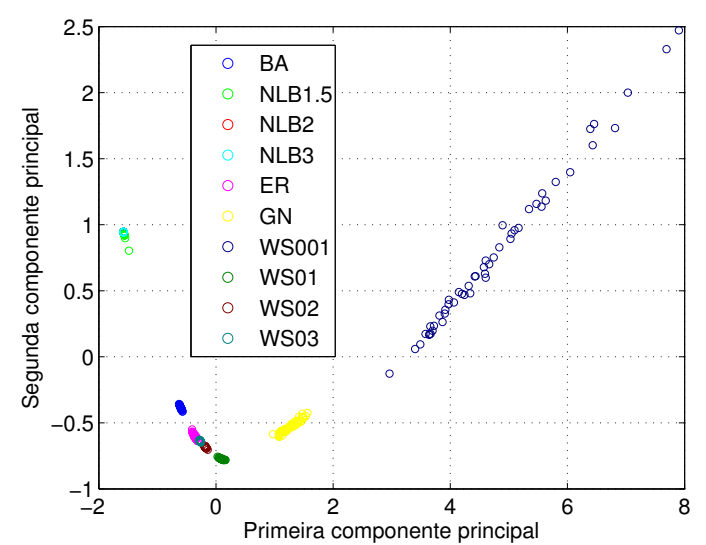

(a) Projeções segundo a técnica PCA considerando os (b) Projeções segundo a técnica PCA considerando os quatro melhores atributos segundo a ordenação para to- quatro piores atributos segundo a ordenação para todos dos os modelos. Ver Tabela 6.2

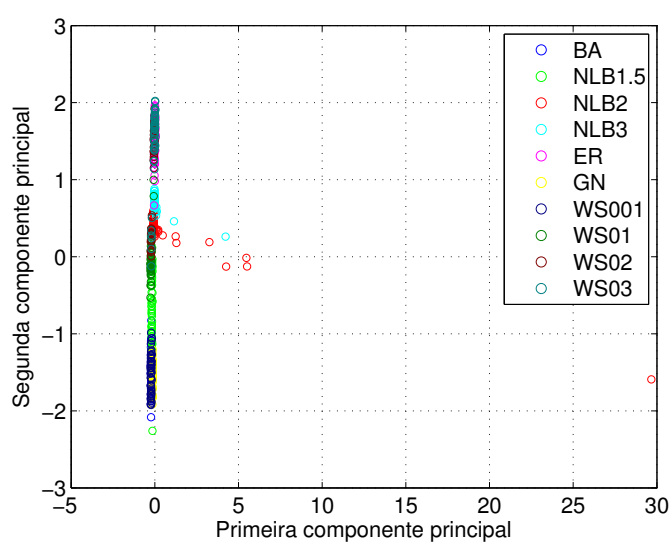

os modelos.

Figura 6.3: Projeções segundo a técnica PCA considerando apenas propriedades estruturais e todos os modelos.

relativamente próximas de redes regulares, como era esperado, devido a distribuição espacial que da origem a este modelo. Quanto as redes livres de escala, nota-se que estas ocupam um lugar distinto das demais redes, afastando-se cada vez mais das outras ao aumentar o valor do coeficiente de conexão preferencial, $\alpha$. Tal fato é esperado, dado que as diferenças entre redes deste modelo e as demais ficam cada vez mais evidentes.

Os procedimentos realizados até aqui consideram apenas a relação entre o atributo e o vetor de classes, desconsiderando, portanto a correlação entre atributos. Para superar tal limitação e obter um subconjunto de atributos, deve-se aplicar um procedimento de seleção de atributos (ver capítulo 4). A metodologia utilizada foi a chamada CFS (abreviação do inglês Correlation Feature Selection) nesta utiliza-se uma função mérito, equação 4.22, que favorece a separação, penalizando a correlação entre atributos. Além disso, outro ponto importante desta abordagem é que a correlação é mensurada pela medida de incerteza simétrica, $U(C, A)$, equação 4.13, que é a mesma utilizada durante a ordenação dos atributos. Entretanto, para se avaliar o melhor subconjunto de atributos é necessário realizar uma busca exaustiva, que consiste em um problema exponencial, $O\left(2^{N}\right)$. Assim, para contornar esta limitação, foi feita uma pre-seleção e utilizouse apenas os 25 melhores atributos durante a seleção, já que a utilização dos 39 atributos faz com que o custo computacional seja proibitivo.

Além da seleção na base de dados contendo todos os modelos de redes, aplicou-se a mesma abordagem para redes livres de escala. Tais resultados estão expostos na tabela 6.3. Porém 
Tabela 6.3: Melhor subconjunto encontrado por busca exaustiva considerando a metodologia CFS para duas classes de problemas: (i) todas as redes, isto é, aleatório de Erdös - Renyi; pequeno mundo de Watts - Strogatz com probabilidades de reconexão de $p=0,01, p=0,1$, $p=0,2$ e $p=0,3$; Barabási - Albert; Barabási não linear com $\alpha=3, \alpha=2, \alpha=1.5$ e redes geográficas segundo o modelo de Waxman; (ii) modelos livres de escala: Barabási - Albert e Barabási não linear com $\alpha=3, \alpha=2, \alpha=1.5$.

\begin{tabular}{|c|}
\hline Todos modelos: 11 medidas selecionadas \\
\hline Comprimento dos menores caminhos: $2^{\circ}$ momento; Comprimento dos menores caminhos: $1^{\circ}$ momento; Eficiência; \\
Comprimento dos menores caminhos: variância; Grau: variância; Comunicabilidade: variância; \\
Average Search Information; Edge Betweenness Centrality: variância; Clustering Coefficient: entropia; \\
Clustering Coefficient: variância; Hiden Information: $1^{\circ}$ momento \\
\hline Modelos livres de escala: 3 medidas selecionadas \\
\hline Access Information: entropia; Clustering Coefficient: entropia; Access Information: $2^{\circ}$ momento \\
\hline
\end{tabular}

deve-se observar que a seleção para redes de pequeno mundo não faz sentido, pois a incerteza simétrica é igual a unidade para as melhores medidas avaliadas, como pode ser observado na tabela 6.1, o que fará com que a função mérito seja igual a um para qualquer subconjunto. Logo, o menor subconjunto para esta classe de redes será qualquer um dos atributos da tabela 6.1 que tenha $U(C, A)=1$.

A tabela 6.3 apresenta descritores complementares, ou seja, diversas propriedades estruturais são exploradas para se construir estes subconjuntos, agregando mais informação. Por exemplo, para o subconjunto selecionado ao considerar todos os modelos de redes, verifica-se propriedades relativas a distâncias na rede, a distribuição de grau, caminhadas aleatórias e também ciclos. Já para redes livres de escala, apenas propriedades relacionadas a ciclos e menores caminhos. Contudo, o número de atributos nesta última base é menor que os obtidos para a primeira, o que é um resultado esperado, pois o resultado acompanha a complexidade da base.

Ademais, foi projetada a base de dados considerando apenas o subconjuntos de atributos selecionados. Este resultado é mostrado na figura 6.4. Há um ganho visual ao se comparar esta projeção com as realizadas na figura 6.3, já que o modelo Barabási não-linear apresenta melhor separação. Além disto, as observações realizadas anteriormente continuam validas neste caso, ou seja, a maneira como as nuvens de pontos se dispõem ao longo do plano.

\subsubsection{Caracterização dinâmica: Propagação de epidemias}

É fundamental compreender como processos dinâmicos evoluem para diferentes modelos de redes. Isto viabiliza um estudo relativo as propriedades estruturais da rede que estão mais in- 


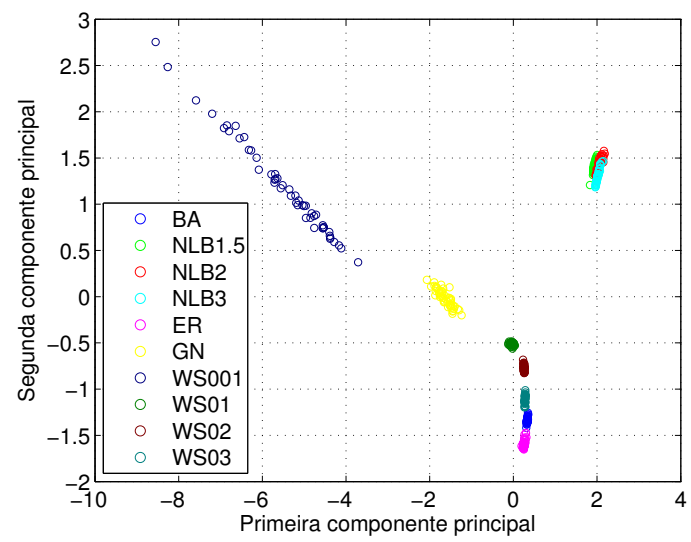

Figura 6.4: Projeções segundo a técnica PCA considerando os os atributos selecionados para todos os modelos, isto é, tabela 6.3.

fluenciando tal processo. Desta maneira é possível controlar a dinâmica por meio da estrutura. Entretanto, vários processos são dependentes de um conjunto de parâmetros, como por exemplo as taxas de propagação e recuperação em dinâmicas de propagação de epidemias (Barrat et al., 2008). Para cada configuração destes parâmetros, o processo sofrerá uma maior ou menor influencia dinâmica. De fato, com altas taxas de infecção a epidemia pode atingir toda a rede muito rapidamente, fazendo com que a importância dos indivíduos seja reduzida (M. E. J. Newman, 2010; Kitsak et al., 2011), diminuindo, assim, a importância da estrutura. Logo, uma escolha adequada dos parâmetros que regem a dinâmica também é fundamental, fazendo com que a dinâmica tenha comportamentos distintos em diferentes classes de redes.

Nesta seção, será avaliada a dinâmica de propagação de epidemias segundo o modelo SIR, que é dependente das taxas de infecção e recuperação (ver capítulo 3). Com sua análise objetivamos verificar qual o par de valores, $(\beta, \mu)$, melhor evidencia os modelos estudados, ou seja, qual o par de taxas de infecção e recuperação melhor caracterizam os modelos. A caracterização da epidemia é dada pelo pico da infecção, mais formalmente, sendo $i_{v}(t)$ a fração de indivíduos infectados para cada instante de tempo, iniciando-se a propagação a partir do vértice $v$, a medida utilizada para a caracterização da epidemia é,

$$
S_{v}=\max \left(i_{v}(t)\right)
$$

que corresponde ao pico da curva de infecção ao longo do tempo. Como esta dinâmica é um processo estocástico, para cada nó realiza-se o processo de propagação 50 vezes e considera- 


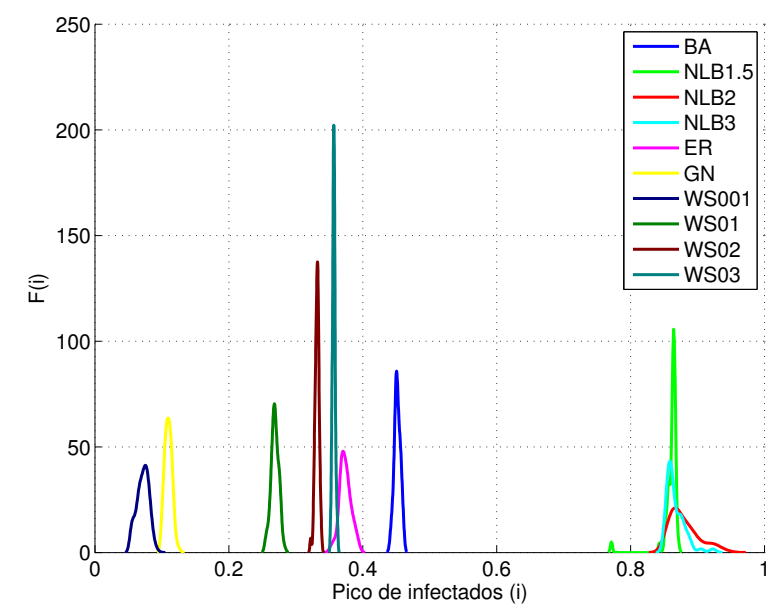

(a) Distribuição do pico de infectados em todos os mo- (b) Distribuição do pico de infectados em todos os delos para o melhor par de parâmetros $(\beta, \mu)$, isto é, modelos para o pior par de parâmetros $(\beta, \mu)$, isto é, $(1.0,0.9)$.

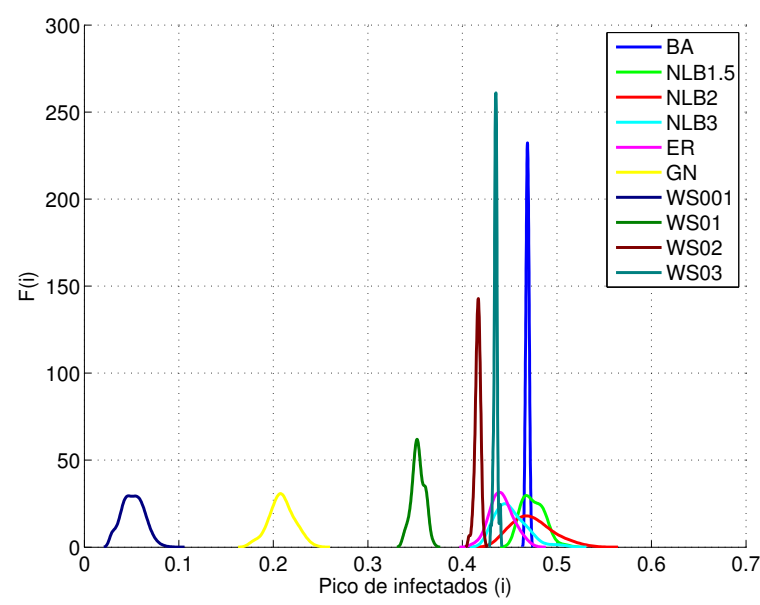

$(0.3,0.1)$

Figura 6.5: Distribuição do pico de infectados em todos os modelos para o melhor par de parâmetros, em (a) e pior, em (b).

se a média. Além disso, esta medida é dependente do vértice que inicia a propagação. Para eliminar esta dependência basta fazermos a média sobre todos os vértices da rede:

$$
S=\frac{1}{N} \sum_{v} S_{v}
$$

Realizou-se a propagação para redes com 1000 nós, grau médio igual a quatro, partindo-se de cada nó. Esta simulação foi feita para todos os pares $(\beta, \mu)$ variando $\beta$ e $\mu$ de 0.1 a 1 em passos de 0.1 e extraiu-se o pico da infecção $S$. Entretanto, deve-se utilizar apenas valores acima do limiar epidêmico (ver capítulo 3), equação 3.16. Assim, para o conjunto de dados utilizado, têm-se $\frac{\beta}{\mu} \geq 0.33$.

A partir deste conjunto de dados, aplicou-se a mesma metodologia utilizada anteriormente a fim de verificar quais parâmetros melhor evidenciam os modelos. Neste caso, o interesse está apenas no melhor e pior par de parâmetros $(\beta, \mu)$. A figura 6.5 mostra a distribuição de probabilidades para as melhores e piores em (a) e (b) respectivamente. Tais resultados foram $(1.0,0.9) \operatorname{com} U(C, A)=0.953$ com a melhor discriminação e $(0.3,0.1) \operatorname{com} U(C, A)=0.731$ para a pior. Estas distribuições foram estimadas por funções kernel Gaussianas, suavizando a curva (Rosenblatt, 1956; Parzen, 1962).

Desta maneira, fica claro que a escolha correta dos parâmetros pode enfatizar ou mascarar as propriedades estruturais da rede. A análise visual concorda com os valores de limiar epidêmico, 
onde redes livres de escala apresentam valores baixos, sendo até mesmo nulos para redes de tamanho infinito. Tais redes estão localizadas no extremo direto dos gráficos, especialmente em 6.5 (a), para o melhor par de parâmetros. Nota-se também que alguns modelos apresentam comportamento muito distinto, mesmo para o caso dos pior par de parâmetros. Como é o caso das redes de pequeno mundo $\operatorname{com} p=0,01$. Tal efeito é uma consequência das longas distâncias que separam os nós, além disto, a homogeneidade dos nós dificulta a propagação, isto é, não há hubs.

Considerando o melhor conjunto de parâmetros, $(1.0,0.9)$, verifica-se que a diferença estrutural entre os modelos é enfatizada, pois a doença espalha-se e é contida com taxas muito altas. Assim, em algumas redes o processo não consegue atingir grandes picos, apesar de atingir uma fração significativa de indivíduos. Um exemplo disto são as redes de pequeno mundo com $p=0,01$ e redes geográficas. Isto é explicado pela ausência de $h u b s$, o que faz com que os caminhos sejam maiores ao longo da rede, dificultando assim, que haja um pico de propagação elevado.

Por outro lado, nos piores parâmetros, $(0.3,0.1)$, a propagação e recuperação ocorrem a taxas menores ao se comparar com os melhores parâmetros. Apesar disto, neste caso as redes mais próximas da regularidade ainda apresentam comportamento semelhante, sendo distintas das demais redes. Entretanto, aqui não há uma grande separação entre os demais modelos, sendo que grande parte deles apresenta picos de infecção aproximadamente iguais, como pode ser observado visualmente na figura 6.5 (b). Novamente, os modelos livres de escala localizamse mais a direita, porém, com comportamento muito semelhantes aos demais modelos, pois suas diferenças estruturais estão sendo mascaradas pela escolha inadequada dos parâmetros.

\subsection{Conclusões}

Tarefas como modelagem, análise, validação e classificação são fundamentais para o estudo de sistemas complexos. Neste capítulo foi apresentada uma metodologia que tem como principal objetivo obter o menor número de descritores, porém, que contenha a maior quantidade de informação possível, reduzindo, também, a correlação entre as medidas extraídas. Tal objetivo foi alcançado por meio de uma abordagem de mineração de dados e teoria de informação, utilizando método de ordenação e seleção de atributos. Além disso, utilizou-se descritores es- 
tatísticos como momentos, variância e entropia para se extrair uma quantidade maior de informações sobre o conjunto de dados. De fato, qualquer medida de centralidade pode ser avaliada de acordo com sua a sua distribuição de probabilidades.

Neste trabalho verificou-se a necessidade de se obter um subconjunto de medidas estruturais que descreva de maneira não enviesada, isto é, livre de subjetividades. Observa-se que determinadas escolhas de medidas não são naturais e podem, até mesmo, ser contra intuitivas. Isto pode ser observado em redes de pequeno mundo, onde as medidas de entropia para Betweenness centrality e variância de Closeness centrality, que apresentam baixa discriminação se comparadas à outra medidas, mesmo sendo baseadas em menores caminhos, uma propriedade fundamental e muito sensível desta classe de redes. Entretanto, foi apresentada uma metodologia para superar tais dificuldades baseada em ordenação e seleção de atributos. Sendo que ambas irão fornecer informações distintas sobre os atributos. A primeira é uma análise que desconsidera correlação entre atributos, enquanto a segunda faz tal consideração. Aqui utilizou-se diversos modelos teóricos na construção das bases de dados, porém é possível utilizar conjuntos de dados reais ou mesmo outros modelos. Além disso, observou-se a necessidade de tal procedimento também na análise de processos dinâmicos, onde uma escolha inadequada de parâmetros pode guiar uma análise e modelagem enviesada. Além disso, diversas conclusões relativas as propriedades estruturais foram realizadas.

Ademais, verifica-se que uma das propriedades fundamentais no estudo de redes complexas é o comprimento dos menores caminhos, como verificado pelos processos de ordenação realizados ao longo deste trabalho. Entretanto tal propriedade não tem informações relativas a outras características, como conectividade e ciclos. O que é verificado pelos subconjuntos selecionados, já que estes possuem medidas relacionadas a estas propriedades, além das medidas relacionadas às distâncias, sugerindo que elas são complementares.

A metodologia apresentada neste trabalho pode ser utilizada também em redes reais, na análise de redes corticais obtidas de pacientes com desordens neurológicas, permitindo assim determinar as propriedades topológicas que mais diferenciam tais redes daquelas obtidas a partir de pessoas sadias. Este estudo possibilitará verificar como a organização cerebral é modificada em pessoas com determinadas doenças neurológicas, como será apresentado no capítulo 7, onde 
será feita uma análise comparativa entre redes de pacientes saudáveis e portadores de esquizofrenia. 



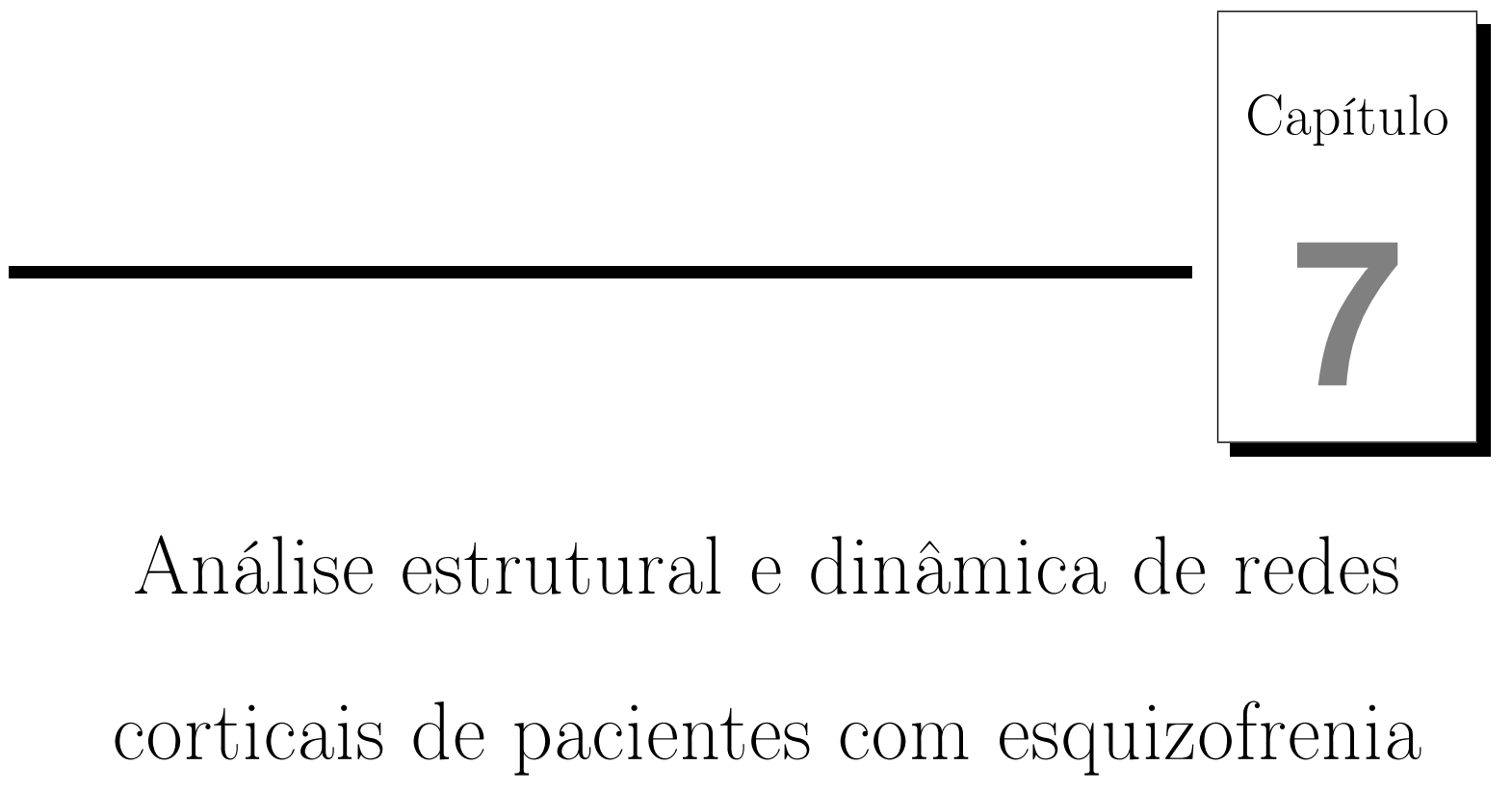

Esquizofrenia é um distúrbio neuropsiquiátrico caracterizado por déficits emocionais e cognitivos. Acredita-se que ela está associada a anormalidades na organização neuronal do cérebro. Entretanto ainda não é claro como estas alterações modificam a organização funcional do cérebro. Neste trabalho, foi realizada uma comparação sistemática de redes corticais, obtidas por meio de fMRI, entre pacientes saudáveis e com esquizofrenia, considerando propriedades estruturais e dinâmicas.

Na primeira seção deste capítulo será feita uma introdução aos trabalhos já realizados dentro do contexto de neurociência e estudo de redes corticais. A seguir é feita uma descrição da base de dados utilizada, expondo de maneira sucinta alguns dos métodos utilizados para extração e construção das redes que foram avaliadas ao longo do trabalho. Na sequência é exposta a metodologia adotada, bem como são apresentados os resultados para a avaliação estrutural e dinâmica destas redes, sendo esta uma aplicação do capítulo 6. Por fim, é feita uma conclusão, sumarizando as contribuições deste trabalho. 


\subsection{Introdução}

Nas últimas décadas houve um grande aumento quanto a disponibilidade de dados de redes corticais, isto, por sua vez, forneceu à neurociência uma nova ferramenta para análise estrutural e funcional do cérebro (Bressler, 1995; Bassett e Bullmore, 2006; Bullmore e Sporns, 2009; Sporns, 2010). Tais redes foram analisadas segundo a metodologia de redes complexas (ver capítulos 2 e 3), sob diversas considerações clinicas e experimentais (Bullmore e Sporns, 2009). Ademais, as redes do cérebro foram analisadas em diversos níveis, desde circuitos neuronais (Watts e Strogatz, 1998) à regiões corticais (Bullmore e Sporns, 2009).

O mapeamento de redes do cérebro é feito em humanos por meio de imagens de ressonância magnética (MRI, do inglês, magnetic resonance imaging). A análise destes mapas mostrou que redes corticais apresentam propriedades de pequeno mundo (small-worldness), alta eficiência de transferência com baixo custo, modularidade além da existência de hubs (Chen et al., 2008; Bullmore e Sporns, 2009; Sporns, 2010). Tais propriedades foram verificadas também em redes de macacos e gatos (Sporns et al., 2004; Kaiser et al., 2007). Ademais, alguns trabalhos sugerem que a organização do cérebro é uma consequência de uma pressão seletiva visando a economia para se estabelecer uma conexão entre duas regiões corticais, minimizando a distância entre as regiões, desta maneira, apresentam uma forte dependência espacial (Bullmore e Sporns, 2012).

Tal estudo permite análises sobre a organização do cérebro humano, bem como criar hipóteses sobre o relacionamento entre doenças neuropsiquiátricas e a organização entre o padrão de conexões destas redes. De fato, algumas diferenças estruturais foram verificadas nestes mapas para doenças como autismo, esquizofrenia, depressão, ansiedade, doença de Alzheimer e demência frontotemporal (Supekar et al., 2008; He et al., 2008; Bassett et al., 2008; Bassett e Bullmore, 2009; Lynall et al., 2010; Menon, 2011). Tais observações permitem um melhor entendimento da relação entre a doença e processos emocionais. Além disto, tal análise pode ser utilizada como uma metodologia não invasiva de diagnóstico, de maneira semelhante a realizada por Supekar et al. (Supekar et al., 2008), que verificou que o clustering coefficient é capaz de diferenciar pacientes com Alzheimer de pacientes de controle com sensibilidade de $72 \%$ e especificidade de $78 \%$. 
Os resultados obtidos anteriormente para redes de pacientes com esquizofrenia sugeriram que as redes com esta doenças possuem menos características small-world, menos hierárquicas, com menores valores de clustering coefficient, com menor eficiência de conexões (Bassett et al., 2008; Bullmore e Sporns, 2009) e menos dominadas por hubs (Lynall et al., 2010).

Neste trabalho foram confirmadas tais observações, entretanto uma pequena quantidade de medidas havia sido extraída e avaliada, como grau de coesão, distâncias e estruturas modulares (Bassett et al., 2008; Bullmore e Sporns, 2009). Aqui foi feita uma análise com um número maior de propriedades estruturais, levando em consideração as diversas medidas de redes, discutidas no capítulo 2. Além disto, será apresentada uma aplicação à metodologia proposta no capítulo 6, verificando desta maneira um subconjunto de medidas que melhor diferenciam a estrutura das redes de pacientes saudáveis e portadores de esquizofrenia, consequentemente, obtendo uma metodologia não invasiva de diagnóstico. Além disso, tais características permitem um melhor entendimento da relação entre a doença e a estrutura destas redes.

\subsection{Base de dados}

A base de dados utilizada foi apresentada em (Vértes et al., 2012) ${ }^{1}$. Os dados são obtidos por meio de fMRI em estado de repouso, medindo oscilações de baixa frequência, para dois grupos de pacientes: (i) 20 saudáveis e (ii) 19 com esquizofrenia infantil, uma forma rara da doença que tem seu inicio antes dos 13 anos de vida.

Não houve diferenças significativas entre os grupos em termos de idade, sexo, ou de deslocamento máximo, devido ao movimento da cabeça (Vértes et al., 2012). Os participantes foram escaneados usando um scanner de ressonância magnética General Electric Signa MRI, operacional a 1,5 T, no centro clínico do NIH, em Bethesda, Maryland, Estados Unidos. Utilizou-se apenas no hemisfério direito para facilitar a aproximação do comprimento da aresta pela distância euclidiana entre regiões do cérebro (Vértes et al., 2012). Isto resultou em 140 regiões cujas séries temporais médias foram utilizadas para a construção de redes cerebrais funcionais. A sobreposição máxima da transformada discreta wavelet foi com 4 wavelets Daubechies (Ingrid, 1992) usada por um filtro passa-banda destas séries e um intervalo de frequência: 0,05-0,111 Hz (Vértes et al., 2012).

\footnotetext{
${ }^{1}$ Disponível em http://intramural.nimh.nih.gov/chp/matlab.html
} 
Os grafos são obtidos por meio de um processo de limiarização, desta maneira, estimando a matriz de adjacências de cada paciente. Para garantir que não haja componentes desconexas utiliza-se a árvore geradora mínima como um suporte e novas arestas são adicionadas em ordem decrescente de correlação, gerando assim, redes binárias com grau médio controlado. Cada rede rede possui 140 regiões corticais do lado direito do cérebro, sendo que seu grau médio é igual para todas as redes.

\subsection{Metodologia e resultados}

Nesta seção será formalizada a metodologia utilizada para análise desta base de dados utilizando os conceitos expostos anteriormente. A primeira parte deste capítulo, seção 7.3.1, é uma aplicação para a metodologia apresentada no capítulo 6. A diferença fundamental é que aqui as classes utilizadas são de pacientes saudáveis e de portadores de esquizofrenia, ao invés dos modelos, que representavam as classes no capítulo 6. Será feita uma análise estrutural, visando obter um subconjunto de características que melhor discrimine as redes em questão. $\mathrm{Na}$ sequência será mostrada a importância de tais características e a possibilidade de utilização de tais medidas para formulação de uma metodologia não invasiva de diagnóstico. Por fim é feita uma avaliação relativa as diferenças entre as classes de redes. Na subseção seguinte será avaliado o comportamento dinâmico destas redes segundo falhas, ataques, sincronização e entropia dinâmica (Ver capítulo 3).

\subsubsection{Estrutura}

As bases usadas para classificação segundo a estrutura de redes são matrizes compostas pelas seguintes características: primeiro e segundo momento, variância e entropia do (i) grau ${ }^{1}$, (ii) clustering coefficient, (iii) comprimento dos menores caminhos, (iv) betweenness centrality, (v) edge betweenness centrality, (vi) closeness centrality, (vii) comunicabilidade, (viii) access information e (ix) hiden information; (x) grau médio dos vizinhos; (xi) Acessibilidade e (xii) índice k-core. Além das medidas globais de: (i) assortatividade; (ii) dominância do ponto central; (iii) eficiência; (iv) average search information; (v) máxima modularidade e (vi) os

\footnotetext{
${ }^{1} \mathrm{O}$ primeiro momento do grau é excluído, pois este é fixado durante o processo de construção da rede.
} 
Tabela 7.1: Ordenação de atributos para propriedades estruturais das redes funcionais utilizando incerteza simétrica e a estatística $\mathcal{X}^{2}$. As medidas foram ordenadas de acordo com a

\begin{tabular}{|c|c|c|}
\multicolumn{3}{c}{ incerteza simétrica. } \\
\hline$U(C, A)$ & $\mathcal{X}^{2}$ & Descritor \\
\hline 0.326 & 15.55 & Variância de closeness centrality \\
0.289 & 10.13 & Primeiro momento estatístico do k-core \\
0.263 & 12.88 & Máxima modularidade \\
0.258 & 12.74 & Variância da acessibilidade \\
\hline
\end{tabular}

dois primeiros momentos espectrais. Desta maneira, este conjunto de medidas define um espaço com 54 atributos para cada rede.

Após a extração destas medidas é feita uma amostragem, pois a classe de pacientes saudáveis possui um elemento a mais que a de pacientes com esquizofrenia, tal diferença poderia gerar modelos tendenciosos. Desta maneira, deve-se excluir aleatoriamente um dos pacientes saudáveis, fazendo com que cada uma das classes tenha 19 amostras. Ademais, é necessário normalizar os dados a fim de eliminar efeitos de escala (ver capítulo 4). Neste trabalho, optou-se pela normalização segundo média zero e variância unitária, equação 4.1.

A tabela 7.1 apresenta a ordenação dos atributos extraídos segundo a incerteza simétrica, $U$ (ver capítulo 4), e também considerando a estatística $\mathcal{X}^{2}$. As medidas que não foram mostradas na tabela possuem tais índices iguais a zero. Assim, a partir de um conjunto de 54 medidas, apenas quatro contribuem de maneira significativa para discriminação destas classes. Tal observação sugere que estas propriedades estão relacionadas a anormalidades causadas pela esquizofrenia. As funções de densidade de probabilidade para estas medidas são mostradas na figura 7.1. Para obter uma melhor visualização as distribuições foram estimadas por funções kernel Gaussianas, suavizando a curva (Parzen, 1962; Rosenblatt, 1956). Observa-se também pela figura 7.1 que a separação concorda com a ordenação apresentada na tabela 7.1.

As redes corticais de pacientes esquizofrênicos apresentam uma variância maior para a medida de closeness centrality e acessibilidade, porém valores menores para as médias de k-core e modularidade. Assim, elas possuem altas variâncias de propriedades centrais, porém estruturas menos modulares. Estes resultados concordam com trabalhos realizados anteriormente (Vértes et al., 2012; Liu et al., 2008), onde foi observado que a modularidade e o clustering coefficient tendem a ser reduzidos em redes com esquizofrenia. Entretanto, aqui observa-se que apenas a 


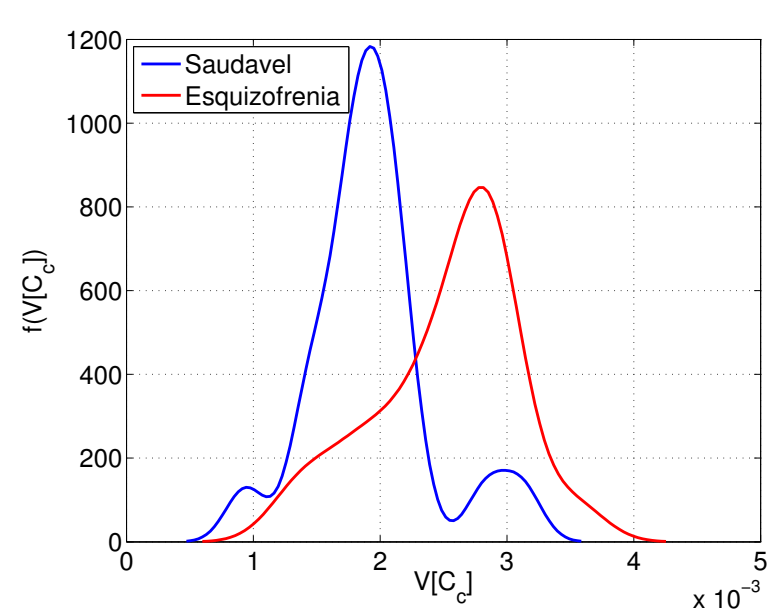

(a)

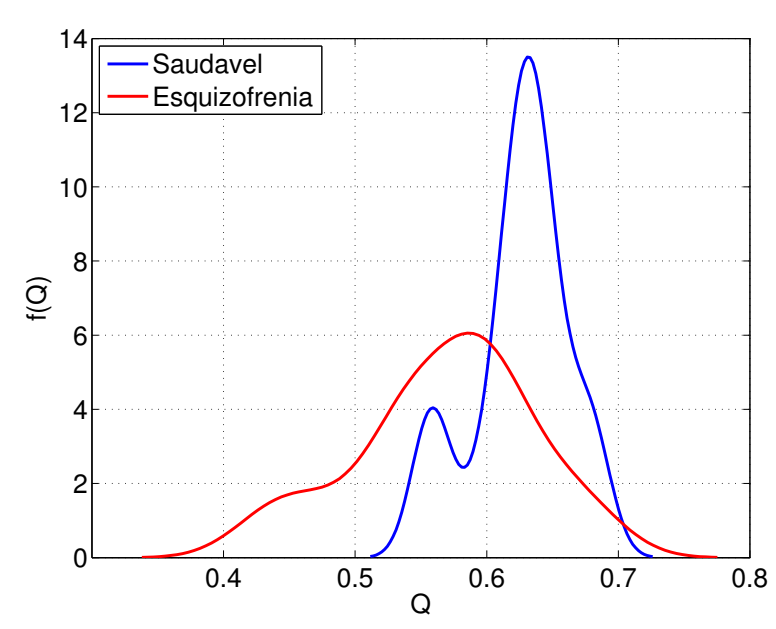

(c)

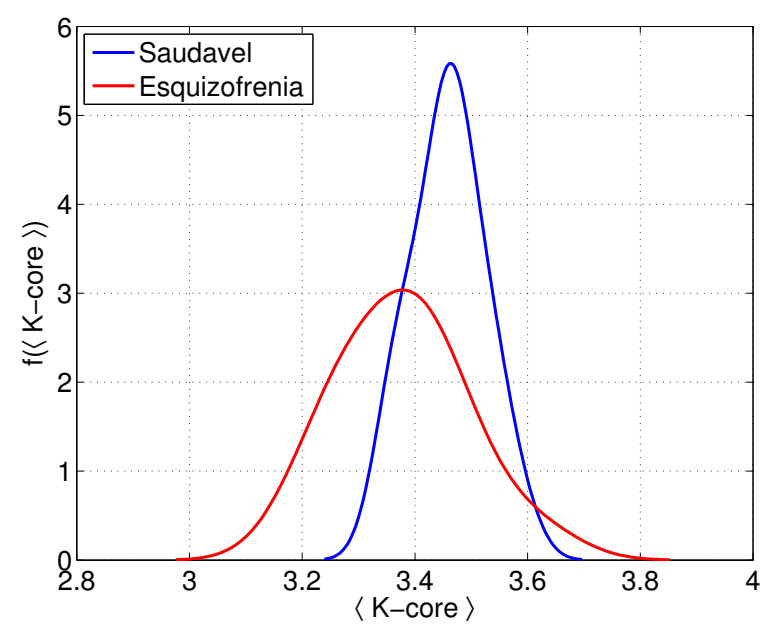

(b)

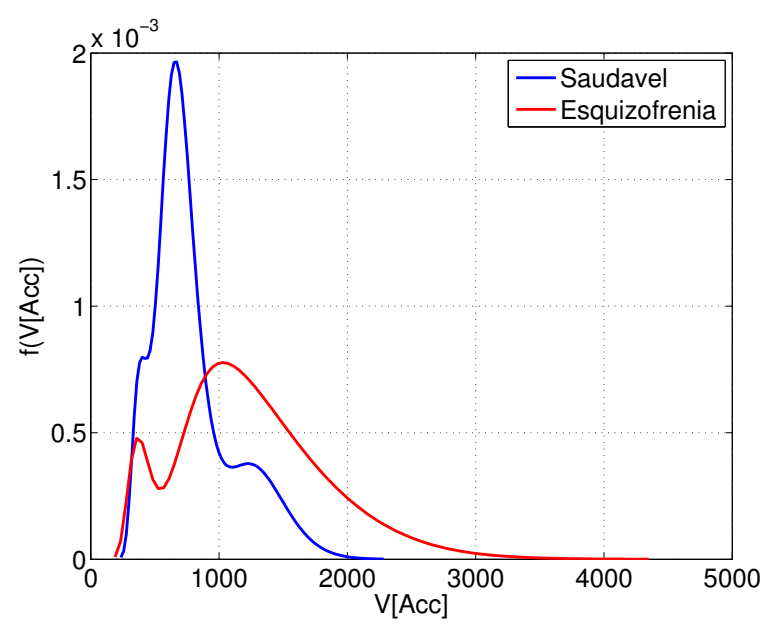

(d)

Figura 7.1: Distribuições de probabilidade estimadas para as medidas que obtiveram as melhores posições na ordenação: (a) variância de closeness centrality; (b) Primeiro momento estatístico do k-core; (c) Máxima modularidade e (d) variância da acessibilidade.

modularidade pode discriminar entre estas classe, pela metodologia adotada. Contudo, a média para o clustering coefficient difere entre as redes saudáveis e com esquizofrenia, porém tal diferença não é estatisticamente relevante. Ademais, observa-se que não há uma diferença entre os menores caminhos para tais redes, sugerindo que apesar da menor modularidade das redes esquizofrênicas isto não implica em uma redução da eficiência de comunicação entre as classes de redes. A figura 7.2 apresenta a distribuição de probabilidades de tais propriedades.

Após a identificação das características mais relevantes foi feita a classificação supervisionada, para verificar o grau de separação entre as classes, bem como sugerir uma metodologia para o diagnóstico automático de maneira não invasiva. Este conjunto de dados foi avaliado para três diferentes classificadores, sendo estes induzidos para as 54 características originais e 


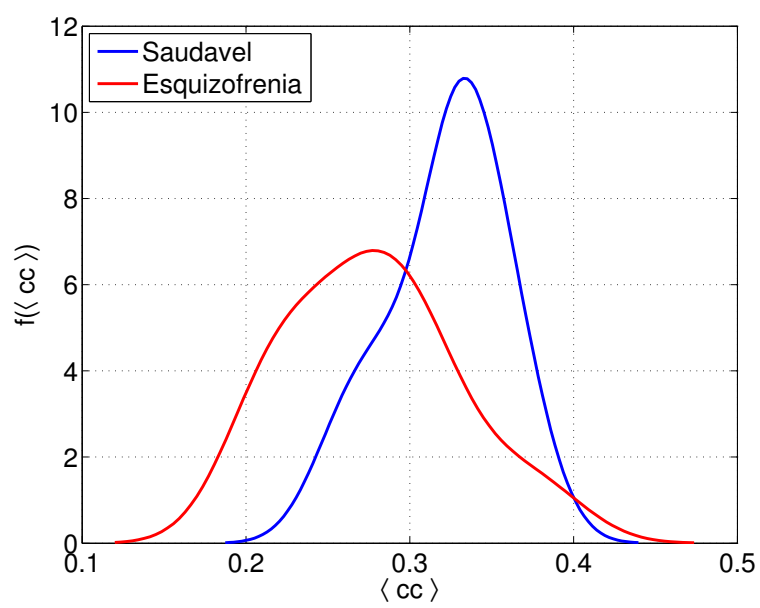

(a)

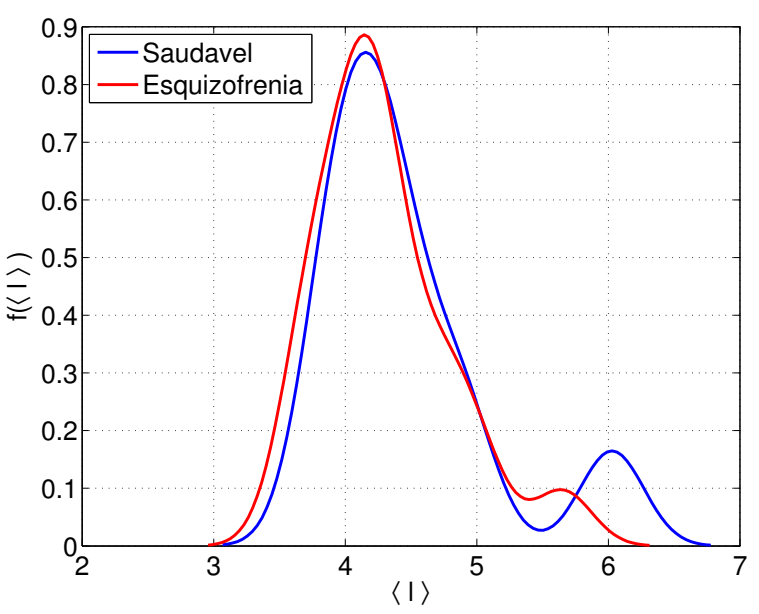

(b)

Figura 7.2: Distribuições de probabilidade para o primeiro momento estatístico do (a) clustering coefficient e (b) menor caminho médio para redes saudáveis e portadoras de esquizofrenia.

Tabela 7.2: Classificação de redes saudáveis e portadoras de esquizofrenia.

\begin{tabular}{|c|c|c|c|c|c|c|}
\hline & \multicolumn{2}{|c|}{ Naive Bayes } & \multicolumn{2}{|c|}{ Redes Bayesianas } & \multicolumn{2}{|c|}{ Árvores C4.5 } \\
\hline & s/ seleção & c/ seleção & s/ seleção & c/ seleção & s/ seleção & c/ seleção \\
\hline Acurácia (\%) & 73.68 & 76.32 & 71.05 & 78.95 & 44.74 & 71.05 \\
\hline Precisão (Classe positiva: Saudável) & 0.68 & 0.727 & 0.7 & 0.762 & 0.458 & 0.682 \\
\hline Recall (Classe positiva: Saudável) ${ }^{1}$ & 0.895 & 0.842 & 0.737 & 0.842 & 0.579 & 0.789 \\
\hline Medida F (Classe positiva: Saudável) & 0.773 & 0.78 & 0.718 & 0.8 & 0.512 & 0.732 \\
\hline Precisão (Classe positiva: Esquizofrênica) & 0.846 & 0.813 & 0.722 & 0.824 & 0.429 & 0.75 \\
\hline Recall (Classe positiva: Esquizofrênica) ${ }^{2}$ & 0.579 & 0.684 & 0.684 & 0.737 & 0.316 & 0.632 \\
\hline Medida F (Classe positiva: Esquizofrênica) & 0.688 & 0.743 & 0.703 & 0.778 & 0.364 & 0.686 \\
\hline
\end{tabular}

também para as quatro selecionadas, possibilitando assim, uma verificação do ganho de desempenho proporcionado pela seleção.

Optou-se pela utilização de classificadores baseados em teoria da informação e técnicas Bayesianas, pois estes são de simples interpretação e fornecem informações relativas ao conjunto de dados avaliado. Desta maneira, utilizou-se três classificadores distintos: (i) Naive Bayes; (ii) Redes Bayesianas e (iii) árvores de decisão C4.5; (ver capítulo 4).

Os resultados da análise de classificação estão na tabela 7.2. Observa-se que a utilização do subconjunto selecionado gera modelos mais eficientes em todos os casos. O modelo mais sensível a seleção é a árvore de decisão, com um aumento de $44.74 \%$ para $71.05 \%$. É importante

\footnotetext{
${ }^{1}$ Também chamado de especificidade (Ver capítulo 4).

${ }^{2}$ Também chamado de sensitividade (Ver capítulo 4).
} 
observar que os índices da tabela 7.2 apresentam desempenho superior com a seleção, não apenas em relação a acurácia.

Além disto, os resultados sugerem que há uma fraca dependência estatística entre os atributos selecionados, pois o desempenho dos classificadores Naive Bayes e a rede Bayesiana apresentam resultados semelhantes. Este fato era esperado, pois tais atributos são baseados em diferentes propriedades de redes. Enquanto a medida closeness centrality é baseada em menores caminhos a acessibilidade utiliza conceitos de caminhadas aleatórias, já o k-core é fundamentado em propriedades de conectividade e a modularidade está relacionada a presença de estruturas modulares na rede. Logo, espera-se que a informação presente em cada uma destas seja de fato diferente, contribuindo assim para uma melhor classificação.

Os resultados obtidos indicam que a estrutura modular e propriedades centrais são aquelas mais relacionadas a esquizofrenia, considerando o conjunto original de medidas avaliadas. Assim, verifica-se que a organização funcional do cérebro de pacientes com esquizofrenia é menos modular, porém com maior variância de propriedades centrais. Desta maneira, tais resultados sugerem que doença está relacionada com estas variações, entretanto mais análises experimentais são necessárias para confirmar estas hipóteses.

As maiores taxas de classificação obtidas foram uma sensibilidade de $74 \%$ e especificidade de $90 \%$, sugerindo uma diferença significativa entre as duas classes de redes corticais, isto é, redes de pacientes saudáveis e com esquizofrenia. Tais resultados indicam a viabilidade de uma metodologia baseada em descritores de redes complexas e mineração de dados para um diagnóstico não invasivo.

\subsubsection{Dinâmica}

Além da análise estrutural foi feita uma comparação entre o comportamento dinâmico das redes de pacientes saudáveis e esquizofrênicos. Foram avaliadas dois processos dinâmicos: (i) sincronização de osciladores acoplados, segundo o modelo de Kuramoto e (ii) robustez à falhas e ataques (ver capítulo 3).

Uma maneira de se quantificar a robustez de redes complexas é por meio da medida de entropia dinâmica, apresentada e discutida no capítulo 3. Esta mede a robustez da rede em relação à falhas aleatórias. A figura 7.3 apresenta a distribuição de probabilidades desta medida para 


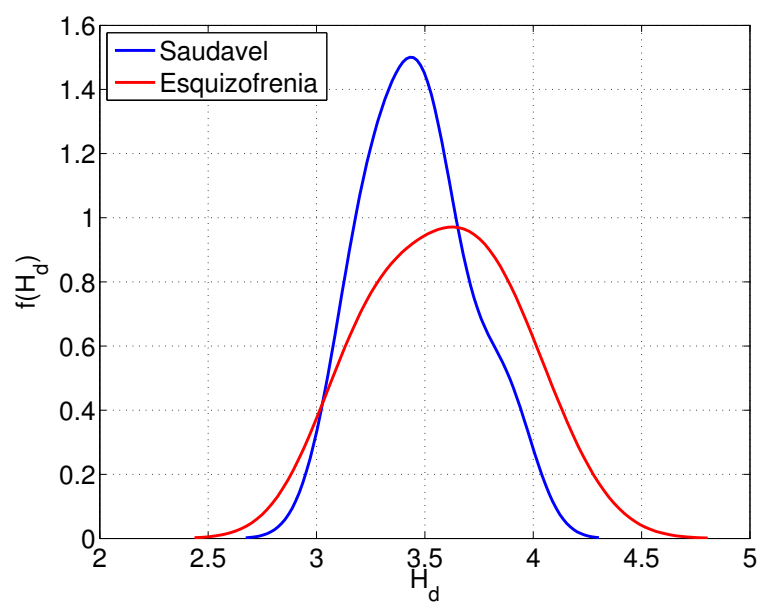

Figura 7.3: Distribuição de probabilidades da entropia dinâmica para redes saudáveis e esquizofrênicas.

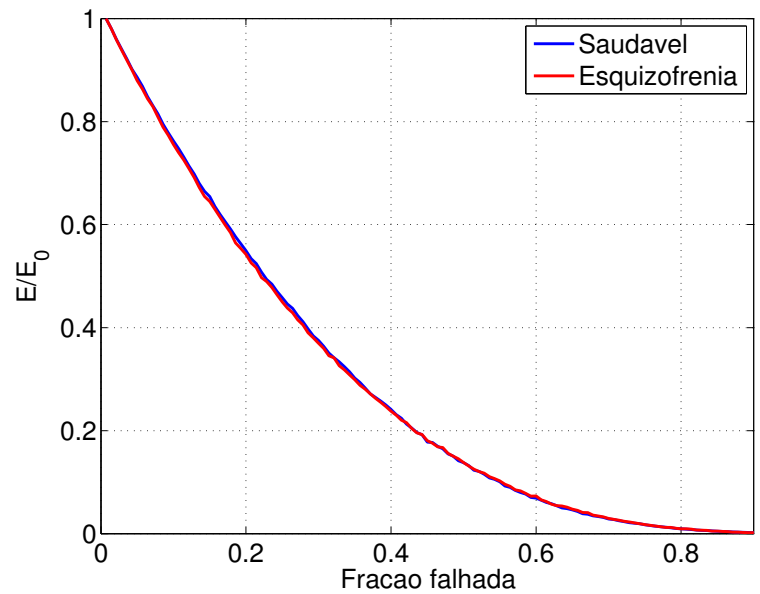

(a)

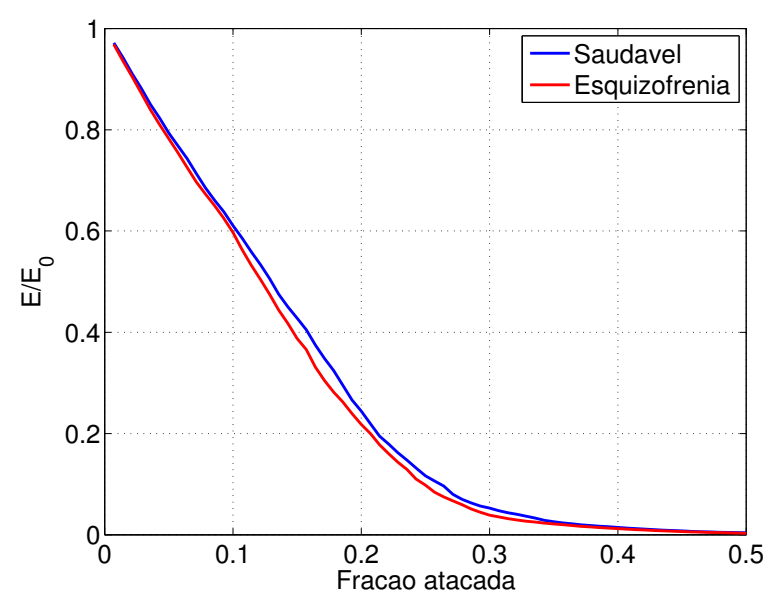

(b)

Figura 7.4: Eficiência relativa obtida pela remoção aleatória em (a) e ataques em (b).

as duas classes de redes. É interessante observar que as redes de esquizofrenia são levemente mais robustas que as saudáveis. Isto confirma os resultados obtidos por Lynall et al. em (Lynall et al., 2010).

Outra análise realizada a respeito da robustez de tais redes foi a simulação de falhas e ataques. Os resultados desta avaliação estão nas figuras 7.4, onde avaliou-se a eficiência após a falha ou ataque em relação a eficiência da rede original. Verifica-se que ambas classes de redes apresentam comportamento semelhante.

Além das dinâmicas relativas à robustez, foi avaliada a sincronização de osciladores não simétricos, isto é, utilizando o modelo de Kuramoto, já que em (Honey e Sporns, 2008), os autores sugerem que esta dinâmica está relacionada com a capacidade de recuperação de lesões. 


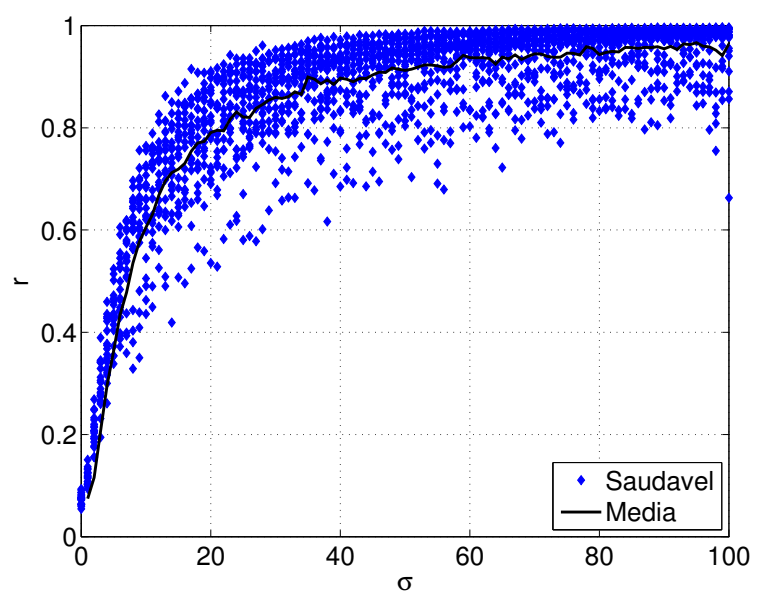

(a)

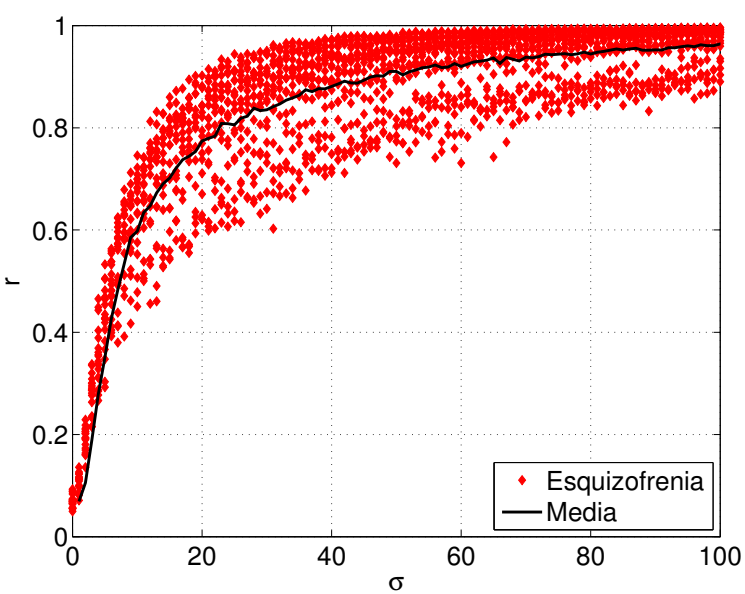

(b)

Figura 7.5: Coerência de fases para redes saudáveis em (a) e para pacientes com esquizofrenia em (b). Cada ponto é o resultado para uma rede.

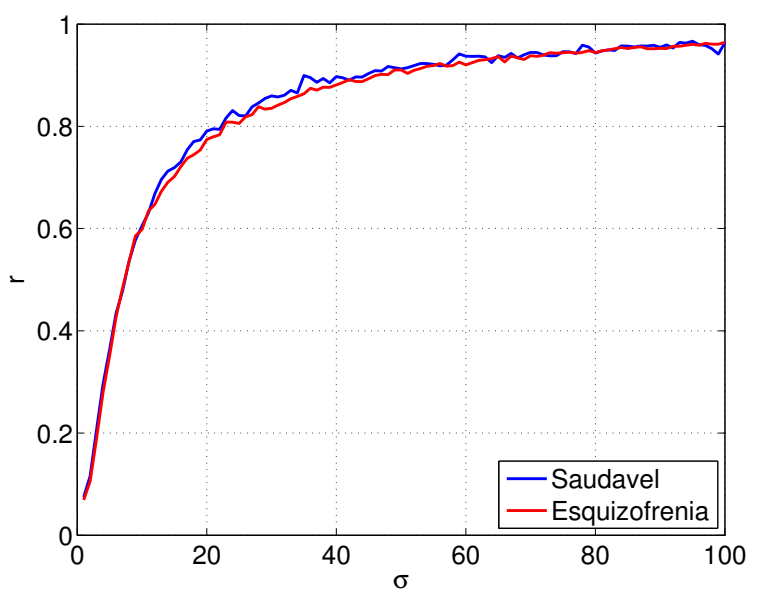

(a)

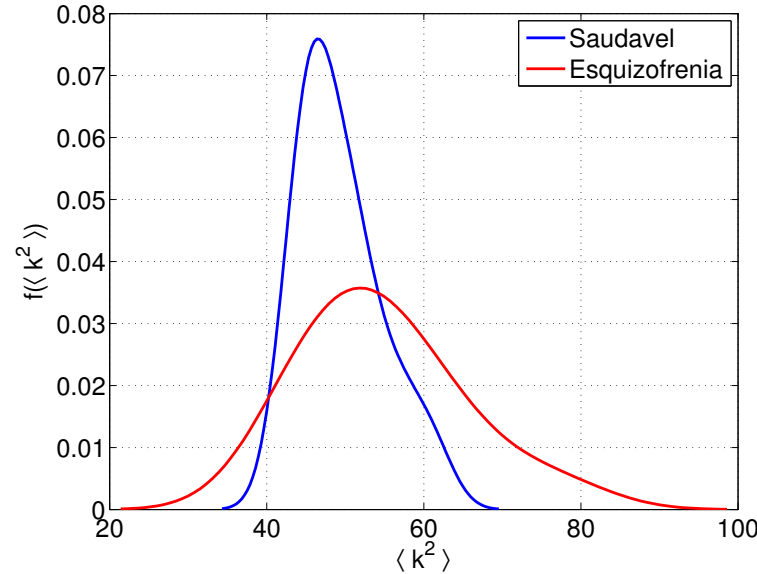

(b)

Figura 7.6: Comparação entre as médias das coerências de fase obtidas para as duas classes em (a). Distribuição de probabilidades do segundo momento estatístico da distribuição de grau em (b).

Na figura 7.5 são apresentados os resultados para coerências de fase, $r$, ao se considerar o fator de acoplamento $\sigma_{i j}=\frac{\sigma}{d(i, j)}$ e as frequências naturais uniformemente distribuídas. Por meio da análise destas, fica claro que a evolução do parâmetro de ordem é similar para ambos tipos de redes. Já a figura 7.6 (a) compara as médias paras as redes saudáveis e esquizofrênicas, onde nota-se que há uma pequena diferença nas médias, sendo que as redes saudáveis apresentam coerências de fase média levemente superior as redes esquizofrênicas. Porém, como há uma alta variância não é possível afirmar que tal diferença seja suficiente para distinguir entre estas classes. Além disto, esta diferença pode ser proveniente dos efeitos de tamanho finito, desde 
de que este efeito apresenta oscilações da ordem de $O(1 / \sqrt{N})$ (Arenas et al., 2008). Assim, como as redes utilizadas possuem $N=140$, têm-se uma flutuação de $8.5 \%$. Logo, não é possível discriminar estas duas classes de redes pelo seu comportamento dinâmico em termos de sincronização.

As análises realizadas em relação ao comportamento dinâmico das redes revelaram que não é possível distinguir de maneira significativa entre as duas classes de redes. Porém, para verificar melhor o efeito de processos dinâmicos nestas redes, avaliamos o segundo momento estatístico da distribuição de grau, $\left\langle k^{2}\right\rangle$, que está intimamente relacionado com a heterogeneidade do padrão de conexões da rede. De fato, vários processos dinâmicos estão relacionados à razão $\frac{\langle k\rangle}{\left\langle k^{2}\right\rangle}$, como por exemplo sincronização, percolação e processos de propagação (Barrat et al., 2008). Entretanto, como as redes utilizadas neste trabalho possuem o mesmo grau médio apenas o segundo momento estatístico será suficiente para caracterizar tais redes. Este pode ser visualizado por meio de sua distribuição de probabilidades, exposta na figura 7.6 (b). Apesar da distribuição do segundo momento do grau ser um pouco maior para as redes de portadores de esquizofrenia, indicando um nível maior de heterogeneidade em relação às redes de pacientes saudáveis, isto não reflete um comportamento dinâmico distinto entre tais redes. Esta análise concorda com o que foi realizado anteriormente, pois o segundo momento do grau não foi suficiente para discriminar as classes, como verificado na seção 7.3.1.

\subsection{Conclusões}

O mapeamento funcional do cérebro tem permitido uma série de análises, especialmente quantificar e avaliar diferenças relacionadas à distúrbios neuropsiquiátricos. Entretanto, ainda não está claro como e quais características realmente se alteram em tais distúrbios. Aqui, foi comparada a estrutura e o comportamento dinâmico de redes extraídas por meio de fMRI em estado de repouso de pacientes com esquizofrenia, bem como pacientes saudáveis. A partir destas redes foi possível observar que, apesar de uma pequena diferença em relação à heterogeneidade, ambas classes de redes possuem comportamento dinâmico semelhante.

Além disto, considerando um conjunto de 54 descritores de redes, apenas um subconjunto de quatro são realmente relevantes para discriminar entre redes de pacientes saudáveis e com esquizofrenia. Verificou-se, também, que diversas propriedades estruturais apresentam valores 
semelhantes para ambos tipos de pacientes, sugerindo que grande parte da estrutura funcional do cérebro é mantida durante o desenvolvimento destes distúrbios neurológicos. Entretanto foi observado que em redes com esquizofrenia a variância das medidas de closeness centrality e acessibilidade é maior, porém com valores menores para a média do índice k-core e modularidade. Indicando, portanto, que tais redes possuem uma maior variância de propriedades centrais, porém são menos modulares.

Ademais, foi mostrada uma metodologia não invasiva de diagnóstico baseado em técnicas de mineração de dados e descritores de redes complexas. De fato, foram considerados três classificadores distintos obtendo uma sensibilidade de $74 \%$ e especificidade de $90 \%$, sugerindo uma diferença significativa entre as duas classes de redes corticais, isto é, redes de pacientes saudáveis e com esquizofrenia. Sendo que um classificador que se destaca é a rede Bayesiana com atributos selecionados. Este que obteve acurácia de 78,95\% com especificidade de $84 \%$ e sensitividade de $74 \%$.

Os resultados sugerem que doença está relacionada com as variações estruturais encontradas, entretanto mais análises experimentais são necessárias para confirmar estas hipóteses. 


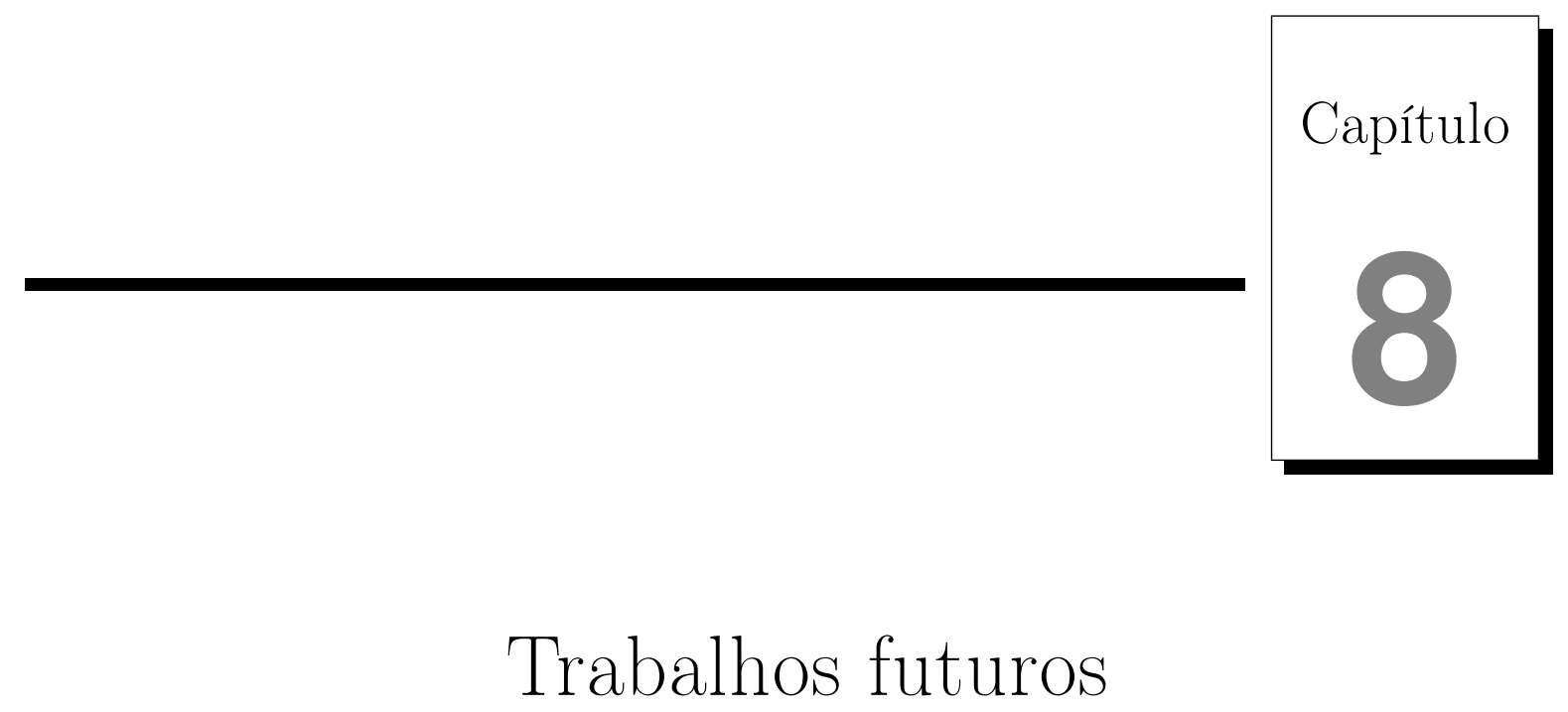

Os trabalhos desenvolvidos serão complementados com análises sobre a relação entre a estrutura e dinâmica de redes complexas, focando em propagação de epidemias e rumores, sincronização e dinâmicas neuronais.

Realizamos investigações na detecção dos nós mais influentes em processos de propagação de epidemias (capítulo 5). Entretanto este trabalho é apenas o inicio de outras investigações que pretendemos realizar. Em (Kitsak et al., 2011) é feita uma análise da obtenção deste tipo de nós por meio da medida k-core, onde os autores sugerem que vértices com maiores valores de k-core são os principais propagadores de epidemias em redes sociais. Entretanto, em (BorgeHolthoefer e Moreno, 2011) os autores argumentam que esta medida é incapaz de realizar tal detecção em processos de rumores. Motivados pelos resultados já obtidos em nossos trabalhos anteriores e análises preliminares para as dinâmicas de rumores, pretendemos demonstrar uma metodologia para encontrar tais nós de maneira sistemática. Vamos desenvolver uma metodologia que seja geral o suficiente para ambas dinâmicas, isto é, tanto para propagação de epidemias, quanto rumores. A partir de tal identificação é possível delinear estratégias mais 
adequadas para imunização, bem como identificar os vértices mais importantes na propagação de um rumor, visando o maior espalhamento possível, ou até mesmo, visando a contenção do rumor.

Além disso, pretendemos estender nossas análises sobre a influência de propriedades centrais em propagação de epidemias, investigando como medidas centrais influenciam diferentes dinâmicas. Não apenas a propagação de epidemias, mas também rumores, dinâmicas de sincronização, falhas, ataques, entre outras. Um ponto fundamental nestas análises é avaliar as semelhanças e diferenças entre a influência e importância de tais nós para cada uma destas dinâmicas. Também vamos estudar a dependência de tais medidas com os parâmetros dos processos dinâmicos. Este estudo levará a um melhor entendimento da importância da centralidade em processos dinâmicos.

Pretendemos, também, realizar a classificação de redes reais em termos de medidas topológicas globais e medidas dinâmicas, como o nível de sincronização de uma rede. Uma combinação de medidas topológicas e dinâmicas também será considerada, já que em trabalhos anteriores (Costa et al., 2007, 2010), apenas medidas topológicas foram utilizadas. De fato, poderemos comparar as classificações obtidas utilizando esses dois tipos de medidas e determinar quais oferecem um maior nível de discriminação entre modelos, bem como selecionar as medidas mais importantes, utilizando os métodos apresentados no capítulo 6.

Por fim, desejamos estender nossas análises para redes corticais, seguindo uma metodologia semelhante a realizada no capítulo 7. Procurando por diferenças e semelhanças entre redes corticais de homens e mulheres ou idade, por exemplo. Além disso, pretendemos considerar dinâmicas entre regiões corticais em futuras avaliações para tais sistemas. 


\section{Conclusão}

Nesta dissertação utilizou-se uma metodologia baseada em mineração de dados para explorar propriedades presentes em redes complexas. Foram apresentadas métodos baseados em conceitos de pré-processamento de dados, seleção e ordenação de atributos, bem como classificação supervisionada e não supervisionada. Sendo que tais técnicas foram aplicadas tanto à análise da estrutura quanto à análise de processos dinâmicos em redes complexas.

No capítulo 5, foram avaliadas as propriedades centrais dos nós em propagação de epidemias. Devido a inexistência de uma medida de centralidade universal, que considere todas as propriedades estruturais, utilizamos uma metodologia baseada em agrupamento de dados para identificar o grupo central de nós. Desta maneira, várias propriedades estruturais são utilizadas durante o processo de identificação. A partir dos grupos identificados é possível observar uma correspondência entre a dinâmica de epidemias e a estrutura. Ademais, foi proposto um método de imunização, sendo que a metodologia foi comparada com os resultados obtidos em (Kitsak et al., 2011), onde os autores utilizam $k$-core e também com métodos de imunização baseados 
em grau e aleatório (Barrat et al., 2008), sendo que nossos resultados foram superiores a tais técnicas em quase todos os casos, no pior caso houve um empate.

Quanto a metodologia de ordenação e seleção de atributos em redes, apresentada no capítulo 6, utilizamos conceitos de teoria da informação para fornecer, de maneira sistemática, o nível de importância de uma determinada medida para discriminação em relação aos modelos teóricos de redes. Esta medida pode ser tanto topológica quanto dinâmica. Assim, o principal objetivo foi obter o menor número de descritores, porém, que contenha a maior quantidade de informação possível. Nesta dissertação, verificou-se a necessidade de se selecionar um subconjunto de medidas estruturais que descreva, de maneira não enviesada, o sistema em estudo. Observou-se que algumas escolhas não são naturais sendo, até mesmo, contra intuitivas. Além disso, verifica-se que uma propriedade fundamental para o estudo de redes complexas é a distribuição dos menores caminhos pela rede, como verificado pelos processos de ordenação. Entretanto, verifica-se também, que esta não tem informações relativas a outras propriedades, como conectividade e ciclos, já que tais propriedades aparecem dentro dos conjuntos obtidos por meio da seleção de atributos. Sugerindo, assim, que tais propriedades são complementares, o que era um resultado previamente esperado.

A metodologia apresentada para ordenação de atributos em redes pode ser utilizada, também, em redes reais, na análise de redes corticais que foram obtidas de pacientes com esquizofrenia, bem como um grupo de controle. Tal estudo possibilitou a determinação das propriedades estruturais que mais diferenciam tais redes. Verificamos que grande parte das propriedades estruturais são semelhantes para ambos tipos de pacientes, sugerindo que grande parte da estrutura funcional do cérebro é conservada durante o desenvolvimento destes distúrbios neurológicos. Entretanto os resultados obtidos indicam que redes de pacientes com esquizofrenia possuem uma maior variância de propriedades centrais, porém são menos modulares. Por outro lado, apesar desta diferença, ambas classes de redes possuem comportamento dinâmico semelhante.

Nossos resultados sugerem que doença está relacionada às variações estruturais encontradas, entretanto, mais análises experimentais são necessárias para confirmar estas hipóteses.

Além disso, apresentou-se uma metodologia não invasiva de diagnóstico utilizando técnicas de mineração de dados e descritores de redes complexas. Os resultados obtidos durante 
a classificação sugerem uma diferença significativa entre as duas classes, pois obteve-se uma sensibilidade de $74 \%$ e especificidade de $90 \%$. É importante ressaltar o desempenho da rede Bayesiana com atributos selecionados, que obteve acurácia de 78,95\% com especificidade de $84 \%$ e sensitividade de $74 \%$.

Ao longo desta dissertação foram apresentadas algumas das possíveis aplicações de métodos de mineração de dados para análise de redes complexas. Outras possibilidades foram apresentadas no capítulo 8, de trabalhos futuros. 



\section{Referências Bibliográficas}

Adamic, L. A. e Glance, N. (2005). The political blogosphere and the 2004 U.S. election: divided they blog. In Proceedings of the 3rd international workshop on Link discovery (pp. 36-43). New York, NY, USA: ACM.

Albert, R. (1999). Emergence of scaling in random networks. Science, 286(5439), 509-512.

Albert, R., Jeong, H. e Barabási, A.-L. (2000, July 27). Error and attack tolerance of complex networks. Nature, 406(6794), 378-382.

Amaral, L. e Ottino, J. (2004). Complex networks: Augmenting the framework for the study of complex systems. The European Physical Journal B-Condensed Matter and Complex Systems, 38(2), 147-162.

Anderson, R. M. e May, R. M. (1992). Infectious Diseases of Humans Dynamics and Control. Oxford University Press.

Arenas, A., Díaz-Guilera, A., Kurths, J., Moreno, Y. e Zhou, C. (2008). Synchronization in complex networks. Physics Reports, 469(3), 93-153.

Barabási, A., Albert, R. e Jeong, H. (1999). The diameter of the world wide web. Nature, 401(9), 130-131.

Barabási, A.-L. (2003). Linked: How Everything is Connected to Everything Else and what it Means for Business, Science, and Everyday Life. Plume.

Barbieri, A. L. (2010). Análise de Robustez em redes complexas. Dissertação de mestrado, Universidade de São Paulo, Instituto de Física de São Carlos, 1-110. 
Barrat, A., Barthlemy, M. e Vespignani, A. (2008). Dynamical processes on complex networks. Cambridge University Press New York, NY, USA.

Bassett, D. e Bullmore, E. (2006). Small-world brain networks. The neuroscientist, 12(6), $512-523$.

Bassett, D. e Bullmore, E. (2009). Human brain networks in health and disease. Current Opinion in Neurology, 22(4), 340.

Bassett, D., Bullmore, E., Verchinski, B., Mattay, V., Weinberger, D. e Meyer-Lindenberg, A. (2008). Hierarchical organization of human cortical networks in health and schizophrenia. The Journal of Neuroscience, 28(37), 9239-9248.

Batagelj, V. e Zaversnik, M. (2003). An O (m) algorithm for cores decomposition of networks. Arxiv preprint cs/0310049.

Bilmes, J. (1998). A Gentle Tutorial of the EM Algorithm and its Application to Parameter Estimation for Gaussian Mixture and Hidden Markov Models (Tech. Rep.).

Bishop, C. (2006). Pattern recognition and machine learning. Springer New York.

Boccaletti, S., Latora, V., Moreno, Y., Chavez, M. e Hwang, D. (2006). Complex networks: Structure and dynamics. Physics reports, 424(4-5), 175-308.

Boguñá, M. e Pastor-Satorras, R. (2002, Oct). Epidemic spreading in correlated complex networks. Phys. Rev. E, 66, 047104.

Bollobás, B. (2001). Random graphs (Vol. 73). Cambridge Univ Pr.

Borge-Holthoefer, J. e Moreno, Y. (2011, December). Absence of influential spreaders in rumor dynamics (Vol. 85) (No. 2). APS.

Bressler, S. (1995). Large-scale cortical networks and cognition. Brain Research Reviews, 20(3), 288-304.

Brin, S. e Page, L. (1998). The Anatomy of a Large-Scale Hypertextual Web Search Engine. In Computer Networks and ISDN Systems (pp. 107-117). Elsevier Science Publishers B. $\mathrm{V}$.

Bullmore, E. e Sporns, O. (2009). Complex brain networks: graph theoretical analysis of structural and functional systems. Nature Reviews Neuroscience, 10(3), 186-198.

Bullmore, E. e Sporns, O. (2012). The economy of brain network organization. Nature Reviews Neuroscience, 13(5), 336-349. 
Chen, Z., He, Y., Rosa-Neto, P., Germann, J. e Evans, A. (2008). Revealing modular architecture of human brain structural networks by using cortical thickness from MRI. Cerebral Cortex, 18(10), 2374-2381.

Cormen, T. H., Leiserson, C. E., Rivest, R. L. e Stein, C. (2001). Introduction to Algorithms (2nd ed.). The MIT Press.

Costa, L., Rodrigues, F., Travieso, G. e Boas, P. (2007). Characterization of complex networks: A survey of measurements. Advances in Physics, 56(1), 167-242.

Costa, L., Villas Boas, P., Silva, F. e Rodrigues, F. (2010). A pattern recognition approach to complex networks. Journal of Statistical Mechanics: Theory and Experiment, 2010, $\mathrm{P} 11015$.

Demetrius, L. e Manke, T. (2005). Robustness and network evolution—an entropic principle. Physica A: Statistical Mechanics and its Applications, 346(3-4), 682-696.

Dempster, A., Laird, N. e Rubin, D. (1977). Maximum likelihood from incomplete data via the EM algorithm, JR Statist. Soc. B, 39(1), 1-38.

Duda, R. O., Hart, P. E. e Stork, D. G. (2001). Pattern Classification (2. ed.). New York: Wiley.

Erdös, P. e Rényi, A. (1959). On random graphs, I. Publicationes Mathematicae (Debrecen), 6, 290-297.

Ernesto, E. e Hatano, N. (2008). Communicability in Complex Networks. Phys. Rev. E, 77, 036111.

Faloutsos, M., Faloutsos, P. e Faloutsos, C. (1999). On power-law relationships of the internet topology. In ACM SIGCOMM Computer Communication Review (Vol. 29, pp. 251-262).

Farkas, I., Derenyi, I., Barabasi, A. e Vicsek, T. (2001). Spectra of a real-world graphs: Beyond the semicircle law. Physical Review E, 64(2), 026704.

Fortunato, S. (2010). Community detection in graphs. Physics Reports, 486(3-5), 75-174.

Freeman, L. (1977). A set of measures of centrality based on betweenness. Sociometry, 40(1), $35-41$.

Friedman, N., Geiger, D., Goldszmidt, M., Provan, G., Langley, P. e Smyth, P. (1997). Bayesian Network Classifiers. In Machine Learning (pp. 131-163). 
Fukunaga, K. e Olsen, D. (1971). An algorithm for finding intrinsic dimensionality of data. Computers, IEEE Transactions on, 100(2), 176-183.

Ghiselli, E. E. (1964). Theory of Psychological Measurement. McGraw Hill.

Girvan, M. e Newman, M. (2002). Community structure in social and biological networks. Proceedings of the National Academy of Sciences, 99(12), 7821.

Goh, K., Kahng, B. e Kim, D. (2001). Spectra and eigenvectors of scale-free networks. Physical Review E, 64(5), 051903.

Guimerà, R., Danon, L., Díaz-Guilera, A., Giralt, F. e Arenas, A. (2003, Dec). Self-similar community structure in a network of human interactions. Phys. Rev. E, 68, 065103.

Hall, M. A. e Smith, L. A. (1999). Feature Selection for Machine Learning: Comparing a Correlation-Based Filter Approach to the Wrapper. In Proceedings of the Twelfth International Florida Artificial Intelligence Research Society Conference (pp. 235-239). AAAI Press.

He, Y., Chen, Z. e Evans, A. (2008). Structural insights into aberrant topological patterns of large-scale cortical networks in Alzheimer's disease. The Journal of Neuroscience, 28(18), 4756-4766.

Honey, C. J. e Sporns, O. (2008). Dynamical consequences of lesions in cortical networks. Human Brain Mapping, 29(7), 802-809.

Ingrid, D. (1992). Ten Lectures on Wavelets. Society for Industrial and Applied Mathematics.

Kaiser, M., Martin, R., Andras, P. e Young, M. P. (2007). Simulation of robustness against lesions of cortical networks. European Journal of Neuroscience, 25(10), 3185-3192.

Kamada, T. e Kawai, S. (1989, April). An algorithm for drawing general undirected graphs. Inf. Process. Lett., 31(1), 7-15.

Kitsak, M., Gallos, L. K., Havlin, S., Liljeros, F., Muchnik, L., Stanley, H. E. et al. (2011, October). Identification of influential spreaders in complex networks. Nature Physics.

Krapivsky, P., Redner, S. e Leyvraz, F. (2000). Connectivity of growing random networks. Physical Review Letters, 85(21), 4629-4632.

Kuramoto, Y. (2003). Chemical oscillations, waves, and turbulence. Dover Pubns.

Latora, V. e Marchiori, M. (2001). Efficient behavior of small-world networks. Physical Review Letters, 87(19), 198701. 
Liljeros, F., Edling, C., Amaral, L., Stanley, H. e Åberg, Y. (2001). The web of human sexual contacts. Nature, 411, 907-908.

Liu, Y., Liang, M., Zhou, Y., He, Y., Hao, Y., Song, M. et al. (2008). Disrupted small-world networks in schizophrenia. Brain, 131(4), 945-961.

Lynall, M., Bassett, D., Kerwin, R., McKenna, P., Kitzbichler, M., Muller, U. et al. (2010). Functional connectivity and brain networks in schizophrenia. The Journal of Neuroscience, 30(28), 9477-9487.

McLachlan, G. e Wiley, J. (1992). Discriminant analysis and statistical pattern recognition. Wiley Online Library.

Menon, V. (2011). Large-scale brain networks and psychopathology: a unifying triple network model. Trends in Cognitive Sciences, 15(10), 483-506.

Molina, L. C., Belanche, L. e Nebot, A. (2002). Feature selection algorithms: a survey and experimental evaluation. Data Mining, 2002. ICDM 2002. Proceedings. 2002 IEEE International Conference on, 306-313.

Moreno, Y. e Pacheco, A. F. (2004). Synchronization of Kuramoto oscillators in scale-free networks. EPL (Europhysics Letters), 68(4), 603.

Narendra, P. M. e Fukunaga, K. (1977, September). A Branch and Bound Algorithm for Feature Subset Selection. IEEE Trans. Comput., 26(9), 917-922.

Newman, M. (2001). Scientific collaboration networks. I. Network construction and fundamental results. Physical Review E, 64(1), 016131.

Newman, M. (2002). Assortative mixing in networks. Physical Review Letters, 89(20), 208701.

Newman, M. (2003). The structure and function of complex networks. SIAM review, 45(2), $167-256$.

Newman, M. E. J. (2010). Networks: An Introduction. Oxford University Press.

Newman, M. E. J. e Park, J. (2003). Why social networks are different from other types of networks. Physical Review E, 68, 036122.

Nishikawa, T., Motter, A. E., Lai, Y.-C. e Hoppensteadt, F. C. (2003). Heterogeneity in Oscillator Networks: Are Smaller Worlds Easier to Synchronize? Phys. Rev. Lett., 91, 014101. 
Onody, R. e Castro, P. de. (2004). Nonlinear Barabási-Albert network. Physica A: Statistical Mechanics and its Applications, 336(3), 491-502.

Parzen, E. (1962). On estimation of a probability density function and mode. The annals of mathematical statistics, 33(3), 1065-1076.

Prass, W. (2007). Numerical recipes: the art of scientific computing. Cambridge University Press.

Press, W., Teukolsky, S., Vetterling, W. e Flannery, B. (1992). Numerical Recipes in C (2nd ed.). Cambridge, UK: Cambridge University Press.

Quinlan, J. (1993). C4. 5: programs for machine learning. Morgan Kaufmann.

Rosenblatt, M. (1956). Remarks on some nonparametric estimates of a density function. The Annals of Mathematical Statistics, 832-837.

Rosvall, M., Trusina, A., Minnhagen, P. e Sneppen, K. (2005). Networks and cities: An information perspective. Physical Review Letters, 94(2), 28701.

Seidman, S. (1983). Network structure and minimum degree. Social networks, 5(3), 269-287.

Shannon, C. e Weaver, W. (1948). A mathematical theory of communication. Bell Syst. Tech. $J, 27(379), 623$.

Sporns, O. (2010). Networks of the Brain. MIT Press.

Sporns, O., Chialvo, D. R., Kaiser, M. e Hilgetag, C. C. (2004). Organization, development and function of complex brain networks. Trends in Cognitive Sciences, 8(9), 418-425.

Sturges, H. (1926). The choice of a class interval. Journal of the American Statistical Association, 21(153), 65-66.

Supekar, K., Menon, V., Rubin, D., Musen, M. e Greicius, M. (2008). Network analysis of intrinsic functional brain connectivity in Alzheimer's disease. PLoS Computational Biology, 4(6), e1000100.

Theodoridis, S. e Koutroumbas, K. (2003). Pattern recognition. Academic Press.

Traud, A. L., Kelsic, E. D., Mucha, P. J. e Porter, M. A. (2010). Comparing Community Structure to Characteristics in Online Collegiate Social Networks. (SIAM Review, in press (arXiv:0809.0960))

Traud, A. L., Mucha, P. J. e Porter, M. A. (2011). Social Structure of Facebook Networks. (arXiv:1102.2166) 
Travençolo, B. et al. (2008). Accessibility in complex networks. Physics Letters A, 373(1), $89-95$.

Vértes, P. E., Alexander-Bloch, A. F., Gogtay, N., Giedd, J. N., Rapoport, J. L. e Bullmore, E. T. (2012). Simple models of human brain functional networks. Proceedings of the National Academy of Sciences, 109(15), 5868-5873.

Watts, D. (1999). Small Worlds: The Dynamics of Networks Between Order and Randomness. Princeton University Press.

Watts, D. e Strogatz, S. (1998). Collective dynamics of small-world. Nature, 393(6684), $440-442$.

Waxman, B. (1988). Routing of multipoint connections. Selected Areas in Communications, IEEE Journal on, 6(9), 1617-1622.

Witten, I. e Frank, E. (2005). Data Mining: Practical machine learning tools and techniques. Morgan Kaufmann.

Xulvi-Brunet, R. e Sokolov, I. M. (2004, Dec). Reshuffling scale-free networks: From random to assortative. Phys. Rev. E, 70, 066102. 